Casa abierta al tiempo
UNIVERSIDAD AUTÓNOMA METROPOLITANA
DIVISIÓN DE CIENCIAS SOCIALALAPA

POSGRADO EN ESTUDIOS SOCIALES

Colonialismo, sistema electoral y bipartidismo

en Puerto Rico: 1898-2012

IDONEA COMUNICACIÓN DE RESULTADOS QUE EN LA MODALIDAD

DE REPORTE FINAL DE INVESTIGACIÓN

\title{
PRESENTA
}

Jesús Emmanuel Vélez Méndez

Matrícula

2143802333

Para optar por el grado de

Maestro en Estudios Sociales

Línea de investigación: Procesos Políticos

Director:

Dr. Víctor Manuel Alarcón Olguín

Jurados:

Dr. Alberto Escamilla Cadena

Dr. Luis Eduardo Medina Torres

Iztapalapa, CDMX., julio de 2016 
I. Introducción 4

1.1Hipótesis 11

1.2 Método 11

Representatividad:

$\begin{array}{lr}\text { A. Momento Fundacional } & 12 \\ \text { B. Sistema Electoral } & 13 \\ \text { C. Parlamento } & 15\end{array}$

II. Revisión de la literatura y marco teórico

Introducción 18

2.1 La representatividad en el momento fundacional del sistema electoral 25

2.2 La representatividad que promueven los sistemas electorales en el 41 parlamento

\section{Puerto Rico: 1898-2012}

Introducción $\quad 55$

3.1 El desarrollo del bipartidismo: 1900-1916 56

3.2 Consolidación del Partido Popular: 1917-1948 68

3.3 Inter-periodo. Constituyente 1951-52 81

3.4 El sistema electoral adoptado en la constituyente $\quad 89$

3.5 Efectos del sistema de mayoría con ley de minoría: 1952-2012 94

IV. Conclusiones 116

V. Anexos

Anexo 1 Propuesta de sistema electoral para Puerto Rico 131

Anexo 2 139

Anexo 3 141

Anexo $4 \quad 142$

Referencias 143 


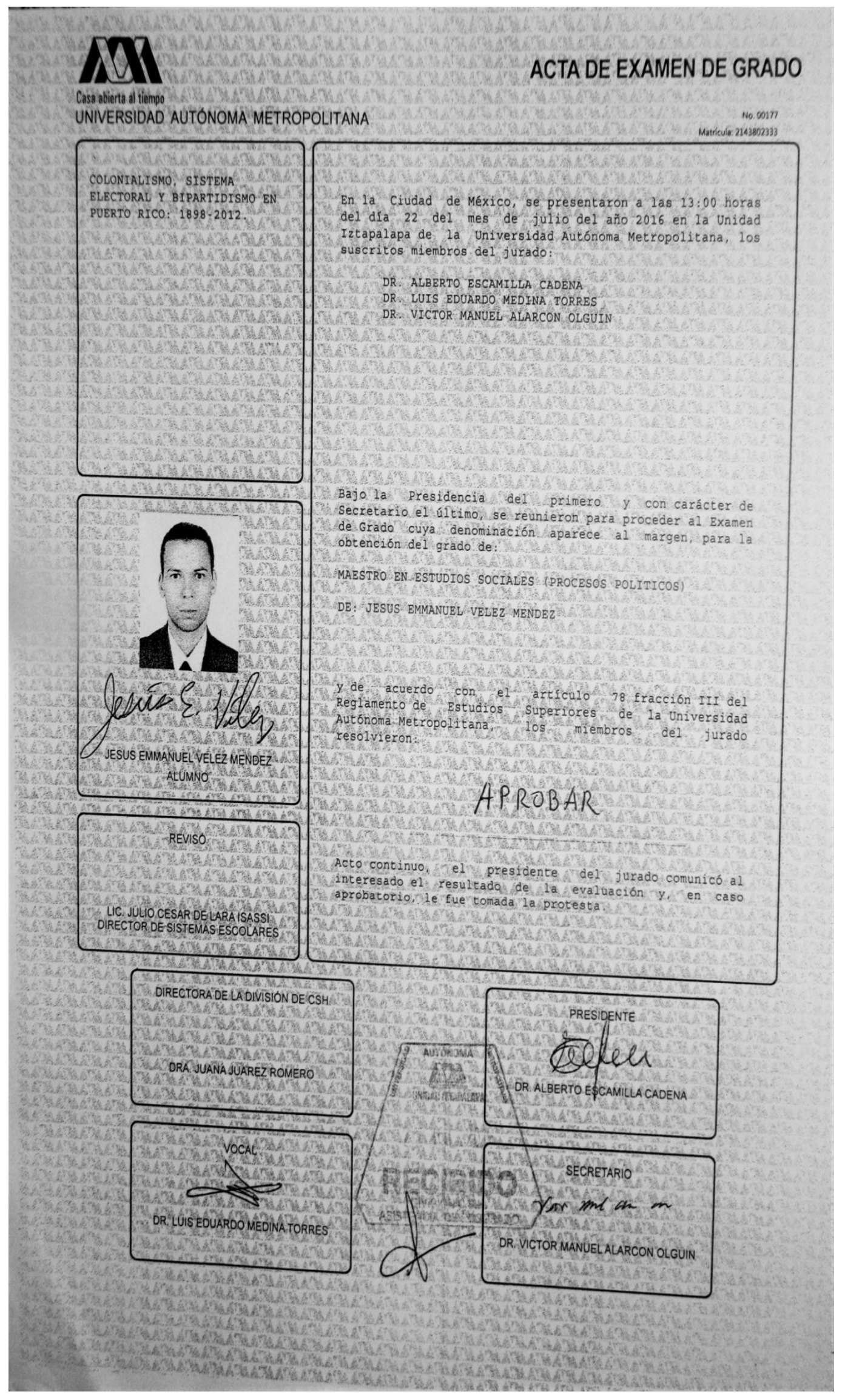




\section{Capítulo I}

\section{Introducción}

La presente investigación tiene como objetivo identificar qué relación existe en los grados de representatividad entre (1) el momento fundacional, ${ }^{1}(2)$ el sistema electoral, ${ }^{2}$ y (3) el parlamento. ${ }^{3}$ Evidenciaremos que existe una relación entre estas tres facetas tomando en cuenta el caso de Puerto Rico. La representatividad es un elemento que depende de los grados de inclusión y exclusión que promueve el sistema electoral en sus principios o proceso en donde se crea un sistema electoral (momento fundacional) y en sus resultados en el parlamento (3). Este trabajo toma en cuenta algo abandonado en los estudios electorales que se refiere al proceso de creación de un sistema electoral. También, retoma la discusión sobre los efectos de los sistemas electorales en el sistema de partidos en el legislativo añadiendo una descripción del contexto que le dará una mayor validez a nuestras conclusiones.

Se crearán instrumentos para la medición de cada una de las facetas de la representatividad que no solo sirven para el caso de Puerto Rico. Estos instrumentos se pueden aplicar a otros casos, ya que consideran todas las fórmulas electorales y otros elementos que no se han considerado en su conjunto para otros estudios. Describimos, empíricamente cómo el sistema electoral ha interactuado con el sistema de partidos en el legislativo puertorriqueño mediante el análisis de los resultados electorales de1898 hasta 2012. Se presentan los grados de inclusión o exclusión de los diversos estratos sociales y políticos en cada una de las

\footnotetext{
${ }^{1}$ Este momento se refiere a cuando se crea o se reforma un sistema electoral.

${ }^{2}$ Este es el aspecto mecánico, de lo que se compone el sistema electoral.

${ }^{3}$ Esto se refiere al efecto inmediato que tenga en la representación del parlamento.
} 
elecciones. Se describe el contexto político del periodo, así como se le da un seguimiento a la historia del sistema de partidos.

Este tipo de estudio es casi inexistente en Puerto Rico por la falta de un programa de investigación en ciencia política. ${ }^{4}$ Una primera aproximación al tema de los partidos lo proveyó Anderson ${ }^{5}$ con su análisis de los partidos políticos en Puerto Rico. También ha habido estudios relacionados al voto en Puerto Rico como "The Phenomenom of Puertorrican Voting" de Luis Raúl Cámara. ${ }^{6}$ Igualmente, la investigación de Ángel Israel Ortiz ${ }^{7}$, utilizando la escuela de Michigan, analiza por qué los puertorriqueños votan como votan. Por su parte, Efrén Rivera ${ }^{8}$ propone, bajo argumentos similares a los que presentamos, el sistema proporcional para P.R. Hay así varias investigaciones sobre el sistema de partidos en Puerto Rico y el voto.

Todos estos autores antes mencionados, categorizan a Puerto Rico (PR) en su sistema de partidos como un "bipartidismo cerrado". No obstante, nunca se han tomado en cuenta dentro de un estudio tan amplio sobre resultados electorales, los conceptos de inclusión y exclusión para evidenciar el bipartidismo en todas sus dimensiones de causas y efectos.

La mayor parte de los estudios importantes sobre ciencia política, incluyendo a los autores con los mejores y más amplios estudios comparados, descartan a Puerto Rico de su análisis, o no lo consideran en su base de datos. Este archipiélago, al ser una colonia desde el siglo XV, no pasó por la etapa de convertirse en un estado internacionalmente reconocido y por eso los estudios sobre cualquier cosa que sea

\footnotetext{
${ }^{4}$ Existe sociología, economía, y administración pública que han aportado en cierta forma al tema.

${ }_{6}^{5}$ Robert W. Anderson, Gobierno y partidos políticos en P.R. Madrid, Tecnos, 1973.

${ }^{6}$ Luis Raúl Cámara Fuertes, The phenomenon of Puerto Rican voting, Gainesville, University Press of Florida, 2004.

${ }^{7}$ Ángel Israel Rivera Ortiz, "La cultura política y la estabilidad del sistema de partidos en Puerto Rico", en Caribean Studies, Vol. 24, Num, 3/4, pp. 175-220, 1991.

${ }^{8} 8$ Efrén Rivera, Hegemonía y legitimidad en el Puerto Rico contemporáneo, Barcelona, Universidad de Puerto Rico (PR), Working paper, n. 129, 1998.
} 
relacionada a Puerto Rico escasean, principalmente en la ciencia política, pese a que el método empírico-comparado está de moda. La ciencia política institucionalista estudia países y no colonias.

De manera que por primera vez se puede presentar una posición al respecto, que abra el debate sobre una reforma del sistema electoral en PR que tanto apremia. PR se encuentra en una de las etapas más críticas de su historia. Los bonos del gobierno de Puerto Rico han sido degradados a chatarra. Como muchos países de la periferia, mantiene una deuda que sobrepasa los 70 billones de dólares, la inversión privada se esfuma, el gobierno no produce, las tasas de asesinatos en los últimos años son las más altas de toda la historia. Esto último, sin tomar en cuenta delitos de menor grado. En diez años han emigrado del país 150,000 personas. Diariamente se van del país 166 ciudadanos. ${ }^{9}$

Considerando que en Puerto Rico hay 3.5 millones de habitantes, esto representa un gran éxodo como resultado de la crisis económica y social que se vive en este momento. En las pasadas elecciones una tercera parte de la población no acudió a votar y ninguna de las terceras y hasta sextas opciones obtuvo representación -y ni siquiera la inscripción como partidos-, pese a la crisis socio-económica que han protagonizado durante décadas los partidos de turno.

A pesar de ello, el gobierno de Puerto Rico se jacta de que por décadas se ha mantenido la estabilidad, la continuidad, y el carácter permanente en las instituciones. El bipartidismo del que se le acusa a PR, según este discurso, mantiene el orden, la seguridad y una estabilidad política. Sin embargo, con este esquema que presentamos, esta última afirmación pareciera desvanecerse en la realidad de la mayoría de la población. Este archipiélago es el único territorio de los Estados Unidos que ha declarado un impago a la deuda del gobierno (en mayo

\footnotetext{
${ }^{9}$ Limarys Suárez Torres. "Se deshabita Puerto Rico de forma acelerada". Consultado el 4 de enero de 2016. Página web. www.endi.com.
} 
de 2016) y en la actualidad se encuentra el congreso estadounidense ha aprobado la reestructuración de su deuda.

Puerto Rico es una colonia donde el congreso todavía mantiene la soberanía política y económica de la isla. Pero este caso es único, porque resulta ser la colonia más vieja del mundo ${ }^{10}$ y por mucho tiempo ha mantenido un sistema electoral y de partidos similar al de Estados Unidos. Incluso los colores de los dos partidos principales en la isla son los mismos que los de Estados Unidos ${ }^{11}$. Estos dos partidos locales, incluso, forman parte de los respectivos partidos estadounidenses.

No obstante, P.R no forma parte de los Estados Unidos y no tiene ni participación en las elecciones, ni elige representantes al congreso. A pesar de que éste mantiene la soberanía de la isla, la ley estadounidense se impone sobre Puerto Rico. Esto es lo que define la realidad constitucional como una colonia. En el año que corre (2016) se aprobó en el congreso de los Estados Unidos el proyecto PROMESA Puerto Rico Oversigth Management Economy Stability Act- (Ley para la supervisión, manejo y estabilidad económica de Puerto Rico) que impone al territorio de P.R una junta de control fiscal nombrada por el presidente de los Estados Unidos. En la práctica, esta junta aboliría los poderes del parlamento puertorriqueño para otorgárselo a un grupo de personas no electas por el pueblo con el fin de reestructurar la deuda externa. ${ }^{12}$ Ante esto que parece la exclusión casi total de la población en la toma de decisiones, la discusión que presentamos del sistema de representación puertorriqueño se hace más que inminente.

\footnotetext{
${ }^{10}$ José Trías Monge, Puerto Rico: Las penas de la colonia más antigua del mundo, Río Piedras, Universidad de Puerto Rico, 1999.

${ }^{11}$ En Estados Unidos, el Partido Demócrata utiliza el color azul al igual que en Puerto Rico el Partido Nuevo Progresista. El Partido Republicano utiliza el color rojo al igual que el Partido Popular Democrático en Puerto Rico.

${ }^{12}$ José Delgado. "Obama convierte en Ley proyecto PROMESA". Endi. Consultado el 30 de junio de 2016. Página Web: www.endi.com.
} 
La relación de Puerto Rico con los EE.UU ha determinado el sistema de partidos proveyéndole que se organicen sobre su posición acerca de la relación con dicha nación: independencia (Partido Independentista), anexión (Partido Nuevo Progresista), status quo (Partido Popular). Estas opciones se han diversificado en varios partidos políticos y múltiples frentes, incluyendo movimientos $\mathrm{y}$ candidaturas independientes.

Sin embargo, solo dos partidos han sido capaces de lograr mayoría legislativa. El resto de los partidos no forman parte de la toma de decisiones. El sistema no parece ser permisivo. Por el contrario, el sistema de partidos parece dirigirse nuevamente a una tercera etapa de sistema de partido hegemónico. El Partido Popular Democrático (PPD), uno de los partidos de mayoría, ha promovido el status quo por más de 70 años, al utilizarlo como un incentivo ideológico. Un aspecto que en los últimos días, más que fortalecerlo lo ha debilitado, le ha hecho perder en ocasiones cientos de miles de votantes. Ante el desgaste del modelo económico, la desafiliación hacia el PPD ha ido ampliándose por la pérdida de su incentivo ideológico.

La otra alternativa, el Partido Nuevo Progresista (PNP), recoge una población más conservadora que promueve la anexión con los Estados Unidos. Contrario al PPD, este partido ha ido fortaleciéndose obteniendo márgenes de ganancia cada vez más amplios quedando una población excluida de la toma de decisiones, como efecto del sistema electoral. A pesar de que hasta el momento el PNP ha mostrado ser el partido más sólido, también muestra desgaste como lo confirman los resultados de las últimas primarias de este partido, en donde hubo una disminución de cientos de miles de votantes. ${ }^{13}$ Desde 1968 en Puerto Rico opera un bipartidismo

\footnotetext{
${ }^{13}$ Francés Rosario. "Partidos no cumplen con sus expectativas en las primarias". Consultado el 6 de junio de 2016. Página web: www.endi.com.
} 
estructurado. Es muy conocida la preposición de Duverger en que un sistema de mayoría promueve el bipartidismo o el monopartidismo ${ }^{14}$.

Entre las funciones de la siguiente investigación se encuentra validar o refutar esta regla para PR. De las dos "tendencias"15 de Duverger, ésta es la que más goza de aceptación científica, lo que la hace pertinente para conocer cómo opera el sistema de mayoría en Puerto Rico y el por qué de sus resultados. Esta investigación pretende dar una respuesta a aquellos puertorriqueños que diariamente se preguntan por qué continúan los mismos partidos en el poder y por qué no hay espacio para otros.

Es necesario que se analice la configuración de los procesos institucionales en Puerto Rico en profundidad, para conocer cómo se junta la realidad colonial con los partidos y comprender lo que en Puerto Rico parece ser un dilema: ¿Por qué se mantiene el presente esquema de partidos en Puerto Rico? De igual forma se pretende contestar: ¿Cuál ha sido el sistema de partidos que se ha mantenido en el legislativo borinqueño a lo largo de su historia? ¿Cuántos partidos se han excluido en todos estos procesos electorales? ¿Qué sectores quedan segregados de representación en el parlamento? Entendemos que considerando siempre la historia electoral de Puerto Rico, el momento en que se crea el sistema electoral, las características que lo componen, así como sus efectos en el sistema de partidos en el parlamento, podremos contestar con claridad las preguntas anteriores.

A continuación en este mismo apartado describimos nuestros objetivos, hipótesis, el método y procedimiento que pretendemos utilizar para medir nuestras variables y evidenciar los argumentos. En un segundo capítulo, dividimos el marco teórico en dos partes principales y una tercera como recapitulación. Estos dos apartados a

\footnotetext{
${ }^{14}$ Mauricie Duverger, "La influencia de los sistemas electorales sobre la vida pública", en Diez textos básicos de ciencia política. Barcelona. Ariel, 1995.

${ }^{15}$ R. Taagepera (2015): "La balanza inclinada. Probando la 'Ley de Duverger' en el nivel nacional". De Política, México, AMECIP, núm. 4/5, enero-diciembre, pp.9-20.
} 
su vez representan las tres facetas de las que se compone nuestro argumento: el momento fundacional, el sistema electoral y el parlamento. En un tercer capítulo se abordará el caso específico de Puerto Rico.

Se pretende analizar en profundidad el caso de Puerto Rico considerando tres etapas históricas y tres etapas electorales, mismas que constituyen más de un siglo en la historia política de la isla: 1900-1914; 1917-1948; y 1952-2012. ${ }^{16}$ En el cuarto capítulo se encuentran las conclusiones. Terminamos esta investigación con un anexo que establece una propuesta de reforma electoral para Puerto Rico.

La intención es describir la configuración del sistema electoral y el sistema de partidos en Puerto Rico. Se pretende evidenciar que el sistema electoral en Puerto Rico al ser resultado de procesos excluyentes provocados por el colonialismo estadounidense impuso el sistema de mayoría y con ello ha mantenido el bipartidismo, excluyendo de representación a las terceras y hasta sextas opciones. Pero también ha mantenido en gran medida una exclusión a sectores de género y étnicos.

Las preguntas generales para contestar en el caso de Puerto Rico son las siguientes:

$1^{\mathrm{a}}$. ¿Cuál es la relación entre el nivel de representatividad de un momento fundacional y el sistema electoral que se elige?

$1^{\mathrm{b}}$. ¿Cuál es la relación entre un sistema electoral y la representación de los estratos sociales en el parlamento nacional?

\footnotetext{
${ }^{16}$ Esta última etapa aún no culmina en Puerto Rico para la fecha en que se cerró esta tesis en el mes de julio de 2016. Sin embargo, debe estar pronto a concluir dicha etapa constitucional por la evidente crisis económica que vive este momento.
} 


\subsection{Hipótesis}

$1^{\text {a }}$. Mientras haya más representación de los estratos sociales y políticos en un momento fundacional de un sistema electoral, mayor posibilidad habrá de que se elijan sistemas electorales que promuevan una mayor representatividad en el parlamento.

$1^{\mathrm{b}}$. Mientras más exclusión se promueva en el momento fundacional de un sistema electoral, hay mayores posibilidades de que se elijan sistemas electorales que promuevan poca representatividad en el parlamento.

\subsection{Método}

\section{Variables}

En el siguiente apartado se define cómo se medirá la representatividad en estos tres sentidos: i. Momento Fundacional; ii. Sistema electoral; iii. Parlamento. Como ya se ha mencionado, a pesar de que esta investigación solo toma en cuenta un caso, el siguiente instrumento puede utilizarse para otros casos porque no está pensado solo para Puerto Rico, como se puede observar en las tablas que se presentarán más adelante en este mismo capítulo. 


\section{Representatividad}

En cada caso se medirá la representatividad en tres aspectos: el momento fundacional, el sistema electoral, y el parlamento. Se evaluará cada aspecto de la representatividad en forma individual para analizar sus efectos. Recordemos que la representatividad tiene que ver con los grados de inclusión que se promueven dentro de un proceso de toma de decisiones.

\section{A. Momento fundacional}

El Índice de Representatividad del Momento Fundacional (IRMF) se generará a partir de las respuestas a las preguntas expuestas en la Tabla 1. La puntuación que se asigna a cada caso aumenta de acuerdo al grado de inclusión o bien la cantidad de sectores que participaron en el proceso. La suma de las puntuaciones indicará el grado de representatividad del momento fundacional. La puntuación del IRMF puede variar desde un mínimo de 0 (representatividad nula) a un máximo de 5.5 (alta representatividad).

Tabla 1 Preguntas que se tomarán en cuenta para calcular el IRMF

\begin{tabular}{llc}
\hline Pregunta & Respuestas & Puntuación \\
\hline ¿De dónde surge la iniciativa de reformar el sistema & Sociedad civil: 1.5 & 1.5 \\
electoral? & Acuerdo & 1.0 \\
& multipartidista: 1.0 & \\
& Partido en el poder: & 0.5 \\
& 0.5 & \\
& Élite política o & 0 \\
\hline ¿Se escogen representantes para la preparación de la & económica & \\
reforma? & Sí & 0.5 \\
\hline
\end{tabular}




\begin{tabular}{|c|c|c|}
\hline \multirow{11}{*}{$\begin{array}{l}\text { ¿Se realizó una elección para elegir representantes? Si la } \\
\text { respuesta es sí ¿qué fórmula electoral se utilizó? }{ }^{17}\end{array}$} & Sí & \\
\hline & D'Hondt & 0.6 \\
\hline & Voto Único & 0.7 \\
\hline & Transferible & \\
\hline & LR-Droop & 0.8 \\
\hline & Modified Sainte- & 0.9 \\
\hline & Lague & \\
\hline & $\begin{array}{l}\text { LR-Hare/Sainte- } \\
\text { Lague }\end{array}$ & 1.0 \\
\hline & Danesa & 1.5 \\
\hline & $\begin{array}{l}\text { Mayoría relativa o } \\
\text { absoluta }\end{array}$ & 0.5 \\
\hline & No & 0 \\
\hline \multirow[t]{3}{*}{ ¿Porcentaje de participación en las elecciones? ${ }^{18}$} & El $100 \%$ a $75 \%$ & 2.0 \\
\hline & $25 \%$ a $50 \%$ “" & 0.5 \\
\hline & $24 \%$ o menos " & 0 \\
\hline \multirow{2}{*}{$\begin{array}{l}\text { ¿Se establecieron mecanismos para que participaran } \\
\text { algunas minorías étnicas, de género, raciales, partidistas o } \\
\text { sociales? }\end{array}$} & Sí & 0.5 \\
\hline & No & 0.0 \\
\hline
\end{tabular}

\section{B. Sistema electoral}

El Índice de Representatividad que promueve el Sistema Electoral (IRSE) se creará a partir de las puntuaciones asignadas a las características en cada caso (Tabla 2). La puntuación final de cada sumatoria será el IRSE, que aumentará de acuerdo a la representatividad que promuevan las características del sistema.

En el caso del primer indicador (Tabla 2), la fórmula y su puntuación se establecen bajo dos criterios. Uno es según el orden de proporcionalidad que sugiere Michael Gallagher. ${ }^{19}$ En segundo lugar, la puntuación que tendrá cada caso será proporcional a la magnitud del parlamento para el cual se utilice la fórmula.

\footnotetext{
${ }^{17}$ Los grados de proporcionalidad de cada fórmula según: Michael Gallagher, "Proportionality, Disproportionality, and Electoral Systems", Electoral Studies n.10, 1991, pp.33-51.

${ }^{18}$ La puntuación depende de qué porcentaje de la población hábil para votar participó de las elecciones de delegados a la constituyente.

${ }^{19}$ Ibid.
} 
Por ejemplo, Japón utiliza la fórmula D’Hondt para un 50\% del parlamento, por lo que entonces la puntuación a otorgar sería, según esta escala, de 0.25. De igual forma, si se utilizara en un 50\% la cuota Hare se le otorgaría 1.0 punto al IRSE. Si se utilizara la D'Hondt para el $100 \%$ de la cámara entonces se le otorga 0.5 pts. Por otro lado, mientras más escaños por circunscripción haya, así como tiers ${ }^{20}$ la puntuación será cada vez más alta, por ser más representativo. De igual forma, la puntuación se otorgará de acuerdo a la proporcionalidad de la magnitud de los distritos con respecto al total de los votos. Si por ejemplo, un país tuviera un $50 \%$ de los distritos uninominales y el resto plurinominales en distritos medianos, el total sería 1.0. Si todos fueran uninominales entonces no le otorgaríamos puntuación.

Dichos indicadores, además de los expuestos en la Tabla 2, se sumarán para calcular el IRSE. Este índice puede fluctuar de 0.50 en los sistemas que sean puramente mayoritarios pero con dos votos preferentes, hasta 13 puntos en sistemas con votos preferentes, fórmulas electorales muy proporcionales y cuotas de minorías.

Tabla 2 Características de los sistemas electorales que se tomarán en cuenta para calcular el IRSE

\begin{tabular}{lcc} 
Indicadores & Respuestas & Puntuación \\
\hline Fórmula $^{21}$ & Mayoría relativa o absoluta & 0.5 \\
& D'Hondt & 0.6 \\
& LR-Droop & 0.7 \\
& Voto Único Transferible & 0.8 \\
& LR-Imperiali & 0.9 \\
& Modified Sainte-Lague & 1.0 \\
&
\end{tabular}


LR-Hare/Sainte-Lague $\quad 1.1$

Danesa 1.2

\begin{tabular}{llc}
\hline Circunscripciones & Uninominales & 0 \\
& Binominales & 0.5 \\
& Plurinominales & 1.0 \\
& \multicolumn{1}{c}{ Pequeñas } & 1.5 \\
& Medianas & 2.0 \\
& Grandes & 2.5 \\
& Tiers & \\
& 1 & 0 \\
& 2 & 0.5 \\
& 3 & 1.0 \\
\hline Cuotas* & De género & 0.5 \\
& Socio-profesional & 0.5 \\
& Étnica & 0.5 \\
& Otros & 0.5 \\
\hline Papeleta & Bloqueada & 0 \\
& Desbloqueada & 0.5 \\
& Voto preferente**23 & 0.25 \\
\hline
\end{tabular}

Nota: *Por cada cuota a minoría se le otorgará 0.5 de puntación en el IRSE. **La puntuación de 0.25 será a cada voto preferente que se permita.

\section{Representatividad en el parlamento}

El Índice de Representatividad del Parlamento (IRP) será calculado de una forma que aunque deficiente, nos puede dar una idea de cómo se ha conformado étnica y políticamente el parlamento. Así también nos deja saber los cambios en los turnos al poder y sus desproporciones. Este índice nos provee los resultados representativos del sistema electoral en el parlamento. Para medir la estratificación social de un parlamento es necesario conocer la estratificación social de la

\footnotetext{
${ }^{22}$ Dieter Nohlen, Elections and electoral systems, India, Macmillan, 1996. Menciona que las circunscripciones pequeñas son de cinco o menos distritos, pero en nuestro caso será de 4 o de 5 para diferenciar las plurinominales que son de 3 escaños, las medianas de 6 a 10, y las grandes de 11 o más.

${ }^{23}$ La postura de que los votos preferentes promueven representatividad es lógica, aunque en la práctica la realidad del voto preferente es que altera la proporcionalidad de la fórmula electoral. No obstante, es necesario mantener la libertad del elector para que, de esta forma, se refleje mejor su intención y por tanto las preferencias. De manera que cuanto mejor se combinen proporcionalidad y la libertad del elector en la papeleta, más se favorece la representatividad. Esta postura será defendida en el apartado de sistemas electorales que desarrollaremos en el transcurso del trabajo.
} 
sociedad en su conjunto. Esto ha implicado en muchos estudios evaluar las clases económicas. No obstante, "las variables de género y etnicidad se han convertido en parte importante de este cambio de mirada de la estratificación social a partir de los 70". ${ }^{24}$ Por ello, para el IRP utilizaré las variables: género, etnicidad ${ }^{25}$ e ideología política.

- Género: Se tomará en cuenta el porcentaje de mujeres en el parlamento. Mientras mayor sea más puntuación tendrá en el IRP. Se otorgará puntuación desde uno hasta 10 dependiendo del porcentaje de representación que tenga la mujer en el parlamento.

Tabla 3. Puntuación según porcentaje de género o etnia.

\begin{tabular}{c|c|c|c|c|c|c|c|c|c}
$* 1-5$ & $10-14$ & $15-19$ & $20-24$ & $25-29$ & $30-34$ & $35-39$ & $40-44$ & $45-49$ & $50-$ \\
\hline$* * 1$ & 2 & 3 & 4 & 5 & 6 & 7 & 8 & 9 & 10
\end{tabular}
*Porcentaje de representación. **Puntuación añadida al IRP.

- Etnicidad $^{26}$ : Para medir la etnicidad tendremos un aproximación al total de grupos étnicos que conviven en cada caso y compararemos el porcentaje de cada grupo con el que está presente en su parlamento (Tabla 3). La escala para medir etnicidad será la misma, sólo que interpretándola de forma distinta. Se considerará la representación de manera proporcional a la que exista en la sociedad.

\footnotetext{
${ }^{24}$ Peter Ratchcliffe (2010), en Denisse Sepúlveda, La variable etnia/raza en los estudios de estratificación social, México, Proyecto desigualdades, Baja California, Universidad de la Frontera Norte, noviembre 2010, p.3.

${ }^{25}$ Ibid. Define la etnicidad como: Un complejo particular que involucra, siguiendo formas especificas de interrelación ciertas características culturales, sistemas de organización social, costumbres y normas comunes, pautas de conducta, lengua, tradición histórica, etcétera" [...] Etnicidad abarca el concepto de étnica y grupos étnicos".

${ }^{26}$ Menciona también Octavio Ianni que "las clases sociales tienden a subsumirse a los diferentes grupos [...] racial étnico, religioso, cultural, regional etcétera. Octavio Ianni, "El Estado y la cuestión nacional", en Pablo González Casanova (coord). El Estado en América Latina: Teoría y práctica, México, Siglo XXI, 3ra reimp., 2000, p.30.
} 
- Promedio de desproporciones: Primero se realiza una suma por partidos. Se resta del porcentaje de votos al partido el porcentaje de representación al parlamento. ${ }^{27}$ Puede estar sub-representado o sobre-representado. Se suma finalmente el resultado de cada partido. Las desproporciones sólo nos muestran cuanto se aleja del valor de cero, por ello no poseemos una escala y sólo consideraremos que mientras más alta sea ésta menos proporcional será al final. Es por ello que para efectos de este índice se restará la desproporción al 100 (\%) y el resultado en la diferencia de la desproporción es el que usaremos. Esto nos ayudará a que mientras más alta sea la desproporción menos puntuación obtendrá para este índice.

- Promedio de número de partidos por legislatura. Mientras más alto el promedio de partidos en la legislatura, habrá más representatividad en el parlamento. Esto lo mediremos según la media aritmética de cada periodo.

\footnotetext{
${ }^{27}$ Esta es la forma en que define Arend Lijphart las desproporciones. Arend Lijphart, Patterns of Democracy: Government Forms and Performance in Thirty-Six Democracies, New Haven, Yale University Press, 1999, p.57. Sin embargo, existe todo un debate sobre cuál es la fórmula más adecuada para medir las desproporciones. En esta investigación se optó por medirla de la manera más sencilla. Para más información al respecto de este debate y sobre las fallas del método que empleamos véase: Francisco A. Ocaña y Pablo Oñate, "Índices e indicadores del sistema electoral y del sistema de partidos. Una propuesta informática para su cálculo", en Revista Española de Investigaciones Sociológicas, n. 86, abril-junio 1999, pp.225-232.
} 


\section{Capítulo. 2. \\ Revisión de la literatura y marco teórico.}

La crisis de representación política en el parlamento, además de ser consecuencia de la intervención externa, de la corrupción y de las consecuentes crisis económicas, es resultado también del diseño de nuestras instituciones. La forma en que se diseñan las instituciones influye en la crisis de representación, porque al ser resultado de acuerdos elitistas y excluyentes, generan y promueven la exclusión en la toma de decisiones legislativa. ${ }^{28}$ La democracia representativa, en este sentido, no debe desaparecer como algunos arguyen sino reforzar sus mecanismos para que promuevan la inclusión.

Teóricamente, la verdadera democracia es en la que todos participan directamente de la toma de decisiones. No obstante, esta afirmación no puede realizarse de forma empírica, porque es imposible poner a millones de personas a tomar decisiones. Por ello, se delega poder a unos representantes; se institucionaliza entonces el poder de la comunidad política. ${ }^{29}$ Sin embargo, es necesario que se

\footnotetext{
${ }^{28}$ Roberto Gargarella, Crisis de representación política, Fontamara, 2002 p.9. Este autor analiza el caso de la constituyente estadounidense.

${ }^{29}$ Enrique Dussel, 20 Tesis de Política. México, Siglo XXI. 2a reimp, 2015. Menciona que "la unanimidad de la democracia directa es un postulado de la razón política; ideal y lógicamente pensable, pero empíricamente imposible. Fue posible en sociedades pequeñas, en parte en Fenicia o Grecia, en Venecia o en la Ginebra de Calvino; pero es factiblemente imposible en comunidades de millones de ciudadanos. Esto no niega la organización creciente de la participación". También menciona que "el consenso, que une las voluntades y ata al poder como fuerza conjunta, se puede alcanzar pero nunca de manera perfecta" (p .51-52).

Esto es una idea que pudo haber sido retomada de Derrida. Como menciona Jenn Webb, Understanding representation, Sage, Los Angeles, 2009: "Derrida points out that representation, whether in language or in politics, promises to deliver presence -to re-present, or bring back into presence something that was there" (p.201). Dussel menciona que el fundamento del poder es el pueblo y el cuerpo representativo es donde se debe manifestar ese poder institucionalizado. El cuerpo representativo trae el poder del pueblo presente ante el gobierno.
} 
mantenga el referente de que "el poder reside en el pueblo", una afirmación que la democracia directa cumple en sus postulados teóricos ${ }^{30}$

Así la democracia es representativa, no directa, siendo inevitable y necesaria para la toma de decisiones nacionales. La representación debe proponer acercar lo más posible la sociedad al parlamento para que los ciudadanos mantengan un control político sobre la institución y pueda cumplir su postulado democrático del "gobierno del pueblo". Estos fueron los fundamentos teóricos del gobierno representativo.

Para cumplir estas aspiraciones se deben aminorar los grados de exclusión que fomentan las instituciones. "La idea de gobierno representativo estuvo ligada desde el principio a la aceptación de diversidad social [...] dar voz a los distintos grupos sociales". ${ }^{31}$ Entre estos, las minorías, quienes en muchas ocasiones forman en su conjunto, la parte "mayoritaria" de una población. John Stuart Mill menciona que: "Es parte esencial de la democracia que las minorías tengan una justa representación; sin esto no hay verdadera democracia; solo existe una falsa experiencia de ella". 32

Sin embargo, este proceso de representación necesita sacrificar individualidades por comunidades, grupos, sectores, estratos, etc. ${ }^{33}$ El sufragio universal, medio por el cual los electores elijen sus preferencias políticas, no permite que las individualidades se vean reflejadas, sino que la organización de estos sujetos sea en

\footnotetext{
${ }^{30}$ Giovanni Sartori, ¿Qué es la democracia?, México, Taurus, 2007. Menciona que la "Democracia representativa...es una democracia indirecta en la que el demos no se autogobierna, si no que elige representantes para que lo gobiernen". (p.94).

${ }^{31}$ Bernard Manin, "Los principios de gobierno representativo", Alianza, Madrid, 1998. p.228. pp.206-207, en Pablo Armando Gonzalez Ulloa Aguirre, Declive y reconfiguración de la democracia representativa, México, Miguel Ángel Porrúa. 2009.

${ }^{32}$ Ibid,. p. 135 .

${ }^{33}$ Hay quienes están en contra de esta concepción por ejemplo: Mónica Brito Viera y David Runciman, Representation. Key Concepts, Malden, Massachusetts, 2008.
} 
colectivos. ${ }^{34}$ Es mediante la acumulación de votos que se puede obtener un escaño representativo. De manera que el legislador siempre representa mucho más que a un individuo, representa ideas, intereses grupales, entre otros.

La representación resulta ambigua porque, en la práctica, genera exclusión. ${ }^{35} \mathrm{El}$ representante "habla por otros" expresa las necesidades de grupos de individuos con ideologías, identidades, lenguajes u otros aspectos en común. ${ }^{36}$ Se excluye inevitablemente en la medida en que el cuerpo representativo no toma en cuenta todos los colectivos $\mathrm{y}$, además, descarta las individualidades. ${ }^{37}$ Aunque hay ambigüedades que son inevitables ${ }^{38}$, la ambigüedad que promueve la exclusión de colectivos puede modularse mediante la creación de instituciones incluyentes.

El sistema electoral es el proceso por el cual se institucionaliza el poder en un cuerpo representativo. ${ }^{39}$ Este proceso implica que la población delegue el poder a sus representantes el día de las elecciones buscando disminuir los grados de ambigüedad, al promover la inclusión de los diversos sectores que conforman la sociedad en la toma de decisiones. El sistema electoral explica cómo debe funcionar el proceso de institucionalización y puede determinar quienes obtienen o no representación. ${ }^{40}$

\footnotetext{
${ }^{34}$ Jenn Webb, Sage, p. 102, menciona: "Perhaps the biggest drawback to representative democracy is the fact that the principle of representation on the hand brings the ordinary person, "me" into the sphere of government, and on the other hand excludes the individual".

${ }^{35}$ Enrique Dussel, libro 20 Tesis de Política, México, Siglo XXI, 2ª reimp, 2015.

${ }^{36}$ Ibid, p.103.

${ }^{37}$ También porque no se está tomando el mensaje directamente y hay un intermediario que lo interpreta. Jenn Webb menciona que "under representative government the power of the people is limited by the need to trust their delegate". Op. cit., p.98.

${ }^{38}$ Es inevitable porque cada individuo interpreta subjetivamente la realidad y por ello, en el proceso de representación siempre existirán puntos de vista divergentes, incongruencias y desafecciones que estimulan la lucha por el poder.

${ }^{39}$ Enrique Dussell, op. cit., Siglo XXI. Menciona que la institucionalización del poder público implica que el pueblo al delegar un poder a un cuerpo deviene institución. De manera que en ese proceso el sistema electoral debe cumplir un rol importante.

${ }^{40}$ Esto quiere decir el cómo debe darse este proceso de institucionalización. Determina en realidad la mayor parte de un proceso de institucionalización al influir en describir cómo debe realizarse una contienda electoral y a quiénes se le otorgan curules.
} 
En un sistema electoral de mayoría se toman en cuenta los votos ganadores para otorgar la representación. En este caso quienes gozan de representación son los ganadores. Por el contrario, en sistemas electorales menos excluyentes, los perdedores intentan transferir estos votos proporcionalmente en escaños. Aunque en menor grado, este último también produce exclusiones y desproporciones por ser un sistema representativo. Así, el sistema electoral se define como los mecanismos, formas y maneras que explican cuáles votos serán tomados en cuenta para otorgar la representación en el parlamento.

La necesidad de crear modelos electorales más incluyentes aumenta en la medida en que los grupos sociales se multiplican a favor de su inclusión en la toma de decisiones. ${ }^{41}$ Pese al desencanto de los partidos políticos, se han multiplicado los modelos de partidos que ya no sólo responden a los valores tradicionales de clase. De ahí el surgimiento de partidos verdes, pacifistas, feministas, de nueva izquierda, nueva derecha, regionalistas ${ }^{42}$, étnicos ${ }^{43}$, entre otros. La llegada de nuevos sectores a la esfera política hace necesario crear instituciones que se adapten a esta realidad: "La democracia representativa, de aliento liberal, ha sufrido una transformación radical que lleva de lleno el problema de los partidos políticos. En los países desarrollados la universalización del sufragio masifica el ejercicio de la función electoral y hace necesario que se establezcan instituciones que encaucen la participación". 44

Se afirma también que de todos los retos que puede enfrentar en la actualidad el liberalismo político, entre los más apremiantes se encuentra la necesidad de

\footnotetext{
${ }^{41}$ Mihir Shah, "Ecology, Exclusion and Reform in Madhya Pradesh: An Introduction", Economic and Political Weekly, Vol. 40, No. 48, November 26 - December. 2, 2005. pp. 5009-5013. De igual forma se puede encontrar evidencia con el caso de Canadá en: Lisa Young, "Gender Equal Legislatures: Evaluating the Proposed Nunavut Electoral System". Canadian Public Policy / Analyse de Politiques .Vol. 23, No. 3, September, 1997, pp. 306-315.

${ }^{42}$ Marcos Novaro, Representación y liderazgo de las democracias contemporáneas, Rosario, Homo Sapiens, 2008, pp.27-28.

${ }^{43}$ Giovanni Sartori, Ingeniería constitucional comparada, México, Fondo de Cultura Económica, 1994.

${ }^{44}$ José Francisco Ruiz Massieu, Normación constitucional de los partidos políticos en América Latina, México, UNAM-Instituto de Investigaciones Jurídicas, 1974, p. 33.
} 
acomodar democráticamente las "colectividades territoriales" como las comunidades indígenas. "Ello se basa, cuando menos en parte, en la tendencia del liberalismo democrático tradicional al uso de categorías abstractas dotadas de un sentido uniformador que rehúye la pluralidad". 45

Ricard Zapata añade a esto que: "Fenómenos como la globalización, el multiculturalismo, o las nuevas relaciones internacionales [...] [implican que] la interpretación habitual de los valores liberales y democráticos fundamentales [...] requieren una reinterpretación". ${ }^{46}$

No es extraño que surjan afirmaciones como las de Boaventura de Sousa, quien menciona que "las luchas democráticas de los próximos años serán fundamentalmente luchas por esquemas institucionales alternativos". ${ }^{47}$ Añade este sociólogo: "El estado moderno [...] ahora [...] se limita a coordinar los distintos intereses [...] Esto significa que [...] el Estado está más directamente comprometido [...] con los criterios de inclusión y exclusión". 48

En el institucionalismo, de lo que se trata es de identificar la exclusión en la institución y proponer el diseño alternativo. Si se asume la necesidad de ser más inclusivos en el diseño se debe optar por sistemas electorales más representativos. Norbert Lechner está de acuerdo con la idea de que es necesario "perfeccionar los mecanismos de representación para que la sociedad influya cada vez más en las decisiones". ${ }^{49}$ Menciona este autor:“El problema de fondo radica, en reconstituir las capacidades estatales de conducción y coordinación en el momento mismo en

\footnotetext{
45 Ricard Zapata-Barrero, Ciudadanía, democracia y pluralismo cultural: Hacia un nuevo contrato social, Barcelona, Anthropos. 2001.

${ }^{46}$ Ibidem, p.viii. Este autor añade que "ya está vedado obtener la respuesta liberal y democrática correcta a los retos que implica el pluralismo", p.viii. Para más argumentos similares véase: Alessandro Ferrara, El horizonte democrático:el hiperpluralismo y la renovación del liberalismo político, Barcelona, Herder. 2014.

${ }^{47}$ Boaventura de Sousa Santos, Reinventar la democracia. Reinventar el Estado, Sequitur, Madrid, 1999, p.50.

${ }^{48}$ Ibid. p. 47.

${ }^{49}$ César Cansino, "La filosofía política", Enrique Dussel, Eduardo Medieta, Carmen Bohórquez (editores), en El pensamiento Filosófico latinoamericano, del Caribe y latino: (1300-2000). Historia, corrientes, temas, filosófos, Siglo XXI, México, 2011. p.460.
} 
que una creciente complejidad pone en entredicho al Estado, en tanto instancia general de representación y regulación social". ${ }^{50}$

¿Cómo puede un parlamento representar adecuadamente la sociedad? El sistema electoral organiza la forma y manera en que se va establecer la representación de la sociedad en el parlamento. Por eso es una herramienta esencial en el proceso de representación y por ello forma parte de la presente investigación como objeto de estudio.

Partimos en esta investigación de la necesidad de construir sistemas electorales altamente inclusivos que promuevan una alta representatividad de los estratos sociales en el parlamento.

La pregunta de la que parte nuestro argumento se deduce de lo que se ha mencionado hasta ahora: ¿Cómo se acuerdan sistemas electorales altamente representativos?; ¿Qué características debe tener un sistema electoral para que promueva una alta representatividad? ¿Son estas características suficientes para representar los estratos sociales? Nuestro argumento se compone de al menos tres facetas importantes que toman en cuenta (1) el principio, (2) las características y (3) el resultado ${ }^{51}$ del sistema electoral.

La primera pregunta se contesta argumentado que mientras más inclusivo sea el proceso por el cual se elabora o se reforma un sistema electoral, hay mayores posibilidades de que se adopte una fórmula electoral más cercana a una que promueva alta representatividad. Este proceso donde se construye el sistema electoral es el momento fundacional, que puede ser el momento en que se acuerda un nuevo modelo o cuándo se debe reformar. ${ }^{52}$

\footnotetext{
${ }^{50}$ Norbert Lechner, "La reforma del estado y el problema de la conducción política", Perfiles Latinoamericanos, n.7, México, 1996, p. 174.

${ }^{52}$ Se ha utilizado el momento fundacional para referirse a la etapa cuando se elabora la constitución. En esta investigación nos referimos al momento en que se crea un nuevo sistema electoral o al momento en que sólo se reforma algún aspecto en una dirección u otra, sea proporcional o mayoritaria.
} 
El argumento dos, unido al anterior, menciona que los sistemas más cerca de la lógica proporcional promueven una mayor representatividad de los diversos estratos sociales en el parlamento. Nos referimos a un sistema más cercano de la lógica proporcional dependiendo de las características que lo compongan.

La intención es evidenciar empíricamente los pasados argumentos con un estudio de caso. Para esto, se crearán los índices de representatividad correspondientes y se evaluará cómo se relacionan las variables. Se espera que los momentos fundacionales influyan, usando como intermediario el sistema electoral en su forma mecánica, en la representatividad que ha existido en la legislatura de Puerto Rico.

Esta investigación pretende aportar al debate sobre cuál es el mejor sistema electoral y proveer evidencia científica para que la politología pueda asumir posturas éticas en cuanto al diseño institucional y no, meramente, posturas pragmáticas. $^{53}$

\subsection{La representatividad en el momento fundacional}

En este primer apartado se describe la función de los sistemas electorales y el debate alrededor de éstos. Tomando en cuenta los diversos puntos de vista con respecto a cuál es el mejor sistema electoral, se asume una postura sobre este debate. Finalmente, se describe y justifica nuestra primera hipótesis que corresponde al momento fundacional del sistema electoral.

El sistema político se encarga de resolver conflictos, en teoría, de forma pacífica. ${ }^{54}$ Conflictos que pueden generarse de muchas maneras cuando se manifiestan las divergencias. Las estratificaciones étnicas y políticas influyen en el devenir

\footnotetext{
${ }^{53}$ Más adelante mencionamos estas posturas que regularmente argumentan que los sistemas electorales se adaptan a las circunstancias.

${ }^{54}$ Josep Grcic, Ethnics and Political Theory, Lanham, Maryland, 2000.
} 
político de una sociedad porque son materia de divergencias. La democracia facilita la toma de decisiones aglutinando divergencias y creando política pública. Es, en esto último, que la democracia puede ganar o perder calidad.

El sistema electoral juega un rol social al lograr que la mayor parte de los estratos sociales $^{55}$ organizados en partidos políticos queden reflejados en el parlamento. Gary $\mathrm{Cox}^{56}$ explica tres etapas donde interactúan los clivajes sociales, los partidos políticos y el sistema electoral. La primera etapa consiste en transformar los clivajes sociales en preferencias partidistas, la segunda en trasformar las preferencias partidistas en votos y la tercera en transformar los votos en escaños. Luego de ese primer paso, donde un estrato étnico, social, político o económico tiene interés de organizarse, el sistema electoral es pieza fundamental en la medida en que le permite convertirse en partido y obtener un escaño.

El sistema de mayoría relativa propone que el escaño se le otorgue al candidato con mayor número de votos. Convierte el proceso electoral en una competencia donde hay ganadores y perdedores. De esta forma, no toma en cuenta la estratificación social ni la necesidad de incluir, sino la necesidad de hegemonizar, lograr mayorías y que sobreviva el más fuerte. Es por ello que se le tiende a llamar "first past the post" y como evaluaremos más adelante fomenta los partidos grandes.

El modelo proporcional busca, en teoría, promover que los votos hacia los partidos se trasladen al parlamento de tal modo que el porcentaje de votos a cada partido y los porcentajes de representación al parlamento sean similares o iguales. Según Sartori, en el sistema de mayoría opera un efecto reductor del número de partidos

\footnotetext{
${ }^{55}$ Puede referirse a divisiones políticas meramente o entendiendo los estratos sociales como menciona Denisse Sepúlveda en "La variable etnia/raza en los estudios de estratificación social. Proyecto desigualdades. 2010. Incluye en la definición: género, raza, etnia, jerarquías económicas.

${ }^{56}$ Gary Cox, La coordinación estratégica de los sistemas electorales en el mundo. Hacer que los votos cuenten, México, Gedisa, 2004, p.45.
} 
en la medida en que aumenta el grado de exclusión que fomenta este mecanismo electoral.

Este autor ${ }^{57}$ también menciona que en el sistema proporcional puro no opera el efecto represor, sino que permite que los partidos formados obtengan representación. La estratificación social, grupos étnicos y/o grupos de género organizados en partidos políticos, pueden reflejarse en el parlamento porque no hay restricciones para que obtengan representación. Bajo esta lógica podemos afirmar que los modelos proporcionales se acercan más a modelos altamente representativos de los diversos estratos, es decir, en teoría fomentan una mayor representatividad. Esto va en consonancia con lo que ya se ha afirmado: El planteamiento de Duverger no es una ley, no lo ha sido nunca. Más bien es una tendencia.

El sistema de mayoría y el de segunda vuelta tienen una tendencia al monopartidismo o al bipartidismo, mientras el proporcional tiende al pluripartidismo. ${ }^{58}$ Una vez se asume esta realidad que tiene mayor fuerza en la primera tendencia que en la segunda, se puede asumir postura a favor o en contra de cualquier sistema electoral.

Es evidente que los defensores del sistema proporcional intentan fomentar la representatividad, que es el aspecto positivo de este facilitador de representación. Por su parte, los defensores del sistema de mayoría promueven la estabilidad y gobernabilidad en el congreso debido al disminuido grupo de partidos con representación.

En ocasiones, hay situaciones apremiantes en que la gobernabilidad es necesaria. El multipartidismo, se argumenta en ocasiones, impide que el sistema electoral

\footnotetext{
${ }^{57}$ Bien dice Sartori que "sostener que los sistema electorales son causados no implica que en ese momento se rompa la cadena causal". Giovanni Sartori, op. cit., Fondo de Cultura Económica, p.65.

${ }^{58}$ R. Taagepera (2015): "La balanza inclinada. Probando la 'Ley de Duverger' en el nivel nacional", De Política, México, AMECIP, núm. 4/5, pp. 9-20.
} 
arroje demandas. Mencionan Guy Hermet, Alan Rouquié y J. J. Linz" que: "El gusto por la unanimidad, la búsqueda incansable del consenso a través de la palabrería, tanto como el prestigio indiscutido de las autoridades sociales "naturales", haría del pluralismo competitivo algo así como una planta exótica mal adaptada al medio".

Por su parte, a pesar de que el multipartidismo puede generar ingobernabilidad también, André Blais ${ }^{60}$ y Juan Linz ${ }^{61}$, entienden que hay elementos importantes para lograr esta eficiencia legislativa, y que tienen que ver con los poderes de control de la agenda y las reglas del sistema de gobierno.

No obstante, en ocasiones se pone en duda la capacidad del pueblo para tomar decisiones. Se ha afirmado, por ejemplo, que "el pueblo no está listo para la democracia" ${ }^{62}$ y por ende, desde esta lógica absurda, sería mejor un modelo mayoritario porque hay una falta de "cultura del consenso". Esta es la visión pesimista, donde se entiende que quienes no tienen la capacidad no pueden participar de la toma de decisiones.

Contrario a esto, tener una concepción optimista del ser humano es entender que la sociedad y las diversas culturas e individuos pueden convivir en un régimen democrático y por ello es en el pueblo donde reside el poder. Confiamos en el poder del pueblo porque entendemos que las decisiones democráticas pueden no ser las correctas, pero si emergen de un poder soberano al menos son legítimas.

\footnotetext{
${ }^{59}$ Guy Hermet, Alan Rouquié y J. J. Linz, ¿Para qué sirven las elecciones?, FCE, México, 1982, p.89.

${ }^{60}$ André Blais, "El debate sobre los sistemas electorales". En Revista Conmemorativa del Colegio Nacional de Ciencias Políticas y Administración Pública. Coord: Víctor Alarcón Olguín y Héctor Zamitis Zamboa. México. 1999. pp. 187-224.

${ }^{61}$ Juan Linz. "The virtues of parlamentarism" Journal of democracy. V.1, n. 4. 1990, pp. 84-91.

${ }^{62}$ Este cuestionamiento se llevó a cabo en México (1917 y 1957), en Puerto Rico (1952), en Estados Unidos (1776). Es decir, específicamente en el momento en que se construía la constitución. Roberto Gargarella, Crisis de representación,. Fontamara. 2002. Evalúa el momento fundacional de los Estados Unidos y explica la concepción que se tenía: "Las mayorías no están capacitadas, por sí solas, a tomar decisiones adecuadas, en materias de interés público", (p.29).
} 
A su vez, si se tiene esta concepción optimista no hay razón para restringir la participación política. No obstante, existen en general concepciones pesimistas sobre los individuos dentro de los grupos de poder. Este razonamiento se utiliza como excusa para restringir la participación de quienes se tiene una concepción pesimista. Esto puede diferenciar regímenes democráticos de autocráticos, una visión optimista y otra pesimista del ser humano, respectivamente.

El que la elite tenga esta visión negativa (o actúe de manera clasista) de la población puede fomentar que las instituciones se configuren a espaldas de esta población menospreciada. Por ejemplo, el negro no cuenta como ciudadano, por ello se restringió el sufragio universal, se excluyó a los indígenas de los preceptos constitucionales liberales acordados en América Latina, y de igual forma también con base en esta lógica se construyeron modelos electorales excluyentes.

Aún cuando se considera que las condiciones son óptimas para dar prioridad a la gobernabilidad por encima de la representatividad, la exclusión puede dar resultados contraproducentes. ${ }^{63}$ Andrés Mejía Acosta y Juan Carlos Machado Puertas comentan, refiriéndose a la situación de los países andinos que: "En la última década estos países han sido víctimas de intensos conflictos políticos producidos por desacuerdos fundamentales entre élites tradicionales de gobierno, y la creciente presencia de una ciudadanía insatisfecha con los desempeños socioeconómicos que busca una mayor inclusión en la toma de decisiones”. ${ }^{64}$

Estos autores añaden varias razones por las que se explica la inestabilidad en dicha zona, entre las cuales se encuentra "la incompleta inclusión de grupos y regiones

\footnotetext{
${ }^{63}$ El debate sobre la gobernabilidad y la estabilidad tiene importancia en Italia, por ejemplo, donde el sistema multipartidista ha resultado en inestabilidades parlamentarias indeseadas. Es por eso que Mateo Renzi, al llegar a formar gobierno insistió en que uno de sus proyectos medulares era la reforma electoral, llamada italicum.

${ }^{64}$ Andrés Mejía Acosta y Juan Carlos Machado Puertas: "La democracia asfixiada en los Andes Altos. Elecciones e inestabilidad en Bolivia, Ecuador y Perú”, en Manuel Alcántara Sáez y Fátima García Díez (coords). Elecciones y política en América Latina. México, IEEM-SOMEE-Miguel Ángel Porrúa, 2008, p. 176.
} 
en el proceso político". ${ }^{65}$ Bolivia, mencionan los autores, teniendo un modelo proporcional, promovió el multipartidismo en conjunto con una estructura presidencial. ${ }^{66}$ Así también, Perú tiene un modelo proporcional que se combina con un sistema de gobierno que, si bien es presidencial, se asemeja al parlamentarismo. ${ }^{67}$

Estos modelos crearon inestabilidad en los respectivos parlamentos multipartidistas y se optó, en Bolivia, por crear bloques de mayoría y en Perú el presidente Alberto Fujimori acabó “con las instituciones fundamentales para construir una democracia". ${ }^{68}$ Sin embargo, la llegada de la estabilidad, a costa de la representación, excluyó, en el caso de Bolivia, a "sectores rurales e indígenas". 69 En el Perú se excluyó a todo lo que implicaba oposición política. Ambos contextos, por supuesto, han alterado la estabilidad política y aumentado las movilizaciones porque los grupos dejaron de formar parte de la toma de decisiones.

Perú y Bolivia son ejemplos de que al momento que la estabilidad se convierte en un principio o necesidad más importante que la representación, comienza un proceso de exclusión contraproducente. Las elecciones no son simples competencias; también son procesos en los cuales se da un traspaso del poder político. Ser el perdedor en unas elecciones consideradas como competencia tiene implicaciones importantes en los estratos sociales no representados y en la legitimidad de la que puede gozar una institución. Nohlen ${ }^{70}$ menciona que: "Una

\footnotetext{
${ }^{65}$ Ibid.

${ }^{66}$ Juan Linz menciona que un sistema presidencial con una estructura multipartidista puede resultar en inestabilidad porque en ocasiones el poder legislativo plural se enfrenta a un poder presidencial fuerte. Por ello, para este autor lo ideal sería que fueran estructuras pluripartidistas pero en un sistema parlamentario. Ver: Larry Diamond y Marc F. Plattner, El resurgimiento global de la democracia, UNAM-IIS, México, 1996.

${ }^{67}$ Mark Payne, Daniel Zovatto y Mercedes Mateo, La política importa. Democracia y desarrollo en América Latina, Washington, D.C: Banco Internacional de Desarrollo e Instituto Internacional para la Democracia y la Asistencia Electoral, 2006.

${ }^{68}$ Acosta Mejía y Machado Puertas, op. cit., Miguel Angel Porrua, p. 178.

${ }^{69}$ Ibid.

${ }^{70}$ Dieter Nohlen, Elecciones y sistemas electorales, Caracas, Nueva Sociedad -Fundación Friedrich Ebert, 1995, p.125.
} 
sociedad fragmentada en términos étnicos sería totalmente equivocado no tomar en cuenta el tema de la representación política" ${ }^{, 1}[. .$.$] Hay expertos que ven en la$ etnicidad, mejor dicho, en la politización de la etnicidad, una circunstancia que puede impedir el desarrollo de la democracia como forma de gobierno". ${ }^{72}$

$\mathrm{El}$ argumento que se ha esgrimido en contra del principio de representatividad es que mientras más partidos estén presentes en un congreso, mayor dificultad encontrarán en pasar proyectos. Es decir, que la representatividad es inversamente proporcional a la gobernabilidad y la estabilidad legislativa. Sin embargo, los sistemas de mayoría al excluir pueden tener efectos contraproducentes.

En el debate sistema mayoritario vs. proporcional (o de igual forma a veces se puede reducir a representatividad vs. gobernabilidad) también se han intentado buscar diversos puntos medios. Una faceta en este debate trata de no asumir postura con respecto a qué sistema es mejor que otro. Esta postura es la pragmática que postula la ciencia política cuando entiende que cada caso tiene sus particularidades, pero que postula mal cuando no asume posición y reduce la contestación de sus preguntas de investigación a un solo elemento.

Es cierto lo que menciona André Blais ${ }^{73}$ de que en todo sistema electoral se beneficia a unos y se perjudica a otros. Pero, desde nuestra perspectiva, si se tiene una concepción optimista del ciudadano, de lo que se trata es de reducir esos grados de exclusión y de desigualdad en la representación. Lo contrario sería argumentar en contra de que otros sectores participan. Pippa Norris ${ }^{74}$ menciona que no hay ningún sistema electoral perfecto, sino que se adaptan a los contextos y a sus respectivas realidades.

\footnotetext{
${ }^{71}$ Ibid.

${ }^{72}$ Ibid.

${ }^{73}$ Agnieska Dobrzynska y Inridi H. Indridason, "To Adopt or Not to Adopt Proportional Representation: The Politics of Institutional Choice “, British Journal of Political Science,. Volume 35 / Issue 01 / January 2005, pp. 182-190.

${ }^{74}$ Pippa Norris, “Choosing Electoral Systems: Proportional, Majoritarian and Mixed Systems”, en International Political Science Review Vol.18, No. 3, (Jul., 1997), pp.297-312.
} 
En el mismo sentido de querer conciliar el debate sobre cuál es el mejor sistema electoral, Dieter Nohlen ${ }^{75}$ argumenta:“Cuanto mayor es la fragmentación social más probable será la adopción de un sistema proporcional, así como el surgimiento de un sistema multipartidista, cuanto mayor es la homogeneidad social, más probable será la adopción del sistema de mayoría relativa, pero también habrá más probabilidades de que surja un sistema bipartidista o un pluralismo limitado..."

A pesar de que la postura de Nohlen tiene lógica y coincide incluso con Pippa Norris, es parcialmente cierta. Obvia, de alguna manera, que un país con alta heterogeneidad social pueda escoger modelos excluyentes. Ya sea porque tenga un sistema electoral impuesto o porque en los procesos de construcción de una institución electoral se dieran casos de exclusión que resultaran en instituciones igualmente excluyentes. Un sistema electoral puede servir a los intereses de un partido de mayoría en la legislatura, pero esto no implica que sirva a los intereses de la mayoría de la población.

Cuando hay grandes desproporciones entre los votos, o cuando hay sobrerrepresentación de un partido en el parlamento, hay exclusiones importantes. Estas desproporciones, que muestra claramente Lijphart ${ }^{76}$, son contrarias a la representatividad, en la medida en que aumenta la sub y sobre representación. De manera conceptual, cuando se promueve la representatividad se promueve inclusión y en la medida en que se producen más altas desproporciones más aumentan las exclusiones. La adopción de un modelo mayoritario siempre tendrá la exclusión como consecuencia y de esta forma podría no adaptarse a las condiciones de heterogeneidad u homogeneidad social. Por eso, la lógica de

\footnotetext{
75 Dieter Nohlen, Sistemas Electorales y Partidos Políticos, México, Fondo de Cultura Económica, 2004 , p.333. También se encuentra en Gary Cox, op. cit., Gedisa, p.38.

76 Arend Lijphart, Patterns of Democracy: Government Forms and Performance in Thirty-Six Democracies, New Haven: Yale University Press, 1999.
} 
Nohlen sólo explica parcialmente por qué en ocasiones circunstancias exógenas o internas pueden promover sistemas que no se adaptan a la sociedad y a la cultura.

Es por ello que es necesario evaluar el momento fundacional de un sistema electoral. Aunque se puede argumentar a favor de la inclusión para defender modelos que promuevan la representatividad, es a causa de la escasez de estudios sobre el origen de las normas electorales que el debate sobre cuál es el mejor sistema se confunde. Es importante el estudio sobre los procesos fundacionales de los sistemas electorales porque al igual que se reconoce, como lo hicieron Max Weber, Maurice Duverger y Angelo Panebianco, que el momento fundacional de un partido determina su evolución y desarrollo. Se puede afirmar entonces que el momento fundacional de un sistema electoral influye en su configuración y resultados.

También es importante para reseñar que los sistemas electorales no necesariamente se adaptan a las necesidades o realidades de un país. Si bien el sistema electoral siempre responde al contexto, también es afectado por las presiones y la realidad del desequilibrio en la repartición de recursos, al igual que a la desigualdad política, a la realidad colonial en muchos casos, o a los intereses de una élite económica y política.

El "quiénes" y el "cómo" del momento fundacional de un sistema electoral explican una parte importante del sistema electoral que se adopta e incluso pudiera explicar los resultados. El cambio institucional se da en un sentido o en otro dependiendo de quienes lo soliciten y de quienes lo elaboren o diseñen. ${ }^{77}$

Se dice que una alta heterogeneidad social puede afectar la estabilidad en un país. A pesar de que esta afirmación encuentra evidencia empírica, Rodolfo

\footnotetext{
${ }^{77}$ Pedro Riera Sagrega, "Los sistemas electorales y la cigüeña. Sobre el origen y la reforma de las reglas del juego democrático", en Revista Española de Investigaciones Sociológicas, Madrid, CIS, no.142, Abril-Junio 2013, pp.141-150.
} 
Stavenhagen ${ }^{78}$ demuestra cómo la intervención externa, especialmente de parte de las potencias mundiales como EE.UU, exacerba y polariza estos conflictos. Esto sucede cuando las potencias mundiales crean instituciones que excluyen a diversos sectores de los procesos en la toma de decisiones y favorecen otros.

Muy común es ese tipo de acciones bajo sistemas coloniales, donde la imposición de leyes e instituciones es la orden del día. De hecho, la forma más común de cambiar o establecer un sistema electoral, es mediante la imposición por parte de una élite política o económica. Al menos esto nos menciona Remwick ${ }^{79}$ en su estudio comparado. No es difícil de presumir que la mayor parte de los sistemas electorales en el mundo se han implementado de forma impositiva. Mucho más cuando sabemos y conocemos la historia de coloniaje que ha vivido América.

Así como puede suceder con influencias de las potencias, también podemos encontrar que una elite política o económica construye instituciones para mantenerse en el poder. Es muy común en partidos de mayoría con supremacía parlamentaria, crear mecanismos electorales restrictivos o intentar mantener el status quo en este sentido. De hecho, ya Katz ${ }^{80}$ nos evidenció este hecho, al igual Renwick $^{81}$ y Lundell ${ }^{82}$, de que los partidos con la capacidad de modificar las reglas electorales son los menos interesados en que se produzcan estos cambios. Menciona Sartori ${ }^{83}$ que la discusión política en estos casos de mayoría se da siempre de manera centrípeta, dirigido a no alejarse del status quo.

Sin embargo, podemos encontrar otras formas de creación del sistema electoral que si responden a realidades sociales. Dieter Nohlen menciona que:"No solo los

\footnotetext{
${ }^{78}$ Rodolfo Stavenhagen, Conflictos étnicos y Estado Nacional, México, Siglo XXI, 2000.

${ }^{79}$ Alan Renwick, The Politics of Electoral Reform: Changing the Rules of Democracy, Nueva York, Cambridge University Press, 2010.

${ }^{80}$ Richard Katz, "Why Are There So Many (or So Few) Electoral Reforms?" en M. Gallagher y P. Mitchell (eds.), The Politics of Electoral Systems, Nueva York: Oxford University Press, 2005, pp.57-76.

${ }^{81}$ Alan Renwick, op. cit., Cambridge University Press.

${ }^{82}$ Krister Lundell, The Origin of Electoral Systems in the Postwar Era: A Worldwide Approach, Nueva York, Routledge, 2010.

${ }^{83}$ Giovanni Sartori, op. cit.,.Fondo de Cultura Económica.
} 
ganadores habituales, sino también los perdedores permanentes pueden adaptarse a jugar con las reglas del juego existentes como consecuencia de los altos costes y los inciertos beneficios esperados de un cambio institucional hipotético." 84

También, los grupos excluidos pueden reclamar mayor apertura en el sistema electoral. Por lo que Nohlen añade que:"Puede considerarse que un sistema electoral es relativamente estable si, dadas las oportunidades que este proporciona a los actores para ganar o compartir poder político e institucional, ninguno de ellos considera rentable emprender nuevas iniciativas para cambiar las reglas del juego". 85

Los grupos no representados, además de los partidos en el poder, pueden sentirse insatisfechos con respecto al sistema electoral. De esta forma se promueven cambios hacia la inclusión. Colomer entendía que el mundo se dirigía hacia una mayor ampliación del sistema electoral, es decir, hacia sistemas menos excluyentes.

Según este autor, los sistemas electorales estarían encaminados a ser cada vez más proporcionales: "Los cambios del sistema electoral tienden a producirse en una inmensa mayor parte a favor de fórmulas cada vez mas incluyentes y menos arriesgadas: desde las elecciones indirectas hacia directas, desde la regla de unanimidad hacia la mayoría, y desde ésta hacia sistemas mixtos y de representación proporcional". ${ }^{86}$

Esto último, Colomer, lo denomina "la regla micro-mega" ya que "el grande prefiere lo pequeño y el pequeño prefiere lo grande". ${ }^{87}$ Partidos grandes prefieren reglas electorales restrictivas y partidos pequeños reglas electorales permisivas.

\footnotetext{
${ }^{84}$ Ibid.

${ }^{85}$ Alan Renwick, op. cit., Cambridge University Press, 2010. Define en parte esta faceta como negociación elitemasa, una forma muy reducida de clasificarlo.

${ }^{86}$ Josep Colomer, Cómo votamos. Los sistemas electorales en el mundo: Pasado, presente y futuro, Gedisa, Barcelona, 2004. p.27.

${ }^{87}$ Ibid. p.25.
} 
Por esto, los sistemas electorales, al pretender absorber la pluralidad de partidos, promueven una menor restricción en las reglas. Es una visión muy similar a la que narra Carstairs, quien había observado que el aumento de la democratización tuvo como consecuencia un aumento en la adopción de los sistemas de representación proporcional. ${ }^{88}$ Algo que parece afirmar la regla de Colomer. Sin embargo, esta afirmación ha sido refutada.

Para Renwick ${ }^{89}$ una presencia de múltiples partidos en el parlamento no es incentivo suficiente para que se produzcan cambios hacia sistemas electorales más permisivos. De manera que hay estudios en contraposición. Sin embargo, el estudio de Colomer contiene más casos que el de Renwick y es evidentemente más riguroso en varios aspectos.

En primer lugar contiene una mayor narración histórica universal y toma en cuenta la mayor parte de las características del sistema electoral. Contrario al estudio de Renwick, que es muy limitado en su definición de sistema electoral, considera cuatro casos que incluso no elabora mucho en sus respectivos contextos históricos. Sartori, en el mismo sentido, menciona el caso de Italia para contrarrestar la regla micro-mega, describiéndolo como el "tiro de gracia" de la hipótesis de Colomer. Aún así, aunque hay casos que contrarrestan la predicción de que los sistemas electorales se dirigen a ser más inclusivos. Sería pertinente evaluar quiénes y cómo decidieron este cambio al sistema electoral mayoritario, para conocer sus intenciones y analizar quiénes se excluyen bajo el modelo mayoritario.

Esto pudiera explicar por qué no se cumple la profecía de Colomer. Sin embargo, y sin llegar a evaluar este proceso, podemos afirmar que no importa cuáles sean sus fines, el sistema de mayoría en su carácter puro tiende a la exclusión.

\footnotetext{
${ }^{88}$ Andrew M. Carstairs, A Short History of Electoral Systems in Western Europe, London, Routledge, 2010.

${ }^{89}$ Alan Renwick., op. cit., Cambridge University Press.
} 
Pero también, encontramos que en Canadá, Tailandia, Japón, Gran Bretaña o Nueva Zelanda, diversos grupos han exigido o menor exclusión de parte del sistema electoral, o bien mayor control sobre la papeleta. Colomer afirmaba, en el mismo sentido, que: "cuanto más restrictivo y excluyente sea el sistema electoral existente -como los basados en reglas de mayoría-, y cuanto mayor sea el número de partidos con apoyo popular o expectativas razonables de obtenerlo, más fuertes serán las presiones para cambiar el sistema a favor de fórmulas más permisivas e incluyentes". 90

Ha habido cambios hacia modelos más cercanos de la lógica mayoritaria, pero estos no pueden responder al propósito de inclusión. Sería necesario analizar el momento fundacional de un sistema electoral para conocer los grados de exclusión que hubo en este proceso. Hay varios estudios ${ }^{91}$ que se han preguntado: "por qué algunos países adoptaron fórmulas de representación proporcional a principios del siglo XX; también se han preguntado cuáles son los factores que explican la expansión de los sistemas mixtos en la década de los noventa". ${ }^{92}$

\footnotetext{
${ }^{90}$ Ibidem.

${ }^{91}$ Josephine Andrews y Robert W. Jackman, "Strategic Fools: Electoral Rule Choice under Extreme Uncertainty", Electoral Studies, V.24, 2005, pp. 65-84.

André Blais, Agnieszka Dobrzynska e Indridi H. Indridason, "To Adopt or Not to Adopt Proportional Representation: The Politics of Institutional Choice”, British Journal of Political Science, 35: 182-190. 2004.

Carles Boix, "Setting the Rules of the Game: The Choice of Electoral Systems in Advanced Democracies", American Political Science Review, V.93, n.3, 609-624. 1999.

Ernesto Calvo, "The Competitive Road to Proportional Representation, Partisan Biases and Electoral Regime under Increasing Party Competition", World Politics, V.61, n.2, 2009, pp. 254-295.

Thomas Cusack., Torben Iversen y David Soskice, "Economic Interests and the Origins of Electoral Systems", American Political Science Review", V.101, n. 3, 2007, pp. 373-391..

Markus Kreuzer, "Historical Knowledge and Quantitative Analysis: The Case of the Origins of Proportional Representation". American Political Science Review, V. 104, n.2, 2010. pp. 369-392.

Alberto Penadés, "The Institutional Preferences of Early Socialist Parties. Choosing Rules for Government", en J. Ma. Maravall e I.Sánchez-Cuenca (eds.) Controlling Governments: Voters, Institutions and Accountability, Nueva York, Cambridge University Press. 2008.

Matthew Shugart, "Extreme Electoral Systems and the Appeal of the Mixed-Member Alternative", en Michael Gallagher y Mitchell (eds.), The Politics of Electoral Systems, Nueva York, Oxford University Press, 2001.

${ }_{92}$ Pedro Rivera Sagrega, "Los sistemas electorales y la cigüeña. Sobre el origen y la reforma de las reglas del juego democrático”. Revista Española de Investigaciones Sociológicas, no.142, abril-junio, 2013, p.141.
} 
Dos textos importantes en esta materia, son el de Renwick ${ }^{93}$ y el de Lundell ${ }^{94}$. El primero considera cuatro casos y el segundo considera varios casos desde 19452007. Renwick menciona que es necesario desechar la hipótesis de que los sistemas proporcionales son adoptados donde hay múltiples partidos. Ambos autores, mencionan que en las próximas reformas electorales habrá más interacción de la ciudadanía, pero esto no implica reformas inclusivas al sistema electoral.

Estos estudios sólo toman en cuenta el aspecto mecánico del sistema electoral. Para Lundell, la característica primordial de un sistema electoral radica que "en su funcionamiento opere un método de divisores y cuotas". 95 No analiza los resultados de los sistemas electorales. De igual forma, sólo toman en cuenta si la fórmula electoral es proporcional, mayoritaria o mixta, y no evalúan las circunscripciones y sus tamaños; tampoco consideran todos los aspectos del diseño de la papeleta, ni los umbrales legales, ni cuotas etc.

Su objeto de estudio es analizado de forma muy limitada. ${ }^{96}$ Ninguno de los dos autores considera el contexto, un elemento esencial para realizar un análisis del momento fundacional que nos permita conocer los grados de democratización del momento. Esto a pesar de que Renwick reconoce que los factores exógenos como la historia, el cambio de ideas, la naturaleza de los partidos, de otros actores individuales, o del sistema de partidos, las instituciones del estado, o un conjunto residual de eventos y circunstancias terminan siendo influyentes en estos procesos de reforma del sistema electoral. ${ }^{97}$

\footnotetext{
${ }^{93}$ Alan Renwick, op. cit., Cambridge University Press.

${ }^{94}$ Krister Lundell, The Origin of Electoral Systems in the Postwar Era: A Worldwide Approach, Nueva York. Routledge,.2010.

${ }_{95}$ Pedro Riera Sagrega. Op. cit., Revista de investigaciones Sociológicas, p.141.

${ }^{96}$ Pedro Riera Sagrega critica a Lunbell y Renwick porque el primero menciona:

"No creo que favorezca en nada el producto final el hecho de que la evidencia multivariable llegue en el penúltimo capítulo y que los modelos econométricos no tengan en cuenta convenientemente la estructura temporal de sección cruzada que presentan los datos", Ibid., p. 148.

El segundo por su parte solo considera cuatro democracias consolidadas: Francia, Italia, Japón y Nueva Zelanda.

${ }^{97}$ Alan Renwick., op. cit., Cambridge University Press.
} 
Ambas investigaciones desconocen las exclusiones, porque no toman en cuenta la división social y la división ideológico-política. Sería pertinente no sólo definir más ampliamente el sistema electoral con el contexto, sino también la historia del sistema electoral y de partidos, así como sus fragmentaciones sociales. Solo así podremos tener una compresión más clara de por qué en un momento fundacional se adoptan ciertos sistemas electorales y de por qué se ha mantenido tal o cual sistema de partidos.

De ahí, que nuestra pretensión sea añadir estos elementos a nuestra investigación y argumentar en un sentido contrario, no porque entendamos que estos estudios carezcan de lógica-teórica, sino por la falta de trasfondo histórico-contextual y de una mejor conceptualización. A pesar de que ambos autores entienden que los episodios de reforma electoral son muy complejos para realizar tipologías, Lundell entiende que esto no quiere decir que escapen a nuestro entendimiento. Por su parte Renwick, quien enfatiza mucho en la complejidad de estos procesos, establece un patrón basado en elementos que consideran la inclusión y exclusión. Menciona: Los cambios se producen dependiendo de si en el momento de la reforma electoral la coalición partidista mantiene o no la mayoría.

Esto abona a nuestra hipótesis porque si el grupo de personas que acuerdan o reforman un sistema electoral no es de múltiples partidos sino que es una mayoría aplastante, sería extraño que adoptasen modelos que fomenten la representatividad y sería más común que adopten modelos que les permita controlar el poder político en el parlamento.

Por el contrario, mientras más colectivos participen de este proceso de acordar un sistema electoral, entonces habrá un mayor número de estos colectivos, partidos, etc. que buscarán representación en el parlamento. Porque los actores, sujetos y colectivos, al momento de querer acordar una institución que los represente 
intentarán "maximizar sus utilidades, sus beneficios". ${ }^{98}$ Por ello, es más probable que se adopte un sistema que promueva una mayor representatividad.

De acuerdo a nuestro argumento y algunos ejemplos que hemos utilizado de Colomer, Nohlen, Renwick, Carstairs y Lundell, podemos deducir que las veces que se llega a acuerdos a favor de características más cercanas de la lógica proporcional hay:

a) Partidos en el poder conscientes de que han perdido la capacidad de ganar elecciones. Así que para las siguientes elecciones tendrán que reformar el modelo. b) Pluralidad de partidos y/o estratos en los procesos de negociación de un momento fundacional.

Y cuando se tiende a escoger modelos más cerca del sistema mayoritario hay:

a) Situaciones no democráticas donde la oposición es excluida del proceso de fundación del sistema electoral. Esto podría implicar un partido de mayoría en el poder con conocimiento de que pueden continuar obteniendo la mayoría de escaños con algunos ajustes al sistema electoral.

Nuestro primer argumento menciona que si los momentos fundacionales son representativos de los estratos sociales, éstos tenderán a acordar modelos electorales más cercanos de la lógica proporcional. A diferencia de si son poco representativos se tenderá a escoger sistemas electorales más cercanos de la lógica mayoritaria.

Las asambleas constituyentes, como ejemplo de momento fundacional, pueden verse como una forma de pactar un acuerdo institucional de manera abierta y por

\footnotetext{
${ }^{98}$ Anthony Downs, An Economic Theory of Democracy, Adison-Wesley. México City, 1956. Queremos añadir que esta idea de explicar el cambio político y de concebir los actores como seres racionales de Josep Colomer, Transición a la democracia española, Madrid, Anagrama, 1998.
} 
tanto inclusiva. Pero si los procesos para elegir constituyentes se impulsan con métodos de mayoría se estaría propiciando la exclusión.

A pesar de que la asamblea constituyente es más inclusiva que un proceso de reforma solo en el legislativo, esto no garantiza que será lo suficientemente representativa de los diversos sectores que conforman la población. Lo que nos garantiza la representación adecuada de los estratos sociales es el modelo de elección más allegado a la proporcionalidad que, a su vez, promueva una mayor representatividad para la constituyente. También, para evaluar la representatividad de este proceso se tendría que considerar la magnitud del grupo excluido.

Bajo cualquier escenario, desde nuestro punto de vista, los grupos intentarán maximizar sus beneficios o, en este caso, asegurarse la mayor representación política posible. Es cierto desde este punto de vista lo que menciona Scott Mainwaring: "Las leyes electorales generalmente se instituyen y cambian más para proteger y favorecer algunos intereses que para realizar un ideal que promueva el sistema electoral". 99

Un partido que tenga expectativas negativas puede promover modelos proporcionales para su beneficio en las próximas elecciones, pero esto lo hace a favor de la representación (consciente o inconscientemente). También cuando un partido en minoría exige cambios al sistema electoral para obtener mayor representación en el parlamento, lo hace promoviendo la representatividad. Esto no sólo beneficia a una minoría sino a varias. La inclusión en la representación parlamentaria es un beneficio colectivo.

Los casos que pudieran contrariar nuestra primera hipótesis son los momentos en que las élites promueven representatividad y las masas reclaman el sistema

\footnotetext{
${ }^{99}$ Scott Mainwaring, Politicians, parties and electoral systems: Brazil in comparative perspective, Notre Dame, The Helen Kellog Institute, Working Paper \#141, Junio de 1990.
} 
mayoritario. Sólo con una evaluación de estos procesos podemos conocer si dichos casos existen y por qué.

Para lograr fomentar la representatividad es necesario conocer cuáles son las características del sistema electoral que técnicamente pueden ayudar en este aspecto ¿Cuáles son las características del sistema electoral que fomentan la representatividad?

\subsection{La representatividad que promueven los sistemas electorales en el parlamento}

En la presente sección se enmarca, primero, el debate sobre las leyes de Duverger. Luego, describimos los componentes de los sistemas electorales. Y por último, se enumeran y explican qué características debería tener un modelo electoral para que promueva una alta representatividad en el parlamento.

Nuestra tarea consiste en identificar las características del sistema electoral que promuevan una mayor inclusión de los diversos estratos sociales en el parlamento. El sistema electoral tiene un efecto importante en el comportamiento de los individuos, pero también tiene efectos mecánicos al momento de traducir los votos en escaños. Ambos efectos tienden a la exclusión.

Las tendencias de Duverger establecen que los sistemas electorales de mayoría relativa y con segunda vuelta "favorecen el formato bipartidista" y los de representación proporcional "favorecen el multipartidismo". El sistema de mayoría puro tiene dos efectos: uno psicológico y otro mecánico. En el primero, cuando hay dos partidos grandes, estructurados alrededor de todas las circunscripciones, se comienza a crear la idea de que no hay alternativas con excepción del menos malo de los partidos de mayoría. De esta forma, funciona elección tras elección una 
fuerza centrípeta que promueve el bipartidismo y que excluye a terceros y cuartos partidos. 100

En el sistema de mayoría con segunda vuelta, donde el ganador debe obtener una mayoría absoluta de votos, el elector, puede ejercer el voto por su primera preferencia en la primera vuelta y en la segunda votar por candidatos que el elector considere como "menos malos"101. En el sistema proporcional, además de quedar anulado el efecto psicológico, tampoco incide el efecto mecánico, según Duverger. El efecto mecánico se resume "en el caso de mayoría simple a una vuelta [cuando] se produce sub-representación del tercer partido, en virtud de que los dos partidos principales disputan los triunfos de mayoría en los distritos electorales". ${ }^{102} \mathrm{El}$ efecto mecánico del sistema de mayoría, como solo le otorga un curul al ganador, excluye al perdedor.

Como el sistema proporcional (RP), suponiendo que es un sistema puro, intenta repartir escaños para la mayor parte de los contendientes que recibieron algún apoyo electoral, anula el efecto mecánico de exclusión. Por ello, un sistema RP suele promover el multipartidismo. Cuando Douglas Rae somete a prueba la primera ley de Duverger encuentra que un $89.7 \%$ de los casos caen dentro de la primera regla de Duverger: el sistema de mayoría promueve el bipartidismo. ${ }^{103}$

Aunque el debate sobre las preposiciones de Duverger giró en torno a las afirmaciones causales que este proponía, se puede reconocer que en el debate hay una aceptación de que nada es unidimensional. Bien dice Sartori "sostener que los sistema electorales son causados no implica que en ese momento se rompa la cadena causal"'. 104

\footnotetext{
${ }^{100}$ Giovanni Sartori, op. cit.., Fondo de Cultura Económico.

${ }^{101}$ Maurice Duverger, Los partidos políticos, México, Fondo de Cultura Económico, 2015.

${ }^{102}$ Leornado Valdés Zurita, "El efecto mecánico de la fórmula electoral mexicana: 1964-1991”, Revista Polis, México, UAM-Iztapalapa, 1994, Se puede consultar en página web: www.juridicas.unam.mx.

${ }^{103}$ Giovanni Sartori, op. cit., Fondo de Cultura Económica, Versión Kindle.

${ }^{104}$ Ibid, p.558.
} 
De lo que se trata es de dar explicación a una parte de estas dimensiones. ${ }^{105}$ Por supuesto que hay sistemas mayoritarios con multipartidismos, al igual que modelos proporcionales restrictivos a las minorías. Pero esta primera afirmación no implica que los modelos mayoritarios promuevan la inclusión y para la segunda afirmación habría que evaluar las características específicas que restringen los partidos pequeños.

Podemos afirmar que el sistema electoral tiene efectos sobre la vida política, pero también es necesario admitir que los efectos de las reglas electorales están mediados por otras cosas. "Reglas electorales aparentemente idénticas pueden dar lugar a resultados muy diferentes en diferentes escenarios políticos". ${ }^{106}$

Como mencionamos en la introducción del capítulo, es difícil negar que tanto el diseño electoral como los clivajes sociales tengan un rol importante en el número de partidos políticos reflejados en escaños. Debe existir un estrato étnico, social, político o económico con interés de organizarse, pero luego de ese primer paso el sistema electoral es pieza fundamental en la medida en que le permite convertirse en partido y obtener un curul. La llegada de un estrato social organizado políticamente al parlamento depende en buena medida de características y aspectos que componen los sistemas electorales.

La pregunta que sigue en la lógica de nuestra argumentación es: ¿Cómo lograr un sistema electoral verdaderamente representativo? La contestación no se reduce al modelo proporcional. Como menciona Leonardo Valdés: "Es verdad que existen dos principios básicos de representación política: el mayoritario y el proporcional, pero ambos pueden materializarse de muy diversas maneras e incluso combinarse,

\footnotetext{
${ }^{105}$ Boaventura de Sousa Santos, Epistemología del Sur, México, Siglo XXI, 2009. En su introducción tiene varios ejemplos de por qué nada es unidimensional o por qué nada es predecible ni siquiera en las ciencias físicas o el resto de las ciencias "exactas".

${ }^{106}$ Shaun Bowler y Bernard Grofman, 2000. Citados por Josep Colomer, Cómo votamos. Los sistemas electorales en el mundo: Pasado, presente y futuro, Gedisa, Barcelona, 2004, p.13.
} 
dando lugar a una amplia gama de opciones y a una extensa tipología de sistemas electorales". ${ }^{107}$

Hay diversas combinaciones de sistemas electorales. En la tipología científica están en uso diversos nombres para referirse a un mismo sistema electoral. Estas diferentes denominaciones de los sistemas electorales suelen diferenciarse entre sí solo en una característica del modelo. Por ello, en el presente trabajo en vez de describir cada uno de los sistemas electorales, se abordará su composición tal y como lo describe David Farrell ${ }^{108}$, pero teniendo también como referencia a otros autores, como Dieter Nohlen, a pesar de que no se utilice una tipología como tal.

En primer lugar, la construcción de un sistema electoral puede verse como un proceso donde se decide quiénes podrán votar en las elecciones. Este elemento, en el pasado, afectaba la representatividad puesto que sólo se les permitía votar a los hombres mayores, blancos y dueños de propiedades. En el momento en que se universaliza el sufragio, este elemento deja de ser una fuente de exclusión porque en la mayoría de los países del mundo se instaura el derecho al voto. En general, ya luego de los dieciocho años de edad es permisible votar.

Luego de determinar quiénes pueden votar hay que establecer las indicaciones sobre cómo será permitido votar. Una de las primeras características a considerar es el diseño de la papeleta. Estas pueden ser cerradas, abiertas, bloqueadas o desbloqueadas. Si son cerradas no se puede votar por el candidato directamente, sino solo por el partido que organiza la lista de candidatos.

Las listas abiertas permiten votar directamente por el candidato. También pudiera determinar la cantidad de candidatos por votos directos o preferentes que se le permitirán al elector. Si la ley dice que son "listas bloqueadas", el elector no puede alterar el orden de la lista de candidatos ni puede votar por candidatos de distintos

\footnotetext{
${ }^{107}$ Leonardo Valdés, Sistemas electorales y de partidos, México, IFE, 1995, p. 7.

${ }^{108}$ David Farrell, Comparing Electoral Systems, Macmillan, London, 1998.
} 
partidos. Si son desbloqueadas, sí se permite votar por candidatos de distintos partidos. El diseño de la papeleta puede tener combinaciones de todos estos elementos.

En los sistemas mayoritarios, por lo general, el elector vota directo por el candidato. No obstante, en sistemas proporcionales, también existen modalidades que permiten al elector votar directo por el candidato al congreso. Siempre es importante darles el mayor poder y control a los electores, para que éstos puedan decidir cómo ejercerán su voto. De eso se trata la democracia representativa real. Podremos establecer, en teoría, que mientras más control tenga el elector sobre la papeleta, habrá menos restricción para el elector, y por ende su voluntad se reflejará con mayor claridad. Esta voluntad es la intención del votante. Cuando se habla de la intención del elector se está diciendo que en una elección los electores tienen intereses, preferencias ideológicas, así como por los partidos y candidatos individuales. Es necesario que el sistema electoral viabilice la potestad del elector sobre la papeleta para que así se reflejen mejor sus preferencias y su intención en los resultados.

Un determinado diseño de papeleta puede restringir al elector de expresar su intención y preferencias. La intención del elector puede limitarse con una lista cerrada y bloqueada. Para diseñar un modelo electoral que favorezca la representatividad se deberá lograr un trade-off entre fórmulas restrictivas al voto directo y libertad del elector. ${ }^{109}$

Luego de diseñada la papeleta se determina cómo se convertirán los votos en escaños; es decir, cuáles votos son válidos y cómo se tomarán en cuenta para el

\footnotetext{
${ }^{109}$ Las fórmulas proporcionales y el voto preferente son incongruentes entre sí. Recordemos que el sistema proporcional necesita la acumulación de votos de los partidos porque representa todo un colectivo. Por su parte, los votos preferentes siempre van a implicar la utilización de la fórmula mayoritaria para decidir el curul. Sin embargo, entendemos que los votos preferentes también son necesarios para la representatividad. Por tal razón, proponemos que debe haber un balance. Este balance es posible sin alterar la matemática de la fórmula sólo limitando el poder interno de los partidos políticos.
} 
escrutinio. Es entonces cuando se elige o se crea la fórmula electoral. Entre la diversidad de fórmulas, las más utilizadas y reconocidas son: el cociente Hare, la D’ Hondt, la Saint Lagüe, o la cuotas Hare y Droop, así como la fórmula danesa.

Todas estas son diversas formas de transferir votos a escaños en los sistemas proporcionales. En los sistemas mayoritarios se utilizan dos fórmulas: mayoría relativa, también conocida como "pluralidad" o mayoría simple; y por otra parte, la mayoría absoluta. En la primera, el candidato con mayor cantidad de votos resulta electo. El más votado se lleva el escaño, aunque no tenga la mayoría absoluta en su distrito. En la otra, en la que se requiere la mayoría absoluta (50\% más uno de los votos) para tener un ganador, se requiere una segunda ronda electiva entre los candidatos con más votos, de no obtenerse la mayoría absoluta, o un cierto porcentaje pre-establecido de distancia entre los votos, en la primera ronda de votación.

La ley de Duverger ${ }^{10}$ distinguía los sistemas de mayoría absoluta porque no tenían lo que su autor denominó como "impacto psicológico". Por ello, podríamos ubicar en orden de representatividad al sistema de mayoría absoluta por encima del de mayoría relativa. La realidad del sistema de segunda vuelta es que no altera significativamente los resultados en relación al impacto psicológico. No obstante, en países donde opera el bipartidismo puro con partidos estructurados alrededor de todo el país, un sistema de segunda vuelta no tiene necesariamente, sentido. Un cambio de una sola vuelta a una segunda no alteraría los resultados y continuaría excluyendo a la minoría del congreso. Es así, porque al momento de transferir votos en escaños el resultado continúa siendo igual de desproporcional y las minorías podrían quedar, fácilmente, excluidas.

\footnotetext{
${ }^{110}$ Maurice Duverger, "La influencia de los sistemas electorales sobre la vida púbica”, en Diez textos básicos de ciencia política. Barcelona, Ariel, 1995.
} 
Lo ideal en un sistema con segunda vuelta es que los electores ejerzan su voto por la primera preferencia, y no por el menos malo como ocurre con la mayoría simple. Pero incluso, en caso de que el partido preferente logre ser electo, siendo la primera opción de un gran sector dentro los partidos de mayoría, se continuaría excluyendo al perdedor en la legislatura, como es natural en los sistemas mayoritarios. Ahora bien, hay otra modalidad de segunda vuelta: el sistema de Voto Único Transferible (VUT). Este permite que los electores enumeren en orden de preferencias la lista de candidatos. Además, posibilita cierto grado de proporcionalidad y, a su vez, le otorga un alto grado de libertad al elector. En Irlanda se puede marcar hasta cinco candidatos en orden de preferencia.

El VUT es una forma de combinar el control de la papeleta con la proporcionalidad. Si se quiere obviar la segunda vuelta electoral por cuestiones de presupuesto, por la posible disminución en la participación, o porque subrepresenta, puede ser una opción implementar este mecanismo.

Dentro de la clasificación de Gallagher ${ }^{111}$ de nueve fórmulas electorales, siendo la primera la de menor proporcionalidad y la novena la de mayor, el VUT se posiciona en la número 4. De manera que este sistema es casi un punto medio entre los dos sistemas puros. De las fórmulas de D’hondt, Hare, Saint Lagüe y Droop, la primera favorece a los partidos grandes porque es la más desproporcional.

El sistema D'Hondt (Tabla 4), utilizado en España, divide el total de los votos de cada partido de forma particular (entre 1, 2, 3, 4, 5, 6 y así consecutivamente). Los cocientes resultantes de estas divisiones determinarán a quién le corresponde el escaño, de manera que el partido con más votos recibe el primer escaño porque el primer divisor es (1).

\footnotetext{
${ }^{111}$ Michael Gallagher, Comparing Proportional Representation. Electoral Systems: Quotas, Threshold Paradoxes and Majorities, British journal of Political Science, Vol.22 No. 4, Cambridge, 1992, pp. 469-496.
} 


\section{Tabla 4}

Aplicación de las fórmulas de D’ Hondt en una circunscripción hipotética de seis escaños con cuatro partidos

\begin{tabular}{lcccccc}
\hline \multicolumn{6}{c}{ Escaños asignados utilizando los divisores D'Hondt } \\
\hline Partido & Voto(v) & Voto/1 & Voto/2 & Voto/3 & $\begin{array}{c}\text { Total de } \\
\text { escaños }\end{array}$ & Escaños (\%) \\
\hline A & 41,000 & 41,000 & 20,500 & 13,667 & 3 & 50.00 \\
B & 29,000 & 29,000 & 14,500 & 9,667 & 2 & 33.33 \\
C & 17,000 & 17,000 & $(5)$ & & & 16.67 \\
D & 13,000 & 13,000 & & & 0 & 0.00 \\
Total & 100,000 & & & & 6 & 100.00 \\
\hline
\end{tabular}

Nota: Las cifras entre paréntesis indican el orden en el cual se asignaron los seis escaños a los partidos. La porción decimal de los números que aparece destacada sirve como base para la asignación de los escaños que quedan una vez que se realiza la distribución mediante cuota. Fuente: Payne, Zovatto y Mateo. La política importa: Democracia y desarrollo en América Latina. Washington, D.C: Banco Internacional de Desarrollo e Instituto Internacional para la Democracia y la Asistencia Electoral. 2006. p.50.

El resultado de esta fórmula es un cierto nivel de sobre-representación de los partidos de mayoría, fomentando el bipartidismo. Sin embargo, el grado de representatividad de esta fórmula, así como de las otras, depende de las circunscripciones, su tamaño y trazado. El crecimiento de un tercer partido con esta fórmula es excepcional, pero no tan difícil como en el caso de la fórmula de mayoría relativa o pluralidad uninominal. La fórmula D'hondt no le otorga todos los escaños al partido con mayor cantidad de votos, como es el caso del sistema mayoritario.

Las fórmulas más proporcionales en la clasificación de Gallagher son el cociente Hare y la fórmula danesa. Ambas son muy proporcionales, pero es la segunda la que favorece en mayor grado a las minorías. La fórmula danesa es una modificación de la fórmula D’Hondt, solo que se altera el orden de los divisores. En vez de ir desde uno (1) hasta la cantidad de escaños que existan, la danesa 
comienza por el uno (1) pero luego divide la cantidad de votos entre cuatro (4) con márgenes de tres $(4+3)$, de manera que el divisor luego de cuatro es 7 . Esto da cierta prioridad a los pequeños partidos. Desde luego, el cociente Hare y la fórmula danesa son proporcionales, pero aun así, cuando se aumenta la cantidad de escaños es que se refleja mejor esta cualidad. De lo contrario, en distritos pequeños o medianos y con un bipartidismo estructurado a nivel nacional pueden darse desproporciones ${ }^{112}$.

Mediante la asignación de escaños por circunscripción se puede sub-representar y sobre-representar partidos y áreas geográficas, así como razas, etnias, entre otros. Por lo tanto, la magnitud de la circunscripción es un complemento importante en materia de representación.

Tanto el elemento de proporcionalidad, como de cuotas de partido y el aumento en el tamaño de las circunscripciones han posibilitado la representación de minorías como las mujeres ${ }^{113}$ e indígenas ${ }^{114}$. En la medida en que haya más candidatos en lista, se aumenta la posibilidad de que exista una diversidad de candidatos, al menos teóricamente. Esto es cierto a pesar de que se aglomeren en un solo partido en ocasiones. Por ello entendemos que promueve la representatividad.

Sin embargo, no perdamos de vista que la posibilidad de aumentar escaños dentro del sistema de mayoría puede generar partidos inmensos, más que una pluralidad de partidos. En primer lugar, porque los partidos afectan las delimitaciones electorales a su antojo; y en segundo lugar, porque las estructuras electorales crecen dentro de las estructuras de los partidos políticos. De manera, que un cambio en la fórmula también es fundamental.

\footnotetext{
${ }^{112}$ Douglas W. Rae, The Political Consequences of Electoral Laws, New Haven, Yale University Press, 1967.

113 ManonTremblay, Women in legislative representation: Electoral Systems, Political Parties, and Sex Quotas, London, Macmillan Palgrave, 2008.

${ }^{114}$ Aida Villanueva Montalvo, "En torno a la representación especial indígena en el Perú: Percepción de líderes indígenas y características del modelo peruano”, Debates en Sociología, n 37, 2012. pp. 43-76.
} 
Para calcular a quién le corresponde cada curul, las fórmulas electorales toman en cuenta la cantidad de escaños disponibles. Mientras más escaños haya, los partidos pequeños tienen mayor posibilidad de quedar representados. No obstante, la manera en que se delinean los distritos electorales es importante, ya que fácilmente se puede sub-representar o sobre-representar algunos sectores.

Un ejemplo palpable de esto es el gerrymandering que suelen hacer los estadounidenses para crear y dibujar sobre el mapa distritos cuya finalidad es proveer poca o ninguna representación en el Congreso a las minorías negra y latina (mayormente hispanos)en Estados Unidos. Se juntan barrios de alta población de las minorías para así garantizar un escaño a ellos: pero sólo uno. La idea es entonces que los demás escaños del estado en el Congreso se elijan en distritos en los cuales la mayoría blanca posee más habitantes y pueden así garantizar que la representación la obtiene uno de los suyos. ${ }^{115}$

El libro "La política importa" de Payne, Zovatto y Díaz ${ }^{116}$ tiene un ejemplo simple que utilizaremos para exponer las diferencias en el tamaño de los distritos. Tenemos a los partidos (A), (B), (C) y (D). Supongamos que esos cuatro partidos tienen dos sistemas electorales distintos. El primero es el sistema proporcional con fórmula D’Hondt con seis escaños disponibles para una circunscripción que vemos en la Tabla 1 y el segundo es uno de representación proporcional con fórmula D’Hondt con diez escaños (Tabla 5).

\footnotetext{
${ }^{115}$ Esta es la razón por la cual siempre vemos en la Cámara de Representantes de Estados Unidos a Luis Gutiérrez, puertorriqueño, en representación de un distrito de Illinois, en la ciudad de Chicago, que ha sido diseñado para que los votos sean preponderantemente latinos, de mexicanos y puertorriqueños, aunque, por supuesto, siempre hay una minoría de blancos estadounidenses que también vota en ese distrito. Algo similar ocurre con las circunscripciones del estado de Nueva York en cuya representación en la Cámara surgen como ganadores, una y otra vez, los puertorriqueños Nydia Vélázquez y José Serrano. Se les dan unos escaños fáciles de obtener a las minorías, pero luego en los demás distritos carecen esas minorías de oportunidades de representación, porque los distritos se han diseñado para que la mayoría de los votantes sean blancos estadounidenses.

${ }^{116}$ Mark Payne, Daniel Zovatto, y Mercedes Mateo Díaz, La política importa: Democracia y desarrollo en América Latina. Washington, D.C: Banco Internacional de Desarrollo e Instituto Internacional para la Democracia y la Asistencia Electoral. 2006.
} 


\section{Tabla 5}

Escaños asignados con fórmula D'Hondt, utilizando cuatro partidos como ejemplos hipotéticos con diez escaños

\begin{tabular}{lcccc}
\hline Partido & Votos & Escaños & Total de escaños asignados & Escaños (\%) \\
\hline A & 41,000 & $(1)(3)(5)(8)$ & 4 & 40.00 \\
B & 29,000 & $(2)(6)(9)$ & 3 & 30.00 \\
C & 17,000 & $(4)(10)$ & 2 & 20.00 \\
D & 13,000 & $(7)$ & 1 & 10.00 \\
Total & 100,000 & 10 & 10 & 100.00 \\
\hline
\end{tabular}

Fuente: Payne, Zovatto y Diaz (2006: 50)

Con seis escaños bajo la fórmula D’Hondt, el partido (A) recibía el 50\% de los escaños y el (D) no recibía escaños. Si aplicamos la misma fórmula pero con diez escaños, el partido (A) recibe el $40 \%$ de los escaños y el (D) $10 \%$ de los mismos. De manera, que los resultados pueden ser más o menos proporcionales bajo los divisores D’Hondt, dependiendo de la magnitud de los escaños. Por ello, lo que solidifica el carácter bipartidista de algún sistema es que los partidos se organizan en todas las circunscripciones y crea una estructura nacional que le permite ganar, con éxito, en la mayoría de las circunscripciones. ${ }^{117}$

El umbral legal o barrea legal, también puede lacerar la representación, ya que determina un porcentaje que puede ser bajo o alto, para que un partido tenga derecho a un escaño. De manera que si se quiere favorecer la representatividad es mejor obviar el umbral o establecer uno bajo. De igual forma, un aspecto muy importante en materia de representatividad son las cuotas étnicas, profesionales, de género, etc.

No hay duda que el sistema de cuotas de minorías se hace a favor de la representatividad. En la mayor parte de los sistemas electorales hay desequilibrios representativos importantes en cualquier materia: partidista, étnica, de género, sexualidad, de religiosa etc. Cuando no se conocen las posibilidades de

\footnotetext{
${ }^{117}$ Giovanni Sartori,op. cit.,Fondo de Cultura Económica.

Giovanni Sartori, "Partidos y sistemas de partidos”, Madrid, Alianza Editorial, 2005.
} 
representación bajo otras fórmulas u otras formas de delimitación territorial, las cuotas o leyes de minoría permiten balancear un poco las desproporciones abrumadoras, cuando se reconoce como un acto de injusticia.

En fin, ya se han evaluado todos los componentes de los sistemas electorales, tomando en cuenta el diseño de la papeleta, la fórmula para transferir los votos en escaños, las circunscripciones y sus tamaños etc. Si se utilizan las características del sistema electoral que fomentan la representatividad se esperaría que el parlamento tenga la mayor parte de los estratos sociales representados.

Es pertinente señalar que incluso los sistemas más puros y proporcionales tienden a favorecer la mayoría en contra de la minoría. Por ello, de lo que se trata es de aminorar este efecto. ${ }^{118}$

Como resumen podemos afirmar que la fórmula, la magnitud o el tamaño de las circunscripciones, así como el umbral o barrera legal estipulada para obtener escaños y las cuotas de minoría, son fundamentales para la representatividad. La representación de las minorías es una preocupación constante en América Latina, según lo revelan las constituciones de Chile, Colombia, Panamá, Venezuela, Ecuador, Uruguay, Costa Rica, Cuba, República Dominicana y Paraguay.

Menciona Aida Villanueva sobre Nueva Zelanda que en "1993, el país votó para descartar el sistema de voto de Mayoría Relativa que se había usado por más de un siglo, en favor de la representación proporcional". ${ }^{119}$ La adopción del sistema proporcional logró el aumento de la minoría maorí. Estos llevaban décadas defendido sus curules debido a la sub-representación que padecían en la toma de decisiones. "La primera elección bajo el sistema electoral hoy vigente [proporcional] se dio en 1996, y significó el primer aumento de la representación

\footnotetext{
${ }^{118}$ La clasificación de Michael Gallagher, op. cit, Cambridge. un poco alterada por este trabajo porque se eliminan tres fórmulas, puede ser muy buena para darnos una idea, las siguientes fórmulas se encuentran en orden de proporcionalidad: 1) Mayoría Simple (Menos Representativo); 2) LR-Imperiali; 3) D'Hont; 4) Voto Único Transferible; 5) LR-Droop; Modified Saint-Lague; 6) LR-Hare / Saint-Lagüe; 7) Danesa.

${ }^{119}$ ACE. The Electoral Knowledge Network. 1998-2015. Página web: www.aceproject.org.
} 
parlamentaria maorí desde que esta se inició en 1867 [...] Hoy se considera que la representación maorí en el Parlamento ha logrado la proporcionalidad a su peso demográfico. ${ }^{120,}$

No es extraño que el sistema proporcional con las características apropiadas, promueva una mayor representación de diversos sectores. De igual forma, el cambio de la mayoría uninominal a un sistema electoral proporcional se dio, en parte, por reclamos de la minoría. Por ejemplo, el Partido Laboral, en una elección obtuvo el $21 \%$ de los votos bajo la insignia y solo el $2 \%$ de la representación legislativa. ${ }^{121}$ Las minorías reclaman a favor de la representatividad y aunque el reclamo surge de un interés partidista, beneficia a un estrato étnico.

Arendt Lijphart y Pippa Norris afirman que el modelo proporcional es más efectivo representando minorías y explican que el sistema de mayoría: "es peligroso en sociedades divididas, porque las minorías que están continuamente negadas a acceder al poder se sienten excluidas y discriminadas por el régimen". ${ }^{122}$ El sistema de representación proporcional es más eficiente que el mayoritario respecto a representar minorías. Esto será así siempre y cuando un modelo proporcional cuente con características que promuevan la representatividad. La representatividad que se promueve en el parlamento aumenta cuando se establecen cuotas y cuando se impiden los umbrales. Pero también si en un territorio dado se aumentan el número de escaños, aumenta la posibilidad de que más sectores obtengan representación.

En segundo lugar, la proporcionalidad permite que quienes participan en la contienda obtenga representación o al menos aumente la posibilidad de que esto

\footnotetext{
${ }^{120}$ Aida Villanueva Montalvo. "En torno a la representación especial indígena en el Perú: percepción de líderes indígenas y características del modelo peruano". Debates en Sociología, n 37, 2012, pp. 43-76.

${ }^{121}$ Comisión electoral de Nueva Zelandia.. Paul Harris. Electoral Commission of New Zealand. Comments during review of text, August 17, 2000. Consultado el 16 de enero de 2016. Página web: www.eceproject.org

${ }^{122}$ Fioran Biebber, Stephan Wolf, The Ethnopolitics of elections. Routlege. Abigdon, Reino Unido. 2007. “... is dangerous in divided societies, because minorities that are continually denied access to political power will feel excluded and discriminated against by the regime". (p.7).
} 
ocurra. Por último, el voto preferente permite al elector tener mayor libertad en la papeleta viabilizando que la preferencia del elector se refleje más claramente. La armonía matemática entre estos tres aspectos promueve fórmulas altamente representativas.

De manera que, nuestro segundo argumento establece que los sistemas electorales con características que promueven representatividad permite una mayor inclusión de los diversos estratos sociales y de partidos a diferencia de modelos con características mayoritarias que no promueven la representatividad.

Para finalizar, tenemos en nuestro argumento tres facetas de representatividad. La primera, el proceso de construcción del sistema electoral o momento fundacional. En segundo lugar, la representatividad que promueve el sistema electoral. Por último, la representatividad en el parlamento nacional. Si desde un comienzo se configuran procesos altamente representativos, es muy probable que en la toma de decisiones estén más sectores representados. Momentos fundacionales inclusivos conllevan parlamentos inclusivos. La inclusión, independiente de sus efectos mediatos o inmediatos en cada país, siempre es una propuesta más democrática. ${ }^{123}$

\footnotetext{
${ }^{123}$ Bernard Manin, Los principios del gobierno representativo, Madrid, Alianza. Pablo Armando y Gonzales Ulloa Aguirre, Declive y reconfiguración de la democracia representativa, Miguel Ángel Porrúa, México, 2009. Mencionan estos últimos que "uno de los supuestos de la democracia representativa es la posibilidad de dar voz a distintos grupos sociales", (p.228).
} 


\section{Capítulo 3.}

\section{Puerto Rico: 1898-2012}

A partir de 1992 la participación electoral en Puerto Rico ha disminuido de manera constante. Desde el año 2000 hasta el 2012, ha habido un decrecimiento de 138,000 votantes, sin tomar en cuenta los electores no inscritos. Si contamos a la población apta para votar, unos 946,525 (casi una tercera parte de la población), no acudieron a las elecciones en el 2012. ${ }^{124}$ Por otra parte, desde las elecciones de 1972 no aparecían tantos partidos en la contienda como se presentaron y lograron inscripción como partidos por petición en 2012.

Sin embargo, entre las terceras y sextas opciones, ninguno logró quedar inscrito como partido oficial. Para las elecciones de 2016 se perfilan alrededor de seis candidatos a la gobernación, cuatro postulados por partidos y dos de ellos como candidatos independientes. Como candidato a legislador a nivel nacional en estas elecciones (2016) se presenta un candidato independiente, el Dr. José Vargas Vidot quien ha expresado su intención de aspirar al senado porque entiende que hay una población que la rama legislativa no ha atendido: la comunidad sin hogar y/o con problemas de adicción.

Aún cuando cada sector interpreta las problemáticas en Puerto Rico de diversas maneras, los candidatos independientes y de minoría tienen escasas posibilidades de salir electos. Esto, a pesar de que estos candidatos deberían recibir mayor apoyo en momentos de crisis social y económica. Un cuestionamiento constante en la mayor parte de la población y en los medios de comunicación es ¿por qué siempre votamos por los mismos? Esta pregunta es parte esencial de este trabajo.

Se presentan continuamente críticas al modelo de partidos y electoral de Puerto Rico, precisamente por su efecto excluyente y por su tendencia al bipartidismo. En

\footnotetext{
${ }^{124}$ Comisión Estatal de Elecciones. Eventos Electorales (SF). Recuperado el: 5/18/2015 de: www.ceepur.org.
} 
este capítulo se observará y analizará el desarrollo del bipartidismo y del sistema electoral ¿Es un sistema bipartidista? Si es así, ¿qué lo provoca? Se responderán a estas preguntas tomando en cuenta no sólo nuestras tres variables en estudio, sino también el contexto de este caso.

La intención de este apartado es presentar en tres etapas el desarrollo del sistema electoral puertorriqueño en conjunto con el sistema de partidos en la rama legislativa. Observaremos las elecciones en Puerto Rico y sus resultados desde1898 hasta 2012. Las tres etapas; 1898-1916; 1917-1951; y 1952-2016, se diferencian debido a un cambio en el sistema electoral. Analizaremos los fundamentos y los efectos de tres sistemas electorales que ha tenido Puerto Rico. En cada uno de los periodos describimos cómo se comportan los tres indicadores que presentamos en nuestras hipótesis: IRMF, IRSE, IRP.

Se calcularán los niveles de cada índice en cada periodo para evaluar si hay una relación positiva entre las tres variables. De esta forma confirmaremos nuestras hipótesis para el caso de Puerto Rico.

\subsection{El desarrollo del bipartidismo: 1898-1916}

El bipartidismo y el sistema electoral son congénitos al sistema político puertorriqueño impuesto por Estados Unidos. El modelo mayoritario ha sido el único que se ha utilizado en la historia moderna de Puerto Rico. Solo hubo una elección bajo el modelo proporcional y sus resultados quedaron anulados. De igual forma, el bipartidismo y el monopartidismo han sido los únicos dos sistemas de partidos que ha conocido Puerto Rico. Esto se explica claramente cuando se unen las variables de colonialismo y sistema electoral. En este apartado veremos cómo ambas explican la razón de esta realidad.

Las dos tendencias políticas principales en España a finales del siglo diecinueve eran la conservadora y la liberal. Ambas se trasladan al espectro ideológico 
puertorriqueño. En Puerto Rico, la primera estaba representada por españoles y nativos. La segunda, compuesta por españoles quienes promovían el status quo. Siendo colonia española, P.R. tenía derecho a once delegados residentes de la isla en las cortes de Cádiz que se organizaban en facciones, no partidos. El Partido Incondicional Español defendió las posturas conservadoras, pero luego desaparece en $1898 .{ }^{125}$

La primera facción creó el Partido Liberal Reformista que, a pesar de ganar las elecciones de 1871, se desorganiza debido a la persecución hacia el autonomismo de parte del gobernador español en P.R., Laureano Sanz. Finalmente, este último pasa a ser el Partido Autonomista Puertorriqueño en 1887, luego de ser asimilista en 1883. Otro gobernador español en P.R. Romualdo Palacios, había comenzado una persecución a quienes promulgaban la autonomía para la isla por entender que estaban defendiendo la independencia. Bajo este razonamiento fueron encarcelados líderes del partido autonomista. Por ello, el espíritu autonomista se enardece en el interior de las facciones asimilistas. Luego de una asamblea en el municipio de Mayagüez, estas tendencias (asimilista y autonomista) se organizan en dos facciones: Partido Autonomista Monárquico y Partido Autonomista Federal. ${ }^{126}$ El movimiento independentista puertorriqueño, además, tenía presencia desde el exilio (principalmente en Nueva York y Cuba) o desde la clandestinidad. Podemos asumir que desde este momento se organizan estas dos tendencias oficiales, ambas autonomistas. Esto implicaba que tenían la intención de obtener más poderes de gobierno propio.

Dichos partidos se diferenciaban por la posible relación con España. Ya fuera que la isla adquiriera una mayor soberanía política (cercano pero no igual a la idea de

\footnotetext{
125 Carmen Ramos Santiago, El gobierno de Puerto Rico: Desarrollo constitucional y político, Rio Piedras, Universidad de Puerto Rico (UPR), 1965.

${ }^{126}$ La primera dirigida por José de Diego y Muñoz Rivera. La segunda dirigida por José Celso Babosa y Manuel Fernández Juncos.
} 
independencia) o que mantuviera la relación España-Puerto Rico (aunque con mayor autonomía). Estas dos facciones eran muy similares a las de España, a tal grado que los líderes políticos en P.R. tenían la intención de adherirse a los respectivos partidos liberales y conservadores españoles. Un grupo importante de liberales estaba en contra de esta postura.

No obstante, una asamblea de autonomistas y asimilistas en 1896 envía una comisión para promover en España esta fusión y negociar mayores poderes políticos. Estos líderes liberales en España tenían buenas relaciones con los autonomistas de la Isla. Así, luego de seis meses, el Partido Liberal de España se compromete, con su líder Práxedes Mateo Sagasta, a otorgarle autonomía a la isla de llegar al poder.

Esto crea una división en Puerto Rico entre quienes están a favor o en contra del pacto. En una segunda asamblea de autonomistas compuesta por 131 delegados, 23 se opusieron. Éstos últimos fundan el Partido Autonomista Histórico. Los 79 votos a favor constituyen, con Luis Muñoz Rivera en su dirección, el Partido Liberal Fusionista.

En 1897, Sagasta es electo en España. Como resultado del acuerdo, entre otras cosas, España le otorga a P.R. una Carta Autonómica que organizaba electoralmente un sistema parlamentario bicameral idéntico al español. La misma concedía un Consejo conformado en la cámara alta por 15 miembros, 8 de ellos electos. En la cámara baja sus miembros se elegirían por cada 25,000 habitantes, mediante un sistema proporcional. ${ }^{127}$ La carta incorporaba prácticamente todas las promesas establecidas en la negociación de los representantes puertorriqueños y la dirección del Partido Liberal Español.

Se podría argumentar en contra de nuestra hipótesis de investigación que este sistema electoral promovía cierta representatividad y que era impuesto. Es decir,

${ }^{127}$ Carta Autonómica de España a Cuba y Puerto Rico. Madrid. Artículos: III. VI. 1987. 
que su momento fundacional fue excluyente. Sin embargo, este sistema no es producto de una imposición, sino que es resultado de un acuerdo bilateral. Se enviaron representantes de ambos partidos a España como producto de una asamblea general de los partidos existentes. Además, la Carta Autonómica representaba un mecanismo alterno a la revolución en Cuba, por ello, iba dirigida en mayor medida al país vecino.

Las únicas elecciones bajo esta ley se celebraron el 27 de marzo de 1898 y participaron solo los dos partidos existentes. El Partido Liberal logró una victoria abrumadora de 85,627 votos obteniendo 27 escaños. El Partido Autonomista Histórico recibió 18,068 votos correspondiéndole 5 escaños. Las desproporciones, bajo este sistema fueron del $2 \%{ }^{128}$, siendo el porcentaje de desproporción más bajo en la historia electoral del país hasta el momento (2012).

Los resultados de las elecciones quedaron anulados por el traspaso de P.R. a manos estadounidenses. Por ello, esta etapa no es considerada en nuestro análisis. Como resultado de la Guerra Hispano-Americana "se dejó al congreso de Estados Unidos la determinación del futuro político de Puerto Rico". ${ }^{129}$ El 28 de julio, a tres días de la invasión de Puerto Rico por la bahía Guánica, el general Nelson Miles proclamó que "hemos venido" refiriéndose a los Estados Unidos y su ejército:“... a traeros protección, no sólo para vosotros, sino para vuestra propiedad, para promover vuestra prosperidad y para procuraros los privilegios y bendiciones de las instituciones liberales de nuestro gobierno". ${ }^{130}$

Así como se traspasó el poder, las facciones también asumieron posiciones autonomistas y asimilistas hacia la nueva metrópoli: el Partido Federal, descendiente directo del Partido Liberal; y el Partido Republicano Anexionista (30

\footnotetext{
${ }^{128}$ El partido ganador obtiene de sobrerrepresentación +1 al igual que el partido perdedor queda sub-representado en -1 , para un total de 2 en desproporción.

${ }^{129}$ Carmen Ramos Santiago, op. cit, Universidad de Puerto Rico (UPR), p.46.

${ }^{130}$ Ibid., p.48.
} 
de octubre de 1898), descendiente del Partido Autonomista Histórico. Desde esta fecha se desarrollan en P.R. las primeras dos ideologías políticas a la par con la invasión norteamericana de 1898.

Durante los primeros dos años bajo dominio estadounidense, en P.R. se estableció un régimen que tuvo tres gobernadores militares. El último gobernador militar, George W. Davis, realizó múltiples reformas. Entre ellas permitió la celebración de elecciones municipales. En estas elecciones participaron republicanos y federalistas, donde estos últimos obtienen la mayoría de los municipios. En 1900, el congreso de EE.UU amparándose en el poder que le confería el Artículo 9 del Tratado de París, aprueba la primera ley orgánica estableciendo un gobierno civil en P.R., conocida como la Ley Foraker. ${ }^{131}$ El liderato político de PR se oponía a esta ley, ya que prácticamente la mayor parte del gobierno insular estaría compuesta por extranjeros. Era un retroceso en los logros por ampliar la autonomía pues concedía menos poderes que la Carta Autonómica de 1897 bajo España. Decía Luis Muñoz Rivera, Comisionado Residente de Puerto Rico en Washington: "La Ley Foraker, señor presidente...nunca debió salir del Capitolio de Washington; es una ley indigna de los Estados Unidos que la imponen y de Puerto Rico que la soporta"132.

Esta ley impuesta por EE.UU. sin ningún tipo de injerencia puertorriqueña obtiene en nuestro Índice de representatividad del Momento Fundacional (IRMF) una puntuación de cero. Esta ley organizaba la rama legislativa y ejecutiva (Sección 27, 28) de forma que:

\footnotetext{
${ }^{131}$ Fernando Bayron Toro, Elecciones y partidos políticos de Puerto Rico, Mayagüez, ed. Isla P.R. 1989.

132 Bolivar Pagán, Historia de los partidos políticos puertorriqueños, Tomo 1, San Juan, Librería Campos, 1959. p. 120 .
} 
- Porto Rico ${ }^{133}$ tendría un gobernador, cabeza de la rama ejecutiva, nombrado por el presidente de Estados Unidos con el aval y consentimiento del Senado federal.

- Un consejo ejecutivo (gabinete) sería seleccionado por el gobernador y conformado por puertorriqueños y norteamericanos, que realizaba labores ejecutivas y legislativas;

- La Cámara de Delegados (cámara baja) estaría compuesta por 35 delegados, todos puertorriqueños, elegidos en 7 distritos, cinco delegados por cada distrito.

- La fórmula a utilizar en la cámara era de mayoría.

El Gobernador tendría poderes similares al del Presidente en EE.UU. Podía otorgar indultos, realizar nombramientos, vetar legislación, etc. (sección 20). De igual manera, en la Legislatura se trataba de emular las instituciones estadounidenses. Era de esperarse que se impusiera una fórmula de mayoría ¿Por qué? "Nada más lógico que establecer en la colonia las instituciones existentes y conocidas en la metrópoli". ${ }^{134}$ Las diferencias en la composición entre la cámara baja y la alta manifestaban que ésta última tenía un sistema electoral más excluyente que la cámara baja. ${ }^{135}$ En el Índice de Representatividad del Sistema Electoral (IRSE), este periodo (1898-1916) obtiene una puntuación de 1.75 por tener un sistema de mayoría en distritos pequeños pero plurales.

Este modelo electoral, produjo una cámara baja dominada o por dos partidos o por un solo partido. Sin embargo, en este periodo no podemos hablar de partidos políticos modernos, sino más bien parecidos a partidos de nobles ('honoratories')

\footnotetext{
${ }^{133}$ Forma en que se le denominaba a Puerto Rico en esta época por parte de los EE.UU. Al no saber pronunciar bien el español decía Porto Rico en vez de Puerto Rico.

${ }^{134}$ Carmen Ramos Santiago, op. cit, Universidad de Puerto Rico (UPR), p.52.

${ }^{135}$ En la cámara alta los miembros eran nombrados a dedo, mientras que en la baja se elegían por voto mayoritario.
} 
como menciona Max Weber. ${ }^{136}$ Los partidos de masas ${ }^{137}$ se comenzaron a formar precisamente por la existencia de una organización electoral que les permitió obtener escaños y crear estructuras partidistas dirigidas por los niveles electorales. Algunos miembros del Partido Federal conformaron parte del grupo de puertorriqueños en el consejo ejecutivo. Se les informó a cinco puertorriqueños que conformaran una comisión para ordenar política y electoralmente el territorio del archipiélago. ${ }^{138}$ Andrés Crosas, quien era candidato independiente, redactó un proyecto que tuvo la oposición del Partido Federal. Este argumentó que el informe estuvo amañado por los intereses del gobierno en detrimento de su partido, quien en este momento procuraba mayores poderes políticos para PR. Los miembros del Partido Federal en el Consejo Ejecutivo, José de Diego y Manuel Camuñas, renunciaron a sus puestos. Ramos Santiago resume bien la situación posterior:

"Nueve días después de la reunión del órgano directivo central del Partido Federal, fueron destruidos los talleres del Diario de Puerto Rico y la residencia de Luis Muñoz Rivera (Líder federalista) fue atacada. Esto llevó a una reunión de la Comisión ejecutiva del partido celebrada en octubre en la cual se acordó ir al retraimiento por cuanto consideraban que había una ausencia total de garantías civiles". 139

Por ello, en las elecciones de 1900 los Federales se encontraban en retraimiento y los Republicanos barren todos los distritos "como era de esperarse". ${ }^{140}$ Para el 1902 y 1904 los Federales salen del retraimiento electoral, logrando cinco de los siete

\footnotetext{
136 Max Weber, Economía y sociedad. México, Fondo de Cultura Económica, 1ª reimp. 1969.

${ }^{137}$ Mauricie Duverger, Los partidos político, México, Fondo de Cultura Económica, 2012. Este libro muestra la forma en que se estructura un partido político, muy similar a como terminan surgiendo en Puerto Rico.

${ }^{138}$ Luis Díaz Soler, Matienzo Cintrón: Orientador y Guardián de una cultura, Tomo 1, San Juan, Instituto de Cultura Puertorriqueña. 1960. p.198.

${ }^{139}$ Carmen Ramos Santiago, op. cit, Universidad de Puerto Rico (UPR). p.60.

${ }^{140}$ Ibid.
} 
escaños en ambas elecciones. Los Republicanos ganaron en dos distritos. En 1906 surge la Federación Libre, como tercer partido, liderado por Santiago Iglesias Pantín.

El 18 de febrero de 1904 los Federales disuelven su partido e invitan a los Republicanos a unirse a un "gran partido". El presidente del Partido Republicano, Manuel Rossy, rechaza la oferta. Algunos la aceptan y como resultado, el 19 de febrero de ese mismo año se funda el Partido Unión por Puerto Rico (PU). Por primera vez, un partido propugna en su programa político la independencia como solución al problema del estatus colonial (llamado en su base quinta: self government). Incluso, ese año, el movimiento obrero dirigido por Santiago Iglesias Pantín decide apoyar al PU. Por su parte, el Partido Republicano se adhiere a la anexión o asimilación, opuesto a los unionistas.

En las elecciones de 1906, donde se presentaron cinco partidos regionales adicionales, el Partido Unión copó los siete distritos al igual que en 1908, 1910 y 1912. En estos años hubo un monopartidismo en la cámara baja, sin ninguna posibilidad de que los segundos y terceros partidos obtuvieran representación. En 1910, republicanos y unionistas llegan a un acuerdo que se concretiza en el 1912 con la aprobación de la primera ley de minoría por parte de la legislatura unionista. La primera ley de minoría evitaba que un partido político obtuviera la mayoría de escaños, obligando a los partidos a no encasillar más de cuatro candidatos por cada distrito. Esta fue una reforma a favor de la representatividad que eliminaba las posibilidades del monopartidismo y abría sus puertas al dualismo de partidos. También, disminuyó las desproporciones que estaban por encima de .60 a menos de .40 y en la última elección bajo ese sistema se redujo a .14 (Figura 1). 
Figura 1. Desproporciones: 1900-1916 ${ }^{141}$

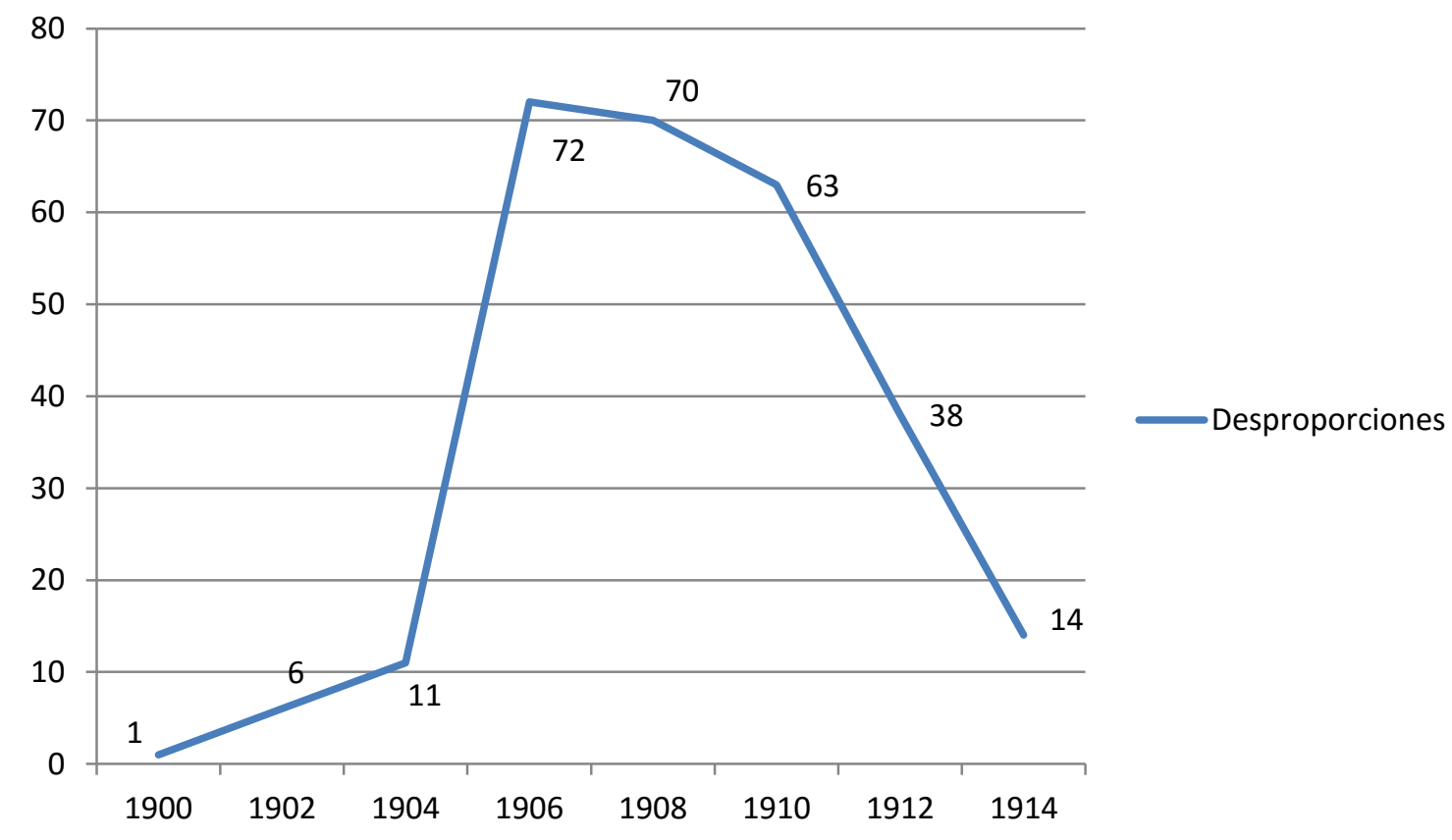

En las elecciones del 1912 el Partido Unión por P.R. no solo pierde escaños por la nueva ley de minorías, sino que también pierde votos, como menciona Carmen Ramos Santiago: "Debido a que sus esfuerzos por conseguir las reformas demostraron ser infructuosos y...que el pueblo ya estaba cansado de darle tanto respaldo sin conseguir nada a cambio". ${ }^{142}$

El Partido Unión estuvo constantemente conjuntando esfuerzos para reformar la ley Foraker con el fin, entre otros, de que los demás miembros de la cámara alta fueran electos por el pueblo. Sin embargo, esta posibilidad quedó derrochada en 1912 cuando el congreso rechaza el proyecto Jones y otro proyecto adicional con el mismo fin. De manera que estos rechazos por parte del congreso estuvieron muy presentes en las elecciones de 1912-14.

\footnotetext{
${ }^{141}$ Los datos fueron obtenidos de tres fuentes: Los datos fueron obtenidos de tres fuentes: La Comisión Estatal de Elecciones, las últimas cuatro se encuentran en su página web: www.ceepr.com. Eventos electorales. 2012. Carmen Ramos Santiago, op. cit., Universidad de Puerto Rico (UPR). Juan José Nolla-Acosta,op. cit., (S.E). ${ }^{142}$ Ibid.
} 
En las elecciones de 1912, el PU obtiene 19 delegados y el Partido Republicano 16. Muy similar a los resultados de 1914 donde el PU gana el 57\% de la representación obteniendo una desproporción de +5 y el Partido Republicano obtiene un sobre-representación de +2 . A pesar de haber disminuido las desproporciones, se mantiene la exclusión en la representación del tercer partido. De igual forma, dos años después en las elecciones el PU obtiene, nuevamente, la mayoría de escaños. Por su parte, la Federación Libre formaliza su estructura y no fue hasta 1915 que funda el Partido Socialista Puertorriqueño.

Un año después, el entonces Comisionado Residente en Washington, miembro del PU, Luis Muñoz Rivera, envía una carta a la legislatura de P.R. donde notifica que se ha alcanzado un acuerdo para reformar la Ley Foraker y menciona que se había logrado que ambas cámaras fueran electivas. ${ }^{143}$ Muñoz Rivera incitaba a todos los partidos a continuar la lucha por una organización política más democrática.

Desde 1902 hasta 1912 se excluyen los segundos y terceros partidos imponiéndose el monopartidismo. En la mayor parte de las legislaturas no había un partido de minoría. Quedaron sin representación alrededor de 10 partidos y la mayoría legislativa solo cambió una vez de partido (Tabla 6). Esto sin mencionar que la cámara alta ni siquiera estaba compuesta por puertorriqueños sino que la mayoría eran extranjeros.

La desproporción promedio de todo este periodo es de .34. Se deja la mayoría a un solo partido manteniendo rasgos del monopartidismo y formando en la práctica un bipartidismo por permitir representación de un segundo partido a través de la ley de minoría. Un elemento que promueve la representatividad añadida por la legislatura de Puerto Rico. Esto en contraposición al sistema impuesto que promovía el monopartidismo y la exclusión. Un hecho que demuestra que cuando no se imponen las condiciones se responde mejor a la realidad social.

\footnotetext{
${ }^{143}$ Carmen Ramos Santiago, op. cit, Universidad de Puerto Rico (UPR).
} 
Tabla 6. Cambios de partidos en la legislatura: 1901-1916. ${ }^{144}$

\begin{tabular}{|c|c|c|c|c|}
\hline Cuatrienio & $\begin{array}{l}\text { Partidos de } \\
\text { mayoría }\end{array}$ & $\begin{array}{c}\% \text { de } \\
\text { representación } \\
\text { de partidos en } \\
\text { minoría }\end{array}$ & $\begin{array}{l}\text { Número de } \\
\text { partidos por } \\
\text { legislatura }\end{array}$ & $\begin{array}{c}\text { Partidos } \\
\text { participantes en las } \\
\text { elecciones }\end{array}$ \\
\hline 1901-02 & PR & - & 1 & 2 \\
\hline 1903-04 & PR & Unión (28) & 2 & 3 \\
\hline $1905-06$ & Unión & PR (28) & 2 & 4 \\
\hline $1907-08$ & Unión & - & 1 & 3 \\
\hline $1909-10$ & Unión & - & 1 & 3 \\
\hline $1911-12$ & Unión & - & 1 & 3 \\
\hline $1913-14$ & Unión & PR (39) & 2 & 3 \\
\hline $1915-16$ & Unión & PR (43) & 2 & 3 \\
\hline $\begin{array}{l}8 \\
\text { elecciones }^{145}\end{array}$ & Cambios: 1 & Cambios: 1 & $\begin{array}{c}\text { Partidos } \\
\text { nuevos:1* }\end{array}$ & $\begin{array}{c}\text { Sin } \\
\text { representación**: } 10^{146}\end{array}$ \\
\hline
\end{tabular}

Nota. *Con esto nos referimos al momento en que aparece alguna nueva tendencia o partido.**Número total de partidos sin representación en la legislatura. Sumando todos los cuatrienios.

Desde el colonialismo español, en P.R. se crearon el mismo número de tendencias principales con representación legislativa y se mantuvieron por imposición de un modelo electoral altamente excluyente (Tabla 7) .Este modelo tiene un índice de representatividad al parlamento (IRP) de 56.5 No hay representación de mujeres y el monopartidismo es el sistema de partidos más común en el legislativo.

\footnotetext{
${ }^{144}$ Los datos fueron obtenidos de tres fuentes: La Comisión Estatal de Elecciones, las últimas cuatro se encuentran en su página web: www.ceepr.com. Eventos electorales. 2012. Carmen Ramos Santiago, op. cit, Universidad de Puerto Rico (UPR). Juan José Nolla-Acosta,op. Cit, (S.E).

${ }^{145}$ Hubo otra elección en 1916 como estaba programada pero no la incluimos porque sus resultados se anularon y pasaron a las elecciones bajo la ley Jones de 1917.

${ }^{146}$ En realidad fueron 12, pero estamos contabilizando 10 porque en la primera elección el voto hacia los federales ya que éstos no estaban participando- no llegó ni a 1\%. De igual forma con las elecciones de 1908 donde la federación libre obtuvo menos del $1 \%$ de los votos.
} 


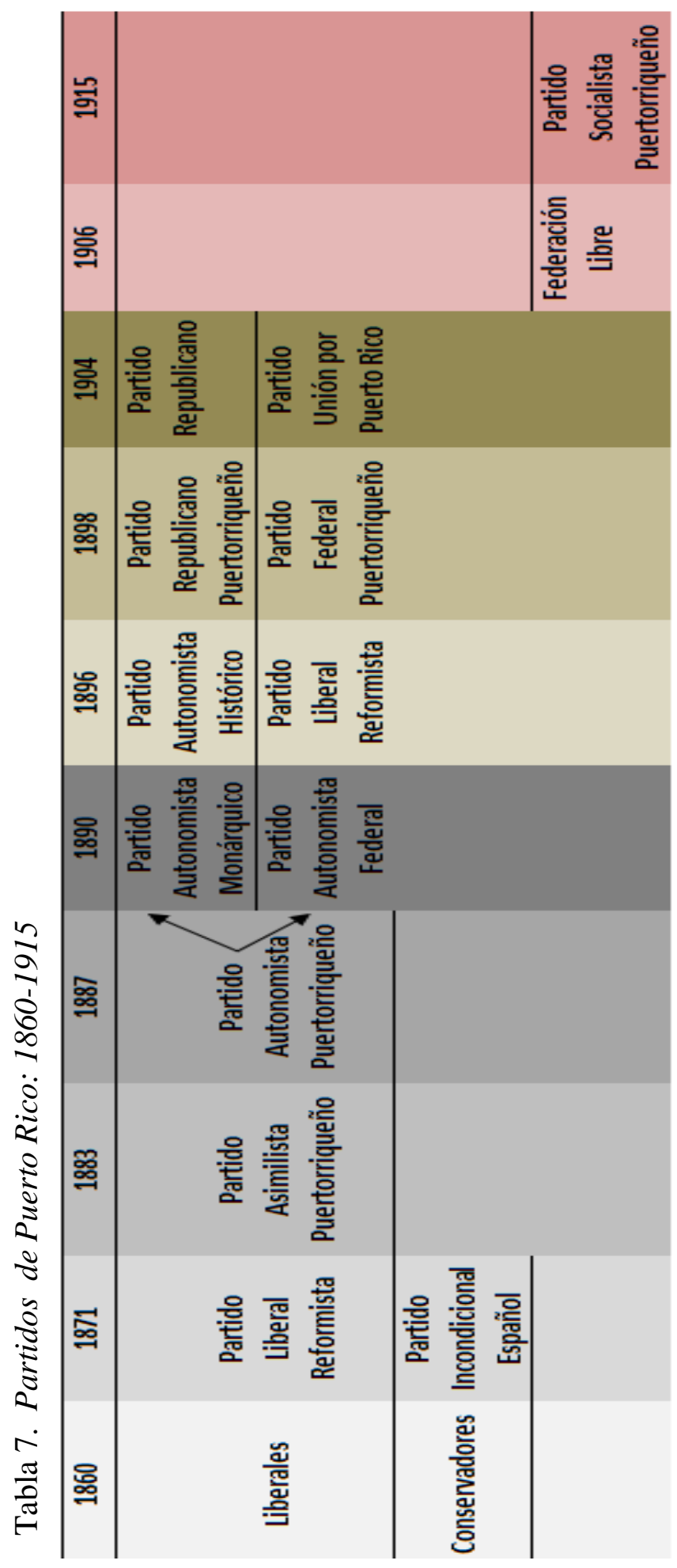




\subsection{Consolidación del Partido Popular: 1917-1948}

En el 1917 se impone a P.R. una nueva ley orgánica, conocida como Jones, debido al nombre de su redactor principal el congresista William Jones Atkinson. Esta nueva ley reformaba el sistema electoral y concedía algunas cosas que muchos líderes políticos llevaban buscando desde el coloniaje español.

Sin embargo, de forma unánime la legislatura compuesta por el PU y el Partido Republicano rechazó la Ley Jones, por ser insuficiente y por contener una ciudadanía de "segunda clase", ${ }^{147}$ aunque, finalmente, esta ley se impuso. El sistema electoral que se concedía fue producto de diversas propuestas y mucho cabildeo por parte de Luis Muñoz Rivera, quien respondía a los partidos principales. De igual forma, se habían nombrado dos miembros puertorriqueños al consejo ejecutivo que creían en las reformas a la Ley Foraker e impulsaron este cambio: Martín Travieso (unionista) y Manuel Domenech (republicano). ${ }^{148} \mathrm{La}$ puntuación que recibe este periodo en el IRMF es de .5 porque la iniciativa salió del partido de turno. Aunque esta ley era insuficiente, desde el punto de vista de todos los delegados puertorriqueños, establece un sistema electoral que promueve una organización más amplia de los partidos.

El primer aspecto que se concedió a los reclamos de estos líderes políticos fue la creación de una cámara alta electa por sufragio. El Senado se compondría de 19 miembros, dos por cada distrito senatorial (los mismos siete distritos que había bajo la ley Foraker) y 5 legisladores por acumulación, nueva modalidad de representación "at-large" que fortalecería el bipartidismo en contra de la tendencia al monopartidismo. ${ }^{149}$ La Cámara de Representantes estaría compuesta por 39

\footnotetext{
147 José de Diego, presidente de la Cámara de Delegados en Puerto Rico, en su discurso utilizó esta frase para referirse a la ciudadanía que había enviado Estados Unidos sin los derechos necesarios para los puertorriqueños en ese momento.

${ }^{148}$ Fernando Bayron Toro, Elecciones y partidos políticos de Puerto Rico, Mayagüez, Isla, 1989.

${ }^{149}$ Como observamos, la ley de minoría de 1912 se transforma en esta representación por acumulación. Un tipo de representación que había defendido por mucho tiempo Luis Muñoz Rivera. Conocemos que antes de las elecciones
} 
miembros, uno por cada distrito. Cuatro escaños asignados por acumulación (la representación at-large que mencionamos antes) o a nivel nacional sin una delimitación territorial. Estos legisladores nacionales no existen, ni han existido en el congreso norteamericano, pero si en los Estados de la Unión. Por eso, no es extraño que se añadiera al sistema electoral en P.R.

Aunque los curules por acumulación en este tiempo se convirtieron en un refugio de los segundos y terceros partidos de minoría, estos quedarían sub-representados. La puntuación del IRSE es de 2.75 ya que este sistema proponía dos niveles más en la representación. En la primera elección de 1917 obtuvieron representación tres partidos. El tercero con una diferencia en proporción de menos once $(-11)$ y con una sobre-representación del partido ganador de +12 . De igual forma, en las elecciones de 1920 el Partido Socialista quedó sub-representado con una desproporción de -19, mientras que el Partido ganador "Unión por Puerto Rico" quedó sobrerrepresentado en +20 (Figura 2).

de 1912 el Partido Unión por Puerto Rico había acaparado la cámara baja en Puerto Rico. Con la intención de evitar esto se aprobó esa ley de minoría en 1902. De igual forma fungirán en esta ocasión los candidatos por acumulación. 
Figura 2. Desproporciones ${ }^{150}$

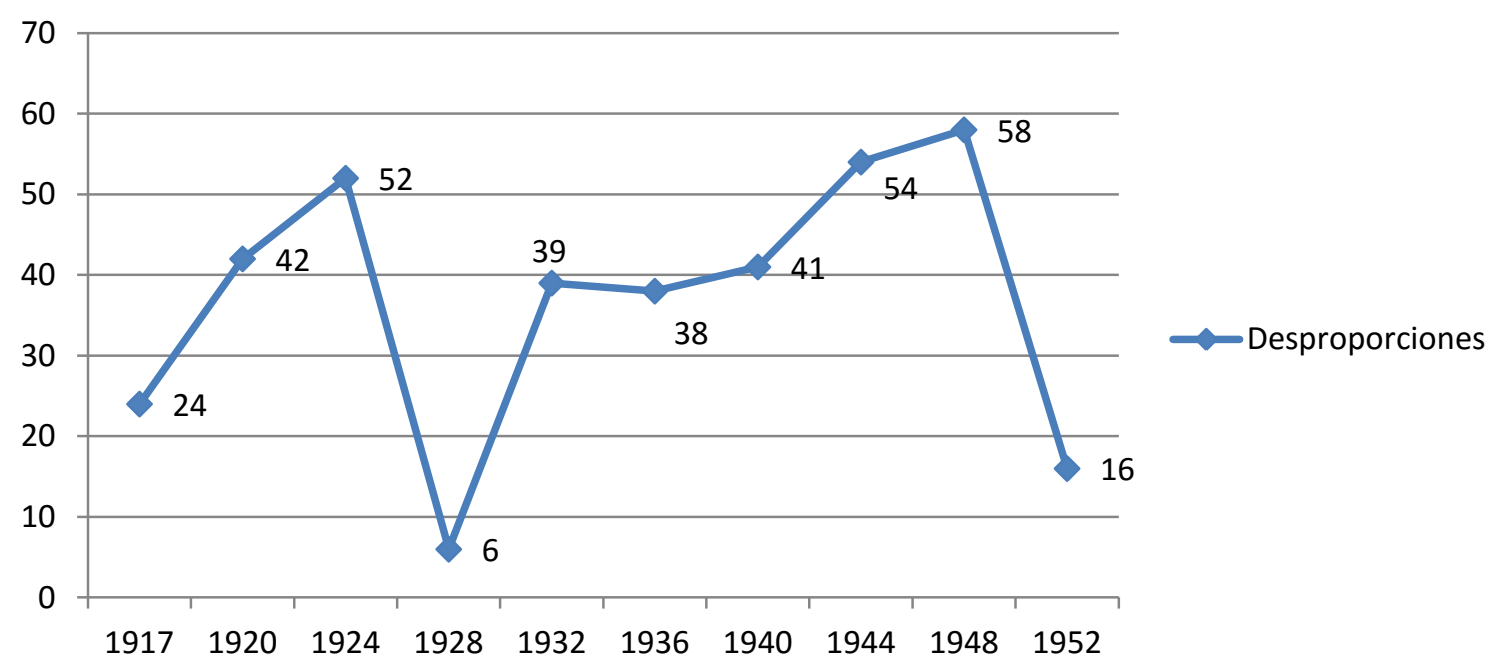

En las elecciones de 1924 se llevó a cabo una coalición entre el Partido Unión y el Partido Republicano formando "La Alianza". Algunos republicanos no estuvieron de acuerdo y fundan el Partido Constitucional Histórico, el cual al unirse los socialistas forman una "coalición socialista-republicana". Mediante estas coaliciones se aseguraban la no exclusión de la representación porque sólo había dos partidos en competencia luego de la unión de estas tres tendencias en dos. Era muy obvio que el sistema de representación sólo le aseguraba la representación a un partido sobrerrepresentado, y a uno sub-representado. Por esto los partidos políticos, ante la incertidumbre de quedar excluidos, realizaban coaliciones. En las elecciones de 1924 hubo una desproporción de los partidos con representación de +26 y de -26 .

\footnotetext{
${ }^{150}$ Este cálculo se realizó, según lo presentamos en nuestra sección de metodológica, sumando la desproporción de cada uno de los partidos. Esta desproporción se calcula restando el porcentaje de votos obtenidos bajo la insignia con el porcentaje de representación en la legislatura. Los datos fueron obtenidos de tres fuentes: Los datos fueron obtenidos de tres fuentes: La Comisión Estatal de Elecciones, las últimas cuatro se encuentran en su página web: www.ceepr.com. Eventos electorales. 2012. Carmen Ramos Santiago, op. cit., Universidad de Puerto Rico (UPR). Juan José Nolla-Acosta, op. cit., (S.E).
} 
En el momento en que un partido está sobrerrepresentado en la legislatura se entiende que hay exclusión como resultado de su efecto mecánico. Esto se puede apreciar claramente por la similitud de los números de sobre y de subrepresentación (Figura 3). Lo que recibe un partido en desproporción se lo quita otro partido en minoría y/o excluido.

Figura 3. Sobre y sub-representación total desde 1917-2012

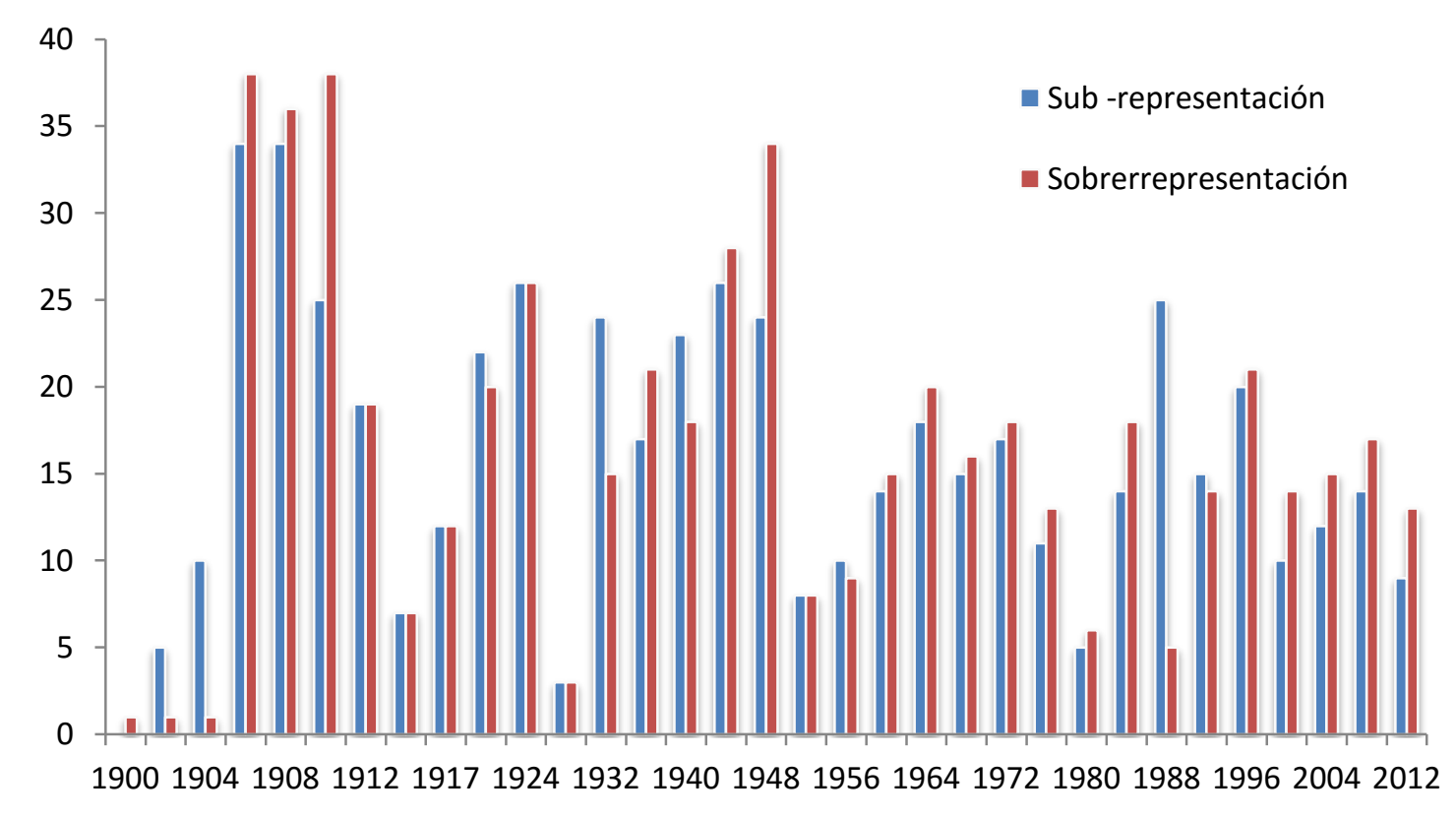

Cuando el bipartidismo se agudiza, con resultados electorales cerrados como en 1928, esta desproporción se reduce. Sin embargo, esto solo ha ocurrido una sola vez en nueve elecciones desde 1917 hasta 1948. De cualquier forma, la baja desproporción implica bipartidismo en Puerto Rico y esto conlleva exclusión de alguna fuerza política, ya que desde 1898 ha habido más de dos tendencias en Puerto Rico. A su vez, desde 1917 hasta 1952, once partidos quedaron sin representación legislativa (Tabla 2) y en promedio hubo una sub-representación de 21.5. En 1932 dos partidos se beneficiaron de la representación por acumulación. Sin embargo, el segundo partido a pesar de recibir el $44 \%$ de los votos a la insignia obtuvo el $21 \%$ de la representación. 
Para 1928, la pugna ideológica sobre el futuro estatus de Puerto Rico al interior de "la Alianza" se recrudece propiciando su rompimiento. Los republicanos miembros de la legislatura, que habían presenciado el rompimiento de la Alianza, forman la Unión Republicana. Entre sus dirigentes se encontraba Miguel Ángel García Méndez. La mayor parte de los unionistas terminaron fundando el Partido Liberal Puertorriqueño.

Los socialistas se encontraban solos y la única forma de obtener escaños legislativos era mediante la coalición. Por ello, en 1932, Miguel Ángel García Méndez les propuso que se aliaran con la Unión Republicana y muchos de estos aceptaron. El sistema electoral sólo permitía dos partidos en la legislatura, por ello era necesario crear coaliciones.

La tendencia bipartidista se puede observar en la mayor parte de las legislaturas y en el caso de que hubiera un tercer partido, éste sería un partido sub-representado y con poca capacidad de negociación. Este modelo electoral mantuvo el bipartidismo en la legislatura y el monopartidismo cuando un partido logra acaparar la mayoría de escaños. Como fue el caso con el Partido Unión bajo la ley Foraker y con el PPD bajo la ley Jones en menor grado.

El Partido Popular Democrático (PPD) surge de una escisión del Partido Liberal por un enfrentamiento entre Antonio R. Barceló y Luis Muñoz Marín, hijo de Muñoz Rivera y nuevo líder en la carrera política. Este joven funda en 1938 el PPD. ${ }^{151}$

Los fundadores del PPD eran originalmente "rebeldes independentistas", ${ }^{152}$ razón por la cual fueron expulsados del Partido Liberal. A pesar de ello mantenían como parte de su campaña en 1944, “el status no está en issue". Con esto se referían a que las relaciones entre Estados Unidos y Puerto Rico no serían parte de su

\footnotetext{
${ }^{151}$ Bolivar Pagán, op. cit., Librería Campos.

152 Carmen Ramos Santiago, op. cit, Universidad de Puerto Rico (UPR), p.75.
} 
proyecto de reformas políticas. Los populares se convierten en defensores del "status quo", aunque manteniendo en su seno un grupo importante de independentistas. En esta etapa, aunque bajo un modelo restrictivo, se abre paso a la participación de las mujeres en la política puertorriqueña. Este elemento llega más tarde que temprano.

En la legislatura de P.R. se habían presentado alrededor de doce proyectos para concederle el derecho de votar a las mujeres, pero no tenían resultado. El primer proyecto lo presenta Nemesio Canales en 1909. Pero este proyecto no se aprueba hasta1929, permitiendo votar sólo a las mujeres que supieran leer y escribir. En 1932 se había elegido a la primera mujer legisladora en P.R. Como resultado de una gran lucha de parte de la Liga femenina dirigida por Ana Roque de Duprey ${ }^{153}$, en 1935 se instaura el derecho al voto de la mujer aunque no supieran leer ni escribir, ya que en este momento esta población analfabeta constituía la mayoría de las mujeres. ${ }^{154}$

Esto correspondió con un aumento en la tasa de participación electoral. En las primeras elecciones donde las mujeres participaron en 1928, la tasa de participación aumentó en comparación con la elección anterior en 127,387 votantes. De igual forma, cuando se elimina el requisito de saber leer y escribir la participación aumenta con respecto a la elección anterior en 165,778 votantes (Figura 4). Aumento que no vuelve a repetirse hasta 1968 por otras circunstancias.

\footnotetext{
${ }^{153}$ A esta mujer se añaden Luisa Capetillo (primera en usar pantalones), Genara Pagán, Milagros Benet.

${ }^{154}$ Hay que tener en cuenta que a las mujeres en este momento ni siquiera les permitían educarse formalmente en una escuela Esto se logra en Puerto Rico en la década de los treinta, a pesar de que en Estados Unidos se había instaurado desde 1919.
} 
Figura 4. Aumento y disminución de la participación electoral en P.R:1900-2012 (expresado en miles)

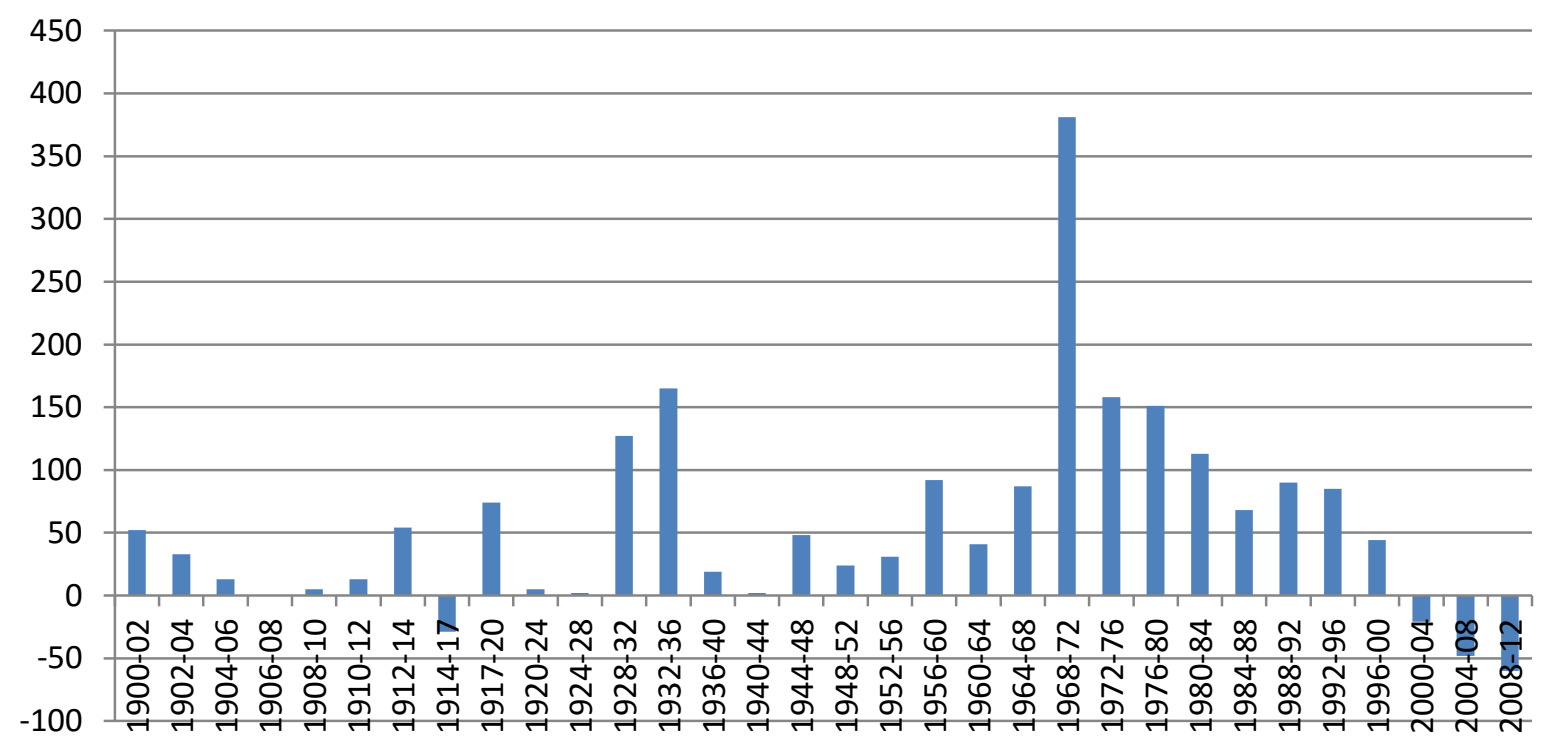

Este aumento no se repite porque todavía no hay un bipartidismo formalizado. Pero es precisamente para estas fechas que el PPD comienza a crecer y a formarse como un partido de masas. Para las elecciones de 1940 la unión entre republicanos y socialistas comenzó a tener problemas internos y se unieron al Partido Liberal formando la Unión Tripartita (UT). Finalmente, el PPD se termina compartiendo los escaños con la UT en unas elecciones muy cerradas en $1940,{ }^{155}$ obteniendo este último la mayoría legislativa.

En 1941, la legislatura aprueba una reforma agraria que elimina los latifundios en P.R. Este tipo de reformas han marcado la hegemonía hacia los gobiernos de manera sorprendente en América Latina. Muy evidente en el caso de Cuba (luego de 1959) y Bolivia (en la década de los 50’s) donde la población permitió o impidió la revolución dependiendo de si había o no reformas agrarias o tierras para

\footnotetext{
${ }^{155}$ Carmen Ramos Santiago, op. cit., Universidad de Puerto Rico (UPR), p.52. Menciona que las coaliciones eran muy inestables porque terminaban adoptando posturas programáticas formándose como partidos pero con gran división en cuanto a las eventuales relaciones con Estados Unidos, lo que provocaba su rompimiento y eventual escisión.
} 
labrar. El partido que permitía la repartición agraria en América Latina ganaba hegemonía. ${ }^{156}$

El PPD no sólo presentó el proyecto en su campaña, sino también en la legislatura logrando mayoría con el grupo de socialistas. Por esto y otra serie de circunstancias ${ }^{157}$, en 1944 el PPD había aumentado su fuerza electoral y copó la mayor parte de los distritos. Esta etapa es considerada, utilizando la tipología de Sartori ${ }^{158}$, como un sistema de partido hegemónico, como ya había ocurrido con el Partido Unión por Puerto Rico. El PPD mantuvo mayoría legislativa desde 1944 hasta 1976, 22 años consecutivos. Hasta el momento, es la principal fuente de división política en P.R., así como el principal promotor de divisiones internas en los partidos, fue la postura sostenida respecto a la relación P.R.-EE.UU. No es extraño, que para esta fecha de dominio PPD surge en 1944 y 45 una nueva escisión de independentistas que formaron el Congreso Pro Independencia.

De ahí, que el mismo PPD luego de haber afirmado que "el status no está en issue" se vio obligado a pedir enmiendas a la ley Jones. ${ }^{159}$ Como resultado, el congreso estadounidense aprueba la ley 362 haciendo electivo el gobernador. Con esta ley se intentaba satisfacer las demandas de los políticos puertorriqueños, ya que por mucho tiempo había conflictos ejecutivos-legislativos debido a las diferencias de criterio entre legisladores puertorriqueños y gobernantes norteamericanos. En la década de los veinte, por ejemplo, los líderes políticos del Partido Unión se encontraban en constante conflicto con el ejecutivo. Se mencionaba por ejemplo, que el gobernador de la isla Beekman Winthrop estaba gobernando a espaldas de las organizaciones políticas reconocidas. ${ }^{160}$

\footnotetext{
156 Timothy Wickham-Crowley, Guerrillas and revolutions in Latin America's, New Yersey.Pinceton, 1992.

${ }^{157}$ Circunstancias internas en la coalición tripartita que se refieren a las diferencias en cuanto al status político.

${ }^{158}$ Giovanni Sartori, Partidos y Sistemas de partidos, Madrid, Alianza Editorial, 2005.

${ }^{159}$ Carmen Ramos Santiago, op. cit, Universidad de Puerto Rico (UPR), p.77.

${ }^{160}$ Bolivar Pagán, op. cit., Librería Campos.
} 
El diseño de la papeleta le facilitaría el trabajo de centralizar el poder político porque ubicaba al principio el puesto de mayor jerarquía en la lista de todos los candidatos unidos en una sola papeleta. Pero ya no figuraría la candidatura a comisionado residente en la papeleta como el candidato de más alta jerarquía, sino el puesto de gobernador electo por los puertorriqueños. La diferencia entre los últimos gobernantes nombrados por Estados Unidos, como Rexford Tugwell y Jesús T. Pinero, y el gobernador electo por los puertorriqueños se refleja cuando advino Muñoz Marín al poder. "Por primera vez se unieron en un solo hombre la jefatura del partido mayoritario y la dirección de los asuntos públicos”.

"La gobernación bajo Piñero es... distinta a lo que esta se convierte al amparo de la ley de gobernador electivo... Bajo Piñero, el centro del poder político local siguió residiendo en la presidencia del Senado...Con el acceso de Luis Muñoz Marín a la gobernación cambió la relación entre las ramas legislativa y ejecutiva. La iniciativa en la legislación se traspasó a esta última...Muñoz Marín... generaba parte sustancial de las nuevas ideas que integraban el programa legislativo.... El proceso estaba altamente centralizado. Ninguna dependencia ejecutiva estaba autorizada a auspiciar legislación sin previa oportunidad al gobernador de... pasar juicio sobre ella... solo un grupo selecto de legisladores... tenía oportunidad... de influir en la determinación de las políticas ${ }^{161 "}$.

A raíz del congreso pro Independencia se funda en 1946 el Partido Independentista Puertorriqueño (PIP) que, como promulga su nombre, busca la libertad política en las urnas a diferencia del Partido Nacionalista Puertorriqueño (fundado en 1937 por José Coll y Cuchí un ex miembro del Partido Liberal) que buscaba esta libertad mediante las armas.

${ }^{161}$ Ibid., p. 145 
Faltaba hasta este momento establecer un régimen democrático. Durante estos años hegemónicos del PPD no existía democracia porque los principales derechos políticos estaban siendo coartados. En 1948, las tensiones entre el Partido Nacionalista y el gobierno de turno se estaban agudizando. Como consecuencia, ese año se aprueba la Ley de Mordaza. Una ley que prohibía cualquier tipo de reunión, manifestación, discurso político que llamara a violencia e incluso se hizo ilegal portar la bandera puertorriqueña, ya que simbolizaba el movimiento independentista. Todo el que ejerció el derecho de libertad de expresión fue encarcelado y/o perseguido. ${ }^{162}$

El movimiento independentista, aunque llevaba la principal ideología de muchos de los partidos de mayoría (como fue con el partido autonomista, el partido unión, el partido liberal en incluso en sus comienzos el PPD), se encontraba en decrecimiento por la terrible persecución que vivía como movimiento político.

Ivonne Acosta ${ }^{163}$ menciona: "ante las acusaciones de populares que no podían admitir el hecho de que un nuevo partido... surgía de las mismas entrañas del Partido Popular, decía Concepción de Gracia (fundador del Partido Independentista Puertorriqueño)".

"Nunca había tenido partido alguno en Puerto Rico que inscribirse con tantas dificultades, con tanta persecución, con tantas amenazas. Y hasta se ha llegado a la pequeñez indescriptible de negarle medicinas a personas pobres que firmaron peticiones de inscripción de nuestro partido, y a la bajeza de despedir de sus empleos a hombres por el delito de ayudar a la inscripción del Partido Independentista Puertorriqueño..."

En las primeras elecciones donde el PIP participa en 1948, a pesar de haber obtenido el 10\% de los votos, no obtuvo ningún escaño. Por su parte, el PPD logra ganar el puesto a la gobernación por un amplio margen. Este hecho en la historia

\footnotetext{
${ }^{162}$ Ivonne Acosta Lespier, La mordaza, San Juan. Editorial EDIL. 1989

${ }^{163}$.Ibid, P.36.
} 
electoral de Puerto Rico fomenta que el partido popular logre centralizarse ${ }^{164}$ como organización por la presencia de un líder ejecutivo. Elemento importante en la articulación de un partido político en los sistemas presidenciales; que en P.R. le otorga centralización y disciplina a los partidos. ${ }^{165}$

Con esto se intentaba aminorar, de una vez y por todas, el conflicto constante entre ejecutivo y legislativo debido a todas las discrepancias entre gobernadores nombrados desde afuera y legisladores del patio. A su vez, fortalecería el voto íntegro en contraposición al mixto ${ }^{166}$, aumentando la articulación del PPD.

Se transita de un comisionado residente en Washington con voz pero sin voto en la cámara de representantes, a un gobernador, residente en P.R., que es líder del partido de mayoría en la legislatura y que tiene, a su vez, el poder de vetar cualquier proyecto legislativo.

A esto le sumamos que en las elección de 1948 el PPD a pesar de tener bajo su insignia el $61 \%$ de los votos obtuvo el 95\% de los escaños. Por su parte, el Partido Republicano, al igual que el PIP, quedó sin representación y había obtenido el $4.5 \%$ del voto bajo su insignia. El Partido Estadista quedó en segundo lugar y obtiene una sub-representación de -9 en la legislatura.

Estos desequilibrios que se han mantenido desde 1902 se reducirían, aunque se mantiene en límites preocupantes desde las elecciones de 1952 gracias a una reforma al sistema electoral. Para efectos de la representación de la mujer, desde 1917-1952 sólo tres mujeres ocuparon el cuerpo legislativo: María Luisa Arcelay (1933-1940), María Pérez Almiroty (1936-1940) y María Libertad Gómez Garriga

\footnotetext{
${ }^{164}$ Mauricie Duverger, op. cit, Fondo de Cultura Económica. Según este autor, cuando un partido esta centralizado es que logró crear una articulación fuerte. Con esto se quiere decir que la comunicación entre un nivel jerárquico y otro es buena. De manera que la base puede comunicarse con el liderato y la estructura absorbe las demandas. Haciendo el partido uno más democrático o al menos se podría argumentar eso desde el punto de vista de Duverger.

${ }^{165}$ Robert W. Anderson, Gobierno y partidos políticos en P.R, Madrid, Tecnos, 1973.

${ }^{166}$ La figura de gobernador atraería la atención pública en un mayor nivel que el legislativo. Lo que implica un arrastre que no es distinto a votar íntegro pasando juicio por el gobernador, por la ideología o por tradición pero no sobre candidatos particulares.
} 
(1941-1952). En ese período, las mujeres no obtuvieron siquiera el 1\% de la representación legislativa, muy por debajo del promedio de representación mundial en la época (Tabla 8).

Desde 1917 hasta 1948 se excluyeron de la representación a 8 partidos, hubo 6 cambios en las minorías y tan sólo 3 en el de mayoría. Esto implica que en el 80\% de las elecciones hubo cambios en las minorías y sólo en el $37 \%$ hubo cambios en la mayoría. Este sistema electoral mantuvo dos partidos al menos y promovió el monopartidismo (véase tabla 10).

La puntuación en el IRP es de 64, mayor que la anterior porque el sistema electoral promueve una mayor representatividad (tiene más escaños, elije la cámara alta, aumenta los niveles a dos). Como resultado hay una mayor representatividad en el parlamento según nuestro índice.

Tabla 8. Promedio Mundial de mujeres en el parlamento ${ }^{167}$

\begin{tabular}{lccccccc}
\hline & $\mathbf{1 9 4 5}$ & $\mathbf{1 9 5 5}$ & $\mathbf{1 9 6 5}$ & $\mathbf{1 9 7 5}$ & $\mathbf{1 9 8 5}$ & $\mathbf{1 9 9 5}$ & $\mathbf{2 0 0 5}$ \\
\hline Mujeres diputas & $3 \%$ & $7.5 \%$ & $8.1 \%$ & $10.9 \%$ & $10.9 \%$ & $11.6 \%$ & $15.9 \%$ \\
Mujeres senadoras & $2.2 \%$ & $7.7 \%$ & $9.3 \%$ & $10.5 \%$ & $12.7 \%$ & $9.4 \%$ & $14.8 \%$ \\
Número de parlamentos & 26 & 61 & 94 & 115 & 136 & 176 & 184 \\
\hline
\end{tabular}

Tabla 9. Partidos Políticos: 1904-1948

\begin{tabular}{|c|c|c|c|c|c|}
\hline 1904-06 & 1924 & 1928 & 1938 & 1946 & 1948 \\
\hline $\begin{array}{l}\text { Partido Unión } \\
\text { Por Puerto } \\
\text { Rico }\end{array}$ & \multirow[t]{2}{*}{ Alianza } & \multirow[b]{2}{*}{$\begin{array}{l}\text { Partido } \\
\text { Liberal }\end{array}$} & \multirow[b]{2}{*}{$\begin{array}{l}\text { Partido } \\
\text { Popular }\end{array}$} & $\begin{array}{c}\text { Partido } \\
\text { Independentista }\end{array}$ & \\
\hline $\begin{array}{c}\text { Partido } \\
\text { Republicano }\end{array}$ & & & & & \\
\hline Puertorriqueño & Coalición & $\sum_{\text {Republicana }}$ Unión & & & $\begin{array}{l}\text { Partido Estadista } \\
\text { Puertorriqueño }\end{array}$ \\
\hline $\begin{array}{c}\text { Partido } \\
\text { Socialista } \\
\text { Puertorriqueño }\end{array}$ & & & & & \\
\hline
\end{tabular}

\footnotetext{
${ }^{167}$ Magdalena Huerta García y Eric Magar Meurs (coord.), Mujeres Legisladoras en México: avances, obstáculos, consecuencias y propuestas".México, septiembre de 2006, p.86.
} 
Tabla 10. Cambios de partidos en la legislatura: 1918-1952 168

\begin{tabular}{|c|c|c|c|c|}
\hline Cuatrienio & $\begin{array}{l}\text { Partidos de } \\
\text { mayoría }\end{array}$ & $\begin{array}{c}\text { Partidos en } \\
\text { minoría }\end{array}$ & $\begin{array}{c}\text { Número de } \\
\text { partidos por } \\
\text { legislatura }\end{array}$ & $\begin{array}{l}\text { Partidos participantes } \\
\text { en la elección }\end{array}$ \\
\hline $1918-20$ & Unionistas & $\begin{array}{c}\text { Republicanos (33) } \\
\text { Socialistas (3) }\end{array}$ & 3 & 3 \\
\hline $1921-24$ & Unionistas & $\begin{array}{c}\text { Republicanos (23) } \\
\text { Socialistas (5) }\end{array}$ & 3 & 3 \\
\hline $1925-28$ & Alianza & Coalición (36) & 2 & 4 \\
\hline $1929-32$ & Alianza & $\begin{array}{l}\text { Partido Socialista } \\
\text { Constitucional (45) }\end{array}$ & 2 & 2 \\
\hline $1933-36$ & $\begin{array}{c}\text { Unión Socialista } \\
\text { Republicano }\end{array}$ & Partido liberal (21) & 2 & 4 \\
\hline $1937-40$ & $\begin{array}{l}\text { Unión Socialista } \\
\text { Republicana }\end{array}$ & Partido Liberal (29) & 2 & 3 \\
\hline $1941-44$ & $\begin{array}{l}\text { Coalición } \\
\text { Socialista- } \\
\text { Republicano }\end{array}$ & Partido Popular (45) & 2 & 5 \\
\hline $1945-48$ & Partido Popular & Unión Tripartita (7) & 2 & 4 \\
\hline $1949-52$ & Partido Popular & Partido Estadista. (5) & 2 & 4 \\
\hline 9 elecciones & Cambios:3 & Cambios:6 & Partidos nuevos: 4* & Sin representación**: 8 \\
\hline
\end{tabular}

Nota. *Con esto nos referimos al momento en que aparece alguna nueva tendencia o partido. ** Número total de partidos sin representación en la legislatura. Sumando todos los cuatrienios.

\footnotetext{
${ }^{168}$ Los datos fueron obtenidos de tres fuentes: La Comisión Estatal de Elecciones, las últimas cuatro se encuentran en su página web: www.ceepr.com. Eventos electorales. 2012. Carmen Ramos Santiago, op. cit., Universidad de Puerto Rico (UPR). Juan José Nolla-Acosta,op. ci.t, (S.E).
} 


\subsection{Inter periodo (1951-52)}

\section{Constituyente de 1952}

Previo a impulsar el proceso constituyente, luego del 1949, "se estudió intensamente el procedimiento de admisión de estados a la Unión Americana y el de la preparación de sus constituciones respectivas" ${ }^{169}$ Como respuesta a los reclamos de líderes políticos en P.R. y a diversas cartas e informes enviados desde la legislatura dominada por el PPD, EE.UU. decidió otorgar la ley 600 que proveía que P.R. organizara un gobierno propio. Menciona Héctor Luis Acevedo (miembro del PPD): "El Comisionado Fernós hizo malabares para conseguir la aprobación de la Ley 600 en tiempo récord en el Congreso a pesar de los obstáculos de los burócratas y congresistas que insistían en mantener su poder sobre Puerto Rico". ${ }^{170}$ La realidad era que la ley poseía tantas trabas al proceso constituyente que era obvia que la soberanía continuaba residiendo en el congreso de EE.UU. y no en P.R. En primer lugar, la vieja ley Jones (impuesta por EE.UU.) en términos de relaciones Estados Unidos-Puerto Rico se transcribiría a la constitución. En segundo lugar, la constitución de Puerto Rico debía regirse por los preceptos establecidos en la constitución norteamericana manteniendo el carácter de gobierno republicano sin posibilidad de establecer otro tipo de organización política. En tercer lugar, al ser aprobada por la constituyente debía ser enviada al congreso de EE.UU. para que la ratificaran.

Este último proceso conllevó enmiendas por parte del Senado estadounidense y tuvo que ser reenviada a P.R. con la condición de que si no se eliminaban dos

\footnotetext{
${ }^{169}$ José Trias Monge, Historia Constitucional de Puerto Rico, T.3, Rio Piedras, Ed.UPR, 1982, p.3.

170 "María Libertad Gómez: La mujer Constituyente". S / F. Página web: http://www.rafaelhernandezcolon.org. Consultado el 1 de mayo de 2016.
} 
secciones, la constitución no se aprobaría. Esto sucedió a pesar de que el entonces gobernador del PPD, Luis Muñoz Marín, había prometido a la ciudadanía que el congreso no podría enmendar la constitución. ${ }^{171}$

Así las cosas, el proceso constitucional comienza y termina subordinado al congreso de EE.UU. La constituyente se realiza con base en la Ley Núm. 1 de 1951 aprobada por la legislatura de P.R. Es interesante que dicha ley se apruebe el mismo día que se está encarcelando a Don Pedro Albizu Campos, líder del Partido Nacionalista, por violar la ley mordaza, específicamente por dar discursos políticos incitando a la revuelta. "El 16 de agosto de 1951 se halló culpable a Albizu y el 29 de agosto, dos días después de la elección se le impusieron doce sentencias consecutivas que conllevan la reclusión en presidio por un término mínimo de doce años y máximo de cincuenta y cuatro". ${ }^{172}$

La ley Núm. 1 explica cómo se elegirían los delegados a la constituyente. Se escogería un sistema electoral de mayoría, similar al que se acuerda luego de la constituyente y al que ya se tenía con la ley Jones (1917). Habría 24 delegados nacionales escogidos por acumulación (como los de la ley Jones, pero aumentados en curules), 72 delegados en representación por distritos, nueve en cada uno de los ocho distritos representativos, añadiendo uno a los siete que existían. Habría un total de 95 constituyentes, aunque finalmente se escogieron $93 .{ }^{173}$

Sin embargo, esta ley permite una cuota de minoría que menciona que los partidos no podrán postular más de 14 candidatos por acumulación, y en los de distrito no se podrán postular más de siete por cada circunscripción. El partido de mayoría podría obtener, como máximo, 70 delegados. Una mayoría aplastante en la

\footnotetext{
${ }^{171}$ Menciona Muñoz que: “Aprobada por el pueblo la constitución, se transmitirá a través del presidente al congreso de Estados Unidos. El congreso la aprobará o desaprobará: pero no podrá modificarla”. Vicente Géigel Polanco, La farsa del Estado Libre Asociado, Rio Piedras, Ed. Edil, 2010, p.153

${ }_{172}$ Antonio Fernós Isern, Ser nosotros mismos, Rio Piedras, UPR, 2003, p.125.

${ }^{173}$ Porque al Partido Independentista le hubiesen correspondido esos curules.
} 
constituyente, suficiente para ignorar la minoría. Las elecciones se celebraron el 27 de agosto de 1951.

La votación a favor o en contra de la ley 600 fue la primera que se llevó a cabo en todo este proceso y luego se daría la votación de los delegados a la constituyente. La aprobación de la población sería más bien la antepenúltima. La última sería la del congreso y la penúltima la de la asamblea constituyente. El orden de estas votaciones demuestra donde reside la soberanía política. La población llegaría a las urnas con límites y trabas; solo había una opción de relaciones políticas (el colonialismo por consentimiento) y los detractores eran perseguidos de manera sistemática.

Finalmente, quedaron constituidos como partidos representados en la constituyente: El Partido Popular Democrático (71 delegados), El Partido Estadista Republicano (15) y el Partido Socialista (7). La comisión nombrada para encargarse del legislativo era la siguiente: Luis Negrón López ${ }^{174}$ (PPD), Rubén Gaztambide Arrillaga (PPD), Francisco Anselmi (PPD), Heraclio Rivera Colón (PPD), Ramón Barreto Pérez (PPD), Augusto Valentín (PPD), Mario Canales (PPD), Ubaldino Ramírez de Arrellano (PPD), Fernando J. Géigel (PRP), Celestino Iriarte (PRP) y Lino Padrón Rivera (PSP).

Los populares (miembros del PPD) contaban con la mayoría necesaria para impulsar un gran listado de reformas que la ocasión requería. Todos los puestos de primera y segunda jerarquía pertenecían al PPD, al igual que la mayoría en asamblea y todas las comisiones.

Se menciona para resaltar un falso elemento representativo, que la constituyente estaba compuesta de 32 abogados, 13 agricultores, 9 líderes obreros, 6 maestros, 6 comerciantes, 5 industriales, 4 médicos, 3 periodistas, 2 jueces, un banquero, un

\footnotetext{
${ }^{174}$ Este fue el creador de la ley de minoría vigente. Una fórmula que es única en el mundo.
} 
dentista, un ingeniero, un farmacéutico y un contador. ${ }^{175}$ Sin embargo, este aspecto sólo menciona un elemento profesional que no tiene una relación significativa con las preferencias políticas de un individuo, su visión político-económica del mundo. Las profesiones son únicamente un elemento de representatividad.

La primera mujer en la legislatura de P.R. fue María Luisa Arcelay de Rosa 19331940. Comenzó militando en el Partido Liberal y luego formó parte del PPD. Esta fue la única mujer que participó en el momento fundacional y recibió el puesto de vicepresidenta en la constituyente. ${ }^{176}$

A pesar de que el independentismo tenía cabida en la constituyente, éste decidió no participar. Las razones son múltiples y se han mencionado en el transcurso del apartado, pero Vicente Géigel Polanco (uno de los fundadores del PIP) las resume en que este proceso fue una farsa. No obstante, siempre quedó la duda sobre si, de haber participado el PIP, hubiese sido posible añadir criterios al sistema electoral que le hubiesen beneficiado a las minorías.

Como se mencionó, eran muchas las razones para no participar. El ambiente antidemocrático en especial hacia el independentismo, las condiciones impuestas por los EE.UU que maniataban a la constituyente, el hecho de que el congreso y el presidente de EE.UU tendrían la última palabra para la constitución, las mentiras que se divulgaron en cuanto a la Ley $600{ }^{177}$ por parte del gobierno de P.R. y el de Estados Unidos ${ }^{178}$, el ambiente de violencia que se propiciaba en la isla hacía que desde hace unos meses atrás se hubiera levantado una revuelta que fue

\footnotetext{
${ }^{175}$ Héctor Luis Acevedo, La generación de 40' y la convención constituyente, Rio Piedras, Ed. Universidad Interamericana de Puerto Rico, 2003. Véase también: Luis Muñoz Marín. Memorias 1940-1952, Hato Rey, Fundación LMM, 2003, pp. 99-111.

176 Los votos a favor de la vicepresidencia fueron similares a todos los demás puestos porque estaban divididos por delegaciones.

${ }^{177}$ Recuérdese que se argumentaba que esta ley 600 otorgaba un grado mayor en los poderes que tendría el gobierno. Pero la realidad era otra. Esta ley dejaba intacta la propiedad territorial de Estados Unidos sobre Puerto Rico, como lo establecía la propia ley en su Artículo. 4.

${ }^{178}$ El presidente Eisenhower llegó a mencionar en un discurso que el ELA era la independencia para Puerto Rico. Una mentira descarada.
} 
violentamente reprimida y que conllevó el bombardeo de parte de la Guardia Nacional de EE.UU. hacia el pueblo de Jayuya, P.R., entre otras cosas. El levantamiento de 1950 conllevó: "veintiocho muertos- siete policías, un guardia nacional, dieciséis nacionalistas y otras cuatro personas. La Revuelta duró tres días. Se arrestaron cerca de 800 personas algunas de las cuales no tuvieron relación con la revuelta". 179

Así las cosas, la autoexclusión del proceso constituyente es, verdaderamente, una exclusión. Es decir, hablar de autoexclusión es omitir todos los hechos mencionados. El movimiento independentista ha sido reprimido desde la etapa española y ahora lo sería bajo los EE.UU. En ese momento, aunque a "el independentismo" los representa una organización partidista, tiene la gran limitante de que la población puertorriqueña, debido a la intimidación, temía adherirse a la ideología independentista y por tanto al partido.

Para esta fecha había comenzado una práctica en P.R. denominada como “carpeteo" que culminó, al menos formalmente, en 1988. Esta práctica la instituyeron tanto la policía de P.R. como el gobierno de EE.UU. con el FBI. ${ }^{180}$ Era una especie de continuación a la ley Núm. 53 de Mordaza. Consistía en perseguir e informar en una carpeta con fotos y documentos la vida de algún independentista. Se recurría a hablar con vecinos, con compañeros de trabajo, familiares, alentándoles que tuvieran cuidado con "el independentista tal” que vivía en los alrededores. Se creaba así todo un estigma que arruinaba la vida de quienes ostentaban esta ideología.

\footnotetext{
179 Héctor Luis Acevedo, La generación de 40' y la convención constituyente, Rio Piedras, Universidad Interamericana de Puerto Rico (UNTER), 2003, p.6.

${ }^{180}$ La policía de Puerto Rico, el gobierno de Puerto Rico, el tribunal supremo de Puerto Rico y el "Federal Bureau of Investigation" han admitido que esta práctica se llevó a cabo y que en el proceso se cometieron grandes errores que destruyeron vidas. Véase la investigación científica más exhaustiva que se ha realizado al respecto por los abogados y politólogos: José Javier Colón Morera y Ramón Bosques Pérez, Las carpetas. Persecución política y derechos civiles en Puerto Rico, Rio Piedras, UPR. 1997.
} 
"La División de Inteligencia reclutaba estudiantes de la escuela superior, pagándoles entre $\$ 40$ y \$50 semanales, para que se infiltraran en grupos llamados "separatistas" y suministraran información de sus simpatizantes e integrantes y de sus actividades. Se les conocía como confidentes, luego los convertían en agentes encubiertos con un nombramiento gubernamental en la Policía". ${ }^{181}$

"Se corroboró la forma en que la gente fue seguida, espiada, controlada políticamente. Carreras fueron arruinadas y familias divididas. No era una colección de información pasiva. Usaban esa información como instrumento de control político y social. Hubo gente que se tuvo que ir de la Isla, otros que desaparecieron". 182

Prácticamente todo el que pertenecía o se relacionaba con el movimiento independentista fue perseguido. De hecho, el propio líder del PPD, Luis Muñoz Marín, por haber pertenecido al independentismo en el Partido Liberal tenía una carpeta. Se han publicado alrededor de 76,000 carpetas que fueron reconocidas como información obtenida de forma ilegal y violentando los derechos de libertad de expresión, intimidad, asociación, etc. ${ }^{183}$

La persecución por parte de EE.UU en P.R. implicó asesinatos, arrestos, intervenciones a llamadas telefónicas, persecución diaria por parte de agentes federales y "estatales", negación de los servicios de salud y educativos, tortura psicológica y física, además de la criminalización hacia el independentismo por

\footnotetext{
${ }^{181}$ Ivonne Acosta, La Mordaza 1948-1957, Rio Piedras, Edil, 1987. Se puede encontrar en el blog de José Juan de la Rosa Nazario "Persecución y Carpetas" en página web: www.juanmariebras.org. Consultado el 1 de mayo de 2016.

182 José A. Delgado. Historia de Puerto Rico desde la perspectiva de las carpetas. domingo, 17 de mayo de 2015. Con referencia al libro de Nelson Maldonado Dennis War against all Puertoricans: Revolution and terrorism in America's colony. New York. 2015. Se puede encontrar en la página web: www.endi.com. Consultado el 30 de junio de 2016.

${ }_{183}$ José Javier Colón Morera y Ramón Bosques Pérez, Las carpetas. Persecución política y derechos civiles en Puerto Rico, Rio Piedras, UPR, 1997.
} 
parte de la propaganda pública controlada por las instituciones de radiodifusión estadounidenses, entre otras cosas.

El independentismo, a pesar de ser la segunda fuerza política, como lo demuestran los resultados del 1952 donde obtuvo el 19\% de la votación, fue excluido del proceso constituyente. La constitución se redacta amañada y rodeada por un contexto antidemocrático. La ley 600 obtiene a favor 387,016 votos y el referéndum tuvo una participación del $65 \%$ de los electores inscritos. Aunque este último porcentaje se calcula considerando los electores inscritos, si consideramos los electores aptos para votar. Esto conlleva una participación de 49\%.

De los electores inscritos un 50\% favoreció la relación. Considerando los electores aptos para votar, esta tasa de aprobación de la Ley 600 se reduce a 25\%. Algo muy similar a la votación para la aprobación de la constitución donde hubo 373,594 votos a favor y 81,877 en contra. La participación constituye un $47 \%$ de los electores cualificados para votar y un 59\% de los inscritos. De manera que la aprobación de la constitución tuvo una tasa de $38 \%$ con respecto a la población apta para votar. ${ }^{184}$ Un porcentaje de aprobación lejos de ser mayoritario Para este periodo el Índice de representatividad de este momento fundacional (IRMF) es de 2.0. No obtiene una puntuación de cero porque hubo participación de parte de tres partidos, aunque uno de estos con una mayoría aplastante, con un sistema electoral mayoritario y sin delegados oficiales de otros sectores aunque con una muy buena ley de minoría. Adicional a esto hubo una votación.

Esta constitución dio por establecida a la comunidad política autónoma puertorriqueña, que es lo que en realidad significa el nombre en inglés: Commonwealth of Puerto Rico -llamado en español el Estado Libre Asociado (ELA). El contexto de represión política es imposible de ignorar. Menciona Ivonne

${ }^{184}$ Juna José Nolla Acosta, “Elecciones de Puerto Rico: 1899-2012”, Libro. Puerto Rico, (s / e.), 2015. 
Acosta en su libro La mordaza, la investigación más abarcadora al respecto de la "ley de mordaza", que la misma:

“...fue instrumental para el establecimiento del Estado Libre Asociado... El proceso estuvo políticamente viciado por la persecución desatada contra los independentistas... Provocó la disminución de la fuerza electoral del PIP. Produjo una represión directa contra los no simpatizantes del gobierno por más de una década; e indirecta, durante las décadas siguientes. Desarrolló y acrecentó una mentalidad generalizada en el pueblo en contra de los... subversivos... generó una persecución secreta y despiadada por la Policía de Puerto Rico... con el FBI, en contra de los opositores a las políticas del gobierno. El miedo generalizado a la independencia y el distanciamiento hacia los que abogan por ella, persiste aún en nuestros días". ${ }^{185}$

Lo que se constituye como ELA es la justificación internacional para mantener a Puerto Rico como territorio arguyendo que era una relación bilateral. Su justificación ante la comunidad internacional se ha basado en la misma estrategia que permitía el colonialismo inglés en India: "el consenso de los oprimidos", denominado cínicamente por el independentismo puertorriqueño como "colonialismo por consentimiento".

Así, la realidad colonial se une al modelo electoral para propiciar el dualismo político en el gobierno y el control político de una mayoría capaz de pasar reformas. La represión sistemática en conjunto con un modelo electoral excluyente, propició y mantuvo respectivamente el dualismo de partidos en P.R., excluyendo a las terceras alternativas y sub-representando a las segundas.

\footnotetext{
${ }^{185}$ Ivonne Acosta, La Mordaza, 1948-1957. Puerto Rico, Edil, 1987, p. 233. Se puede encontrar en el blog de José Juan Nazario de la Rosa. "Persecución y Carpetas", página web: www.juanmariebras.org. Consultado el 1 de mayo de 2016.
} 


\subsection{El sistema electoral adoptado en la constituyente}

Para la redacción de la constituyente se prepararon dos anteproyectos: 1) FortesTrias-Monge y 2) Fiedrich. Ambos, proponían modelos electorales más excluyentes que el que resultó finalmente. En el primero, se transcribía el sistema vigente bajo la ley Jones. El segundo, no recomendaba la representación proporcional, ni el sistema de representación minoritario porque:"el sentimiento en Puerto Rico era contrario a la representación proporcional, por miedo a la pluralización de partidos". ${ }^{186}$

Por otra parte, el proyecto del PPD afirmaba que no habría una legislatura con menos de 14 miembros en el senado, ni de 35 en la cámara. "En función de que se facilite representación a la oposición", ${ }^{187}$ se tenía la intención de otorgarle una mayor representación a la oposición en la legislatura mediante los legisladores por acumulación. De ahí se crea la ley de minoría en la constituyente.

La ley de minorías, creada por Luis Negrón López, consiste en que si un partido obtiene más de 2/3 partes en cualquiera de las cámaras se aumenta el número de legisladores hasta una tercera parte de la cámara permitiendo entrar a los que siguen en votación. Para tener una idea, si este mecanismo hubiese existido para las elecciones de 1948, la segunda fuerza hubiese recibido nueve senadores y diecisiete representantes adicionales.

Adicional a esta ley de minoría, la constituyente añade un octavo distrito senatorial y cinco representantes, así como duplica los legisladores por acumulación. Hay entonces un cambio en la cantidad de legisladores y en la cantidad de distritos representativos, además de una disposición para otorgar mayor representación a la oposición, como lo señala el anteproyecto del PPD.

\footnotetext{
${ }^{186}$ Este proyecto promovía la legislatura unicameral. De igual forma proponía que el ejecutivo tuviera la facultad para delinear los distritos.

${ }^{187}$ El programa del PPD para la convención constituyente. José Trías Monge, op. cit, Universidad de Puerto Rico, p.76.
} 
Sin embargo, la intención de los líderes constituyentes nunca fue fraccionar el parlamento, sino por el contrario, se pretendía la creación de mayorías. Curiosamente, los dos partidos en minoría en la constituyente creían en la representación proporcional (republicanos y socialistas). No es casualidad que las minorías reclamen representatividad.

De igual forma, la escuela de Administración Pública de Puerto Rico ${ }^{188}$ criticó duramente el sistema electoral que se proponía, porque no tenía una verdadera representación de la minoría, pero sí avalaba el sistema pluralista como adecuado en el momento. El PPD necesitaba una mayoría que lograra pasar reformas y entablar proyectos, y esto sólo lo aseguraría el sistema mayoritario de representación -no el proporcional. "Se temía el fraccionamiento y la proliferación de los partidos usualmente resultantes de este tipo de sistemas. Se estimaba que Puerto Rico necesitaba partidos fuertes, capaces de dirigir por sí solos el país en la difícil tarea de su reconstrucción, sin necesidad de coaliciones comprometedoras". ${ }^{189}$

Por ello, también se pretendía un ejecutivo fuerte que ya había comenzado a formarse con la ley de gobernador electivo de 1947, como se describió anteriormente. La comisión de reorganización de la rama ejecutiva había realizado un informe donde afirma la necesidad de expandir el ejecutivo. Recomendaba a la constituyente: "El jefe ejecutivo debería estar equipado...Una nueva era de liderato unificado acaba de comenzar". ${ }^{190}$

Mantener el modelo de mayoría encaja a la perfección con el proyecto de reformas que se tenía en mente y con el plan de fortalecer el ejecutivo. Menciona un testigo

188 Esta escuela universitaria estuvo en el plano de la asesoría. Mario Negrón Portillo. La voz del Centro. "La Unicameralidad y el Informe de la Escuela de Administración Pública de la UPR a la Convención Constituyente en el 1952". Se puede encontrar grabación en la página web. www.lavozdelcentro.net Consultado el 15 de mayo de 2016.

${ }_{190}^{189}$ José Trías Monge, op. cit, Universidad de Puerto Rico, pp.107-08.

190 Marshall Dimock, "Los objetivos de la reorganización gubernamental", en la reorganización de la rama ejecutiva. Informe para la constitueyente, 1951, p.3. Dice en inglés: "the chief executive should be equipped...A new era of unified leadership has begun". 
ocular de la constituyente, el ex juez José Trias Monge que: "La asamblea legislativa, de tiempos de la convención constituyente, era un organismo de prestigio y eficiencia declinantes; sin la continuidad necesaria para rendir una labor creadora". ${ }^{191}$ Añade, también, que esto incidió en la redacción del Artículo III referido al legislativo.

El resultado en materia de reforma legislativa no estuvo a la altura de sus tiempos. Los miembros de la constituyente tenían concepciones que desconfiaban de la legislatura como cuerpo político. Menciona Monge que: "Esta actitud fortalecida por la doctrina del Laissez Faire y el deseo de los grandes intereses de permitirle el mínimo de intervención legislativa en sus asuntos, produjo parlamentos débiles, impedidos de reunirse con la debida frecuencia y sujetos a toda suerte de trabas y limitaciones". 192

En fin, la constituyente no tiene la intención de realizar una gran reforma legislativa. Como resultado de esta maniatada convención constituyente, el elector puertorriqueño tiene ante sí una papeleta el día de las elecciones donde se encuentra la insignia del partido, el candidato a la gobernación, el cargo a la comisaría residente en Washington, los legisladores y los alcaldes. La ley electoral vigente permite que en esta papeleta se puedan ejercer votos combinados entre cada columna. La parte que corresponde al legislativo, donde el elector puede marcar un representante y hasta dos senadores por su distrito. Puede, a su vez, ejercer el voto por un senador en la lista de candidatos por acumulación y escoger también un representante por acumulación.

En la constituyente, el permitir un solo voto por candidato se justificó bajo los siguientes argumentos:“Que los issues locales no estuvieran tan oscurecidos en la mente del pueblo por los issues centrales [...] Que los electores se informaran

\footnotetext{
${ }^{191}$ José Trías Monge, op. cit, Universidad de Puerto Rico, p.140.

${ }^{192}$ Ibid., vol 3, p.123.
} 
adecuadamente sobre méritos de cada candidato y votaran a base de esa información $[. .$.$] que la gente votara por candidatos y no por partidos...". { }^{193}$

Lo anterior tiene características que se espera que cumpla un modelo mayoritario. ${ }^{194}$ Por su parte, los legisladores por acumulación, en ocasiones, se observan como líderes nacionales ya que acumulan votos alrededor de todo el país. Menciona Virgilio Ramos González ${ }^{195}$ :

"La convención constituyente entendió que las cualificaciones que debían reunir un representante o un senador, de un distrito representativo o senatorial y las que debía reunir un representante o un senador por acumulación eran distintas. Unos eran líderes políticos de los distritos senatoriales o representativos, los otros eran líderes escogidos por los partidos políticos para diseminar y hacer efectiva su plataforma a través de toda la isla". ${ }^{196}$

Con estas intenciones se crea, en resumen, un sistema de mayoría simple o pluralista con una ley de minoría para "suavizar" un poco las injusticias representativas que suelen provocar. Hay dos cámaras, la de senadores y de representantes, ambas con representación en dos niveles o dimensiones (tiers). El

\footnotetext{
${ }^{193}$ Carmen Ramos Santiago, op. cit, Universidad de Puerto Rico (UPR). p.182.

${ }^{194}$ IDEA International. Manual para el diseño de sistemas electorales. México. IFE. 1997.p.27. En esta página se argumenta que el sistema de mayoría ayuda a mantener la gobernabilidad y a mantener un vínculo fuerte entre el electoral y el legislador.

195 Virgilio Ramos, Voto particular del miembro asociado, Junta constitucional de distritos senatoriales y representativos, San Juan, Puerto Rico, 2011, p.6.

${ }^{196}$ No obstante, se ha presentado la crítica de que esos legisladores por acumulación, en la práctica, se convierten en líderes distritales. Esto ocurre ya que los partidos obtienen una gran cantidad de votos bajo su insignia. Como estos votos se le adjudican al candidato por acumulación primero en la lista, quien resulta electo, en la mayoría de los casos, es ese mismo candidato. Los partidos configuran un orden de lista distinto en cada uno de los distritos. Por ello, los legisladores que van primero en la lista de algún distrito enfocarán sus esfuerzos en el distrito donde estarán primero y se convierten en líderes regionales.
} 
primer nivel es el de distrito, con 16 senadores y cuarenta representantes (cinco por cada distrito senatorial).

El segundo nivel de representación son los representantes y senadores por acumulación establecidos por la Ley Jones en 1917 y aumentados en la constituyente. Son once en cada cámara y acumulan votos alrededor de todo el país. Se pensaba que estos legisladores funcionarían como líderes nacionales, ya que la forma de elegirse en listas era muy similar al modelo proporcional y su delimitación territorial abarca todo el país. Sin embargo, la manera en que se asignan estas curules es bajo la fórmula mayoritaria. El número de curules por acumulación aumenta en el momento en que se activa la Ley de Minorías contenida en el Artículo III, Sección 7 de la Constitución. La puntuación que recibe este periodo en el Índice de Representatividad del Sistema Electoral (IRSE) es de 3.25, porque amplia la representación y establece una ley de minoría.

En Puerto Rico veremos cómo las aspiraciones de los constituyentes se cumplen solo a medias. Mantener el sistema mayoritario respondía a la necesidad de crear partidos grandes, fuertes y asemejar el sistema en lo mayor posible al norteamericano. Esto, con la intención de darle continuidad a las reformas que se estaban gestando.

En 1949, Luis Muñoz Marín había afirmado en el congreso que los puertorriqueños "estamos tratando de salir adelante por nuestros propios medios". Por ello, se le denominó al proyecto de industrialización por invitación como "operation bootstrap" 197 conocido en P.R. como "operación manos a la obra". Este proyecto consistía en sustituir la pesca y agricultura, la actividad económica principal en el país, por la manufactura. El plan de industrialización, combinado

\footnotetext{
${ }^{197}$ James L. Dietz, Economic History of Puerto Rico: Institutional Change and Capitalist Development, New Jersey: Princeton University Press, 1986.
} 
con políticas de estado de bienestar, podría alivianar la gran pobreza que existía en la isla.

Esto resultó beneficioso para las manufactureras porque se invitaba a estas a la isla promoviendo bajos salarios, ya que no aplicaba el salario mínimo federal. La ley del mínimo federal es la única ley estadounidense que no ha aplicado a P.R. bajo el supuesto de que su condición económica la hacía "localmente inaplicable". ${ }^{198}$ Este proyecto de modernización del país no encontró obstáculos en la legislatura. Menciona Trias Monge que en el legislativo de este momento: "Las votaciones a favor...eran... por unanimidad. Los nombramientos...no se cuestionaban...La frustración subyacente se revelaba en diversos modos". ${ }^{199}$.

Este último escenario es contrario a lo que hubiese sucedido en una legislatura plural y multipartidista, para añadir un elemento contra-fáctico a nuestro argumento. Más aún, cuando la oposición representaba una ideología antidependencia, y que de haber obtenido representación en la legislatura probablemente hubiese propiciado votos en contra de algunos proyecto.

Por eso se elabora un sistema mayoritario a dos niveles y en dos cámaras. Pero ¿Qué ha permitido este sistema electoral? ¿Cuáles han sido sus resultados representativos en el parlamento?

\subsection{Efectos del sistema de mayoría con ley de minoría: 1952-2012}

Luego de la constituyente de 1952, P.R. continuó con un sistema de mayoría. Esto respondió a varios factores. El sistema electoral de mayoría había sido impuesto desde 1917. Este modelo propició la formación de partidos grandes por sus altas

\footnotetext{
${ }^{198}$ La ley jones menciona que todas las leyes estadounidense aplican a Puerto Rico porque es "localmente inaplicable". Se puede conseguir en página web: www.lexjuris.com. Consultado el 12 de abril de 2016.

${ }^{199}$ José Trías Monge, op. cit, Universidad de Puerto Rico, p.140.
} 
desproporciones y exclusiones (véase Tabla 2 y Figura 1). A su vez, tuvo un alto nivel de volatilidad por la coyuntura de inestabilidad política. ${ }^{200}$

Este modelo de mayoría permitió al PPD quedar sobrerrepresentado en la legislatura (véase Figura 2). El PPD siendo el partido de mayoría en la constituyente y en la legislatura del momento no tuvo interés en promover un sistema realmente representativo porque no les otorgaría la mayoría de los escaños. Un sistema de mayoría como el que estaba vigente les propició el control legislativo que mantuvieron hasta 1976. El PPD pudo llevar a cabo su proyecto político en P.R. a costa de la exclusión y la sub-representación.

El líder del PPD, Muñoz Marín, se convirtió en el gran caudillo por ser el promotor de las nuevas políticas de modernización, logrando mantenerse en el puesto ejecutivo desde 1948 hasta 1964. Este partido se mantuvo como mayoría y controlando todo los puestos gubernamentales, constituyéndose como principal defensor de las instituciones del ELA. Las primeras elecciones bajo este modelo en 1952 produjeron resultados con desproporción de -16. Sin embargo, estas desproporciones comenzaron a aumentar a niveles parecidos a los que se producían en el periodo de 1917-1948. En 1956 aumentó a 19, en 1960 a 29 y luego a 38 (Figura 5).

\footnotetext{
${ }^{200}$ Hay que recordar que la formación y rompimiento de los partidos políticos en Puerto Rico siempre tuvo que ver con las diferencias en las expectativas de las relaciones Puerto Rico- Estados Unidos.
} 
Figura 5. Desproporciones 1952-2012 201

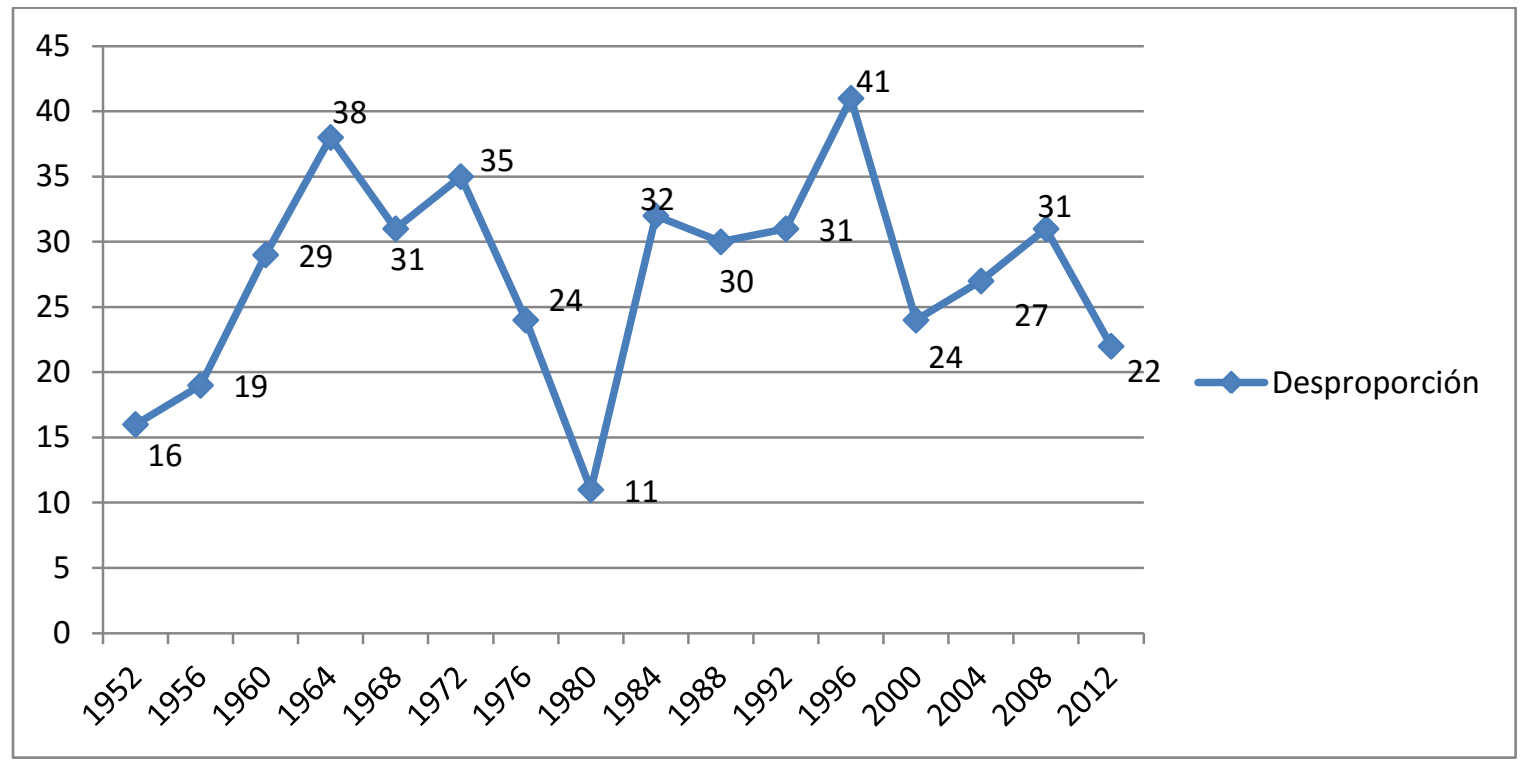

Este partido logró estructurarse alrededor de todos los distritos representativos delimitados por el sistema electoral. La atracción hacia la figura de Muñoz Marín era tal que muchos promulgaban, incluso, "antes que popular soy muñocista". ${ }^{202}$ Ninguna fuerza política representaba en sí una amenaza a la mayoría popular en la legislatura. En ese período histórico se mantiene un "sistema de partido hegemónico" "203. Carmen Ramos Santiago ${ }^{204}$ sostiene que: “[el] sistema de representación territorial en Puerto Rico, basado en el distrito unipersonal, en el caso de la cámara de representantes y del distrito bi-personal para el senado, ha tendido a darle grandes ventajas legislativas al partido de la mayoría".

Añade también esta autora que de no estar en la constitución la representación por acumulación y la ley de minoría, toda representación estaría en manos del PPD aun cuando el Partido Estadista Republicano de entonces obtuviera el segundo lugar en

\footnotetext{
${ }^{201}$ Los datos fueron obtenidos de tres fuentes: La Comisión Estatal de Elecciones, las últimas cuatro se encuentran en su página web: www.ceepr.com. Eventos electorales. 2012. Carmen Ramos Santiago, op. cit, Universidad de Puerto Rico (UPR). Juan José Nolla-Acosta, op. cit., (S.E).

${ }^{202}$ Ibid., p.214.

${ }^{203}$ Giovanni Sartori, op. cit.., Alianza Editorial, 2005.

${ }^{204}$ Carmen Ramos Santiago, op. cit., Universidad de Puerto Rico (UPR). Juan José Nolla-Acosta, op. cit., (S.E).
} 
los comicios y un número significativo de votos. Así, las leyes que favorecen a la minoría ayudan a la formación de una segunda fuerza política, y por su parte, la representación del sistema de mayoría ayudaba al sostenimiento del primer partido. Aún con la representación de la minoría, el movimiento estadista no lograba hacerle oposición fuerte al PPD.

Durante un periodo considerable (1960-1968), el anexionismo monopolizó los escaños por acumulación a excepción de algunos que recibía el PIP. En las elecciones del 1952 el PIP se posicionó como segunda fuerza política por conflictos internos en el PER (el mismo Partido Estadista Puertorriqueño). No obstante, en 1956 el PER había postulado a Luis A. Ferré para la gobernación por primera vez y logró regresar al segundo lugar. Para las elecciones de 1956, el PER logra 6 escaños por acumulación entre las dos cámaras y el PIP, sólo por haber postulado más candidatos obtuvo 9. Pero en 1960 el PER obtuvo 24 legisladores por acumulación y el PIP no obtuvo ninguno. Los mismo ocurrió en 1964, donde el PER obtuvo en la cámara 17 escaños y el PIP ninguno. ${ }^{205}$

En 1968, el PPD comienza a tener conflictos internos, y el modelo económico presentó algunas fallas en conjunto con la creciente figura de Luis A. Ferré como líder del naciente Partido Nuevo Progresista (PNP)- escisión del PER. Por primera vez, el PPD pierde la gobernación, aunque no así el legislativo, las alcaldías y la comisaría residente. En estas elecciones, el PPD tiene una disminución en el número de votos que recibe. De 492,531 en 1964 pasa a 374,040 en 1968. El aumento en la base del anexionismo aglutinado en el PNP coincide con un aumento en la población de individuos con18 años de edad. En el censo de 1950 se percibe un aumento en población de habitantes que supera los 300,000 (Figura 6). Esta población en aumento hacia 1968 estaría apta para votar en las elecciones. Para esas elecciones hubo un aumento de 87, 000 votantes.

${ }^{205}$ Juan J. Nolla Acosta, op. cit., (s/e). 
Figura 6. Cambio poblacional en Puerto Rico ${ }^{206}$

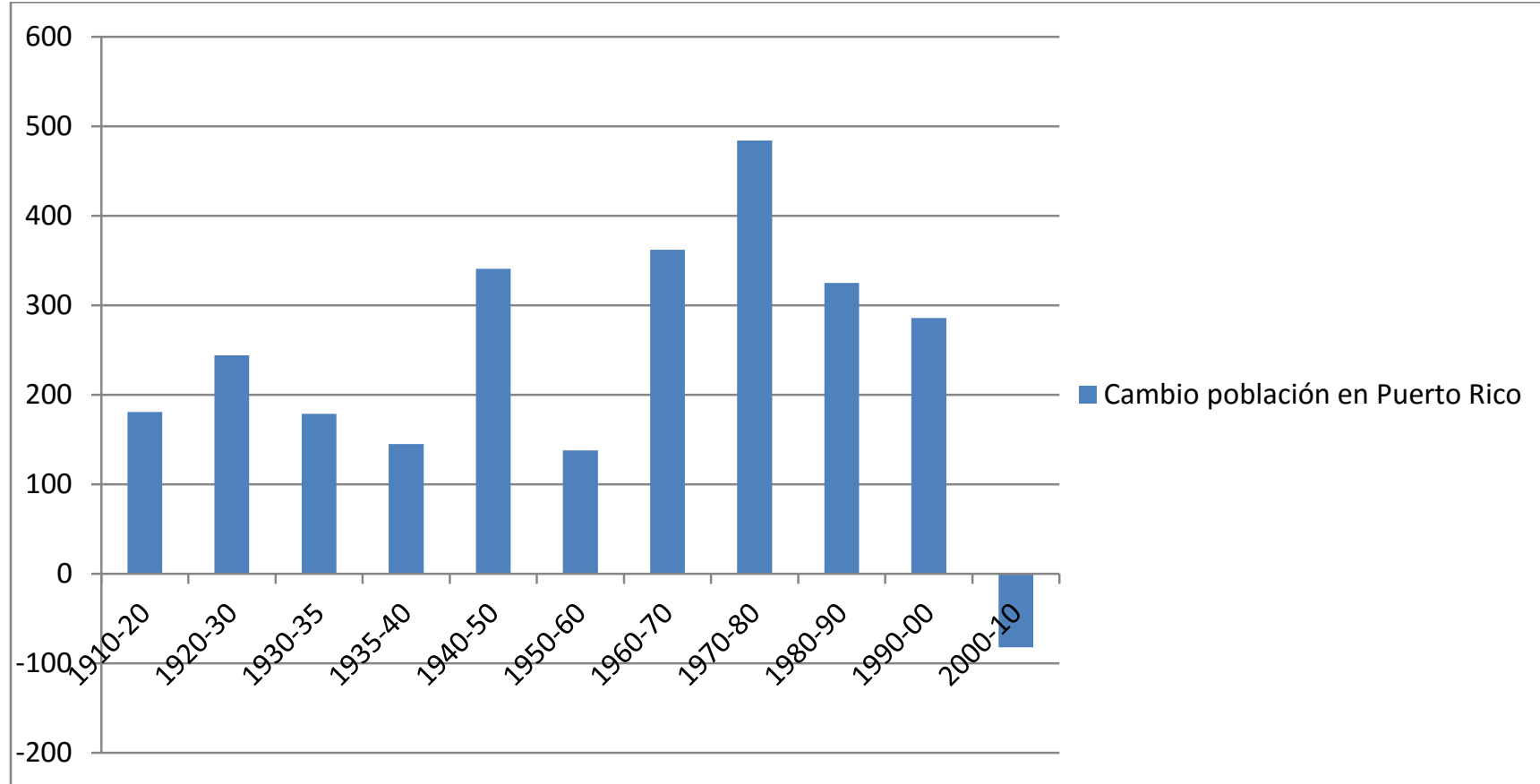

Como observamos con los resultados de 1968, el PPD incluso con el contexto desfavorecedor a su partido, mantiene su mayoría casi intacta. Antes y durante este primer cuatrienio en manos del gobierno compartido, aumentaron significativamente los programas sociales y ayudas federales por parte de EE.UU. hacia P.R., llegando a representar alrededor de un $25 \%$ del ingreso personal del puertorriqueño. $^{207}$

Efrén Rivera ${ }^{208}$ menciona que una característica que mantuvo la hegemonía hacia EE.UU. de una parte considerable de los puertorriqueños fue: "La concesión de una significativa gama de transferencias monetarias tanto al gobierno del territorio

\footnotetext{
${ }^{206}$ Los datos de esta figura se consiguen en la página web: demografía.rcm.upr.edu. Series históricas. Datos Censales 1910-2010. Consultado el 27 de febrero de 2016.

${ }^{207}$ Efrén Rivera, Hegemonía y legitimidad en el Puerto Rico contemporáneo, Barcelona, Ed. UPR, Working paper n. 129, 1998. Véase también el libro de Linda Colón Reyes. Sobrevivencia, pobreza y mantengo: La política asistencialista estadounidense en puerto Rico: el PAN y el TANF. Rio Piedras. Callejón, 2011, p.76. Esta autora enumera los programas implementados en la década de los 60. El programa de cupones de alimentos y la ley de incentivos del trabajo. Esto como resultado de una serie de reformas al modelo de estado benefactor.

${ }^{208}$ Ibid. p.1.
} 
como directamente a individuos". Así, la ideología anexionista y la del status quo que se formaron y promovieron durante esos años, tuvieron grandes incentivos económicos que sostuvieron a estos dos partidos, también fortalecidos por el intento de desaparición del independentismo. En otras palabras, el independentismo se fue quedando sin "base social", mientras que la "base social" del PPD y del PNP se fortalecía en la medida en que se priorizaba la dependencia en ayudas económicas estadounidenses para atender a los marginados y en inversiones industriales provenientes de EE.UU. para el sostenimiento de una clase media en expansión.

En 1968 el movimiento estadista se aglutina en el PNP de manera efectiva, logrando una transición entre el "partido hegemónico" (PPD) y el "bipartidismo" (PPD-PNP). En esta etapa, el bipartidismo se fortalece. En las elecciones de 1972 se evidencia un aumento significativo en la participación electoral que pudiera provenir del aumento en la base de apoyo del PNP (véase Figura 3). Ambos partidos se fortalecieron en 1972. El PNP aumentó unos 162,794 votos y recibió más de medio millón de votos. Nunca una fuerza anexionista había obtenido tanto apoyo electoral antes de 1968. La elección donde el PPD obtuvo una mayor cantidad de votos antes de perder en 1968 había sido en 1964 con 492,531 votos. En la elección de 1972 el PPD obtiene 659,856 votos bajo su insignia.

Estos partidos crean un liderato regional de líderes municipales, legislativos y uno central formado por candidatos a puestos nacionales y ex líderes. Sus niveles internos son: municipios -donde conservan un comité conformado por comités de barrio-, regiones -compuesta por líderes municipales y legisladores- y liderato 
nacional -formado por el presidente de la colectividad en general y líderes de otros organismos-. 209

En las elecciones de 1972 hubo una desproporción de .35. El PPD quedó sobrerrepresentado en +18 , mientras que el PNP se sub-representa en -15 . El PIP obtiene una sub-representación de -2. Se mantienen desproporciones que propician el monopartidismo.

Hasta el momento, el día de las elecciones, se le entrega al elector una papeleta donde figuran todos los candidatos de todos los puestos electivos: estatales, legislativos y municipales. Se dice que el propio Muñoz Marín decía que él podía "postular una vaca en Mayagüez y que ésta saldría electa". ${ }^{210}$ Pero una reforma legislativa de 1983 permitió separar la papeleta municipal para promover lo que se conoce equivocadamente como "voto inteligente", porque evalúa los candidatos por separado. Desde 1985 hasta 1995 estuvo en la legislatura, gracias a ese mecanismo, el único legislador dominicano que ha habido en la historia de Puerto Rico: Fernando Tonos (PPD). ${ }^{211}$

Este mismo legislador en 1993 presenta un proyecto para separar la papeleta legislativa, pero su proyecto recibe un informe negativo de parte de la comisión de gobierno. Sin embargo, la delegación del PNP estando en mayoría para 1995 aprueba este proyecto presentado por Sergio Peña Clos. Anteriormente este mismo proyecto había recibido dos informes negativos de la comisión de gobierno, uno al proyecto presentado por Rubén Berrios del PIP y otro presentado por otro miembro

\footnotetext{
209 Véase Reglamento del Partido Popular Democrático y del Partido Nuevo Progresista. Se consiguen en sus respectivas páginas web: www.partidopopulardemocrático.pr.com. www.partidonuevoprogresista.pr.com. www.independencia.net. Consultado el 16 de marzo de 2016.

${ }^{210}$ No he encontrado una referencia donde él lo diga, pero es popularmente conocido de que lo dijo más o menos esas palabras.

${ }^{211}$ Daniel Nina. "Una dominicana a la legislatura en Puerto Rico". El Post-Antillano. Miércoles 14 de agosto de 2013. Se consigue en página web: www.elpostantillano.net. Consultado el 12 de febrero de 2016.
} 
de la delegación popular, ambos con el mismo fin de separar la papeleta legislativa. $^{212}$

Al separar la papeleta legislativa de una elección a otra disminuyeron los votos mixtos (Figura 7), porque son los candidatos legislativos los que acumulan más votos mixtos o por candidatura. La diferencia entre uno y otro es que el voto mixto marca la insignia del partido y los candidatos, pero los votos por candidatura dejan en blanco la columna donde están las insignias de los partidos.

Figure 7: Votos Mixtos en las tres papeletas 1956-2012 ${ }^{213}$

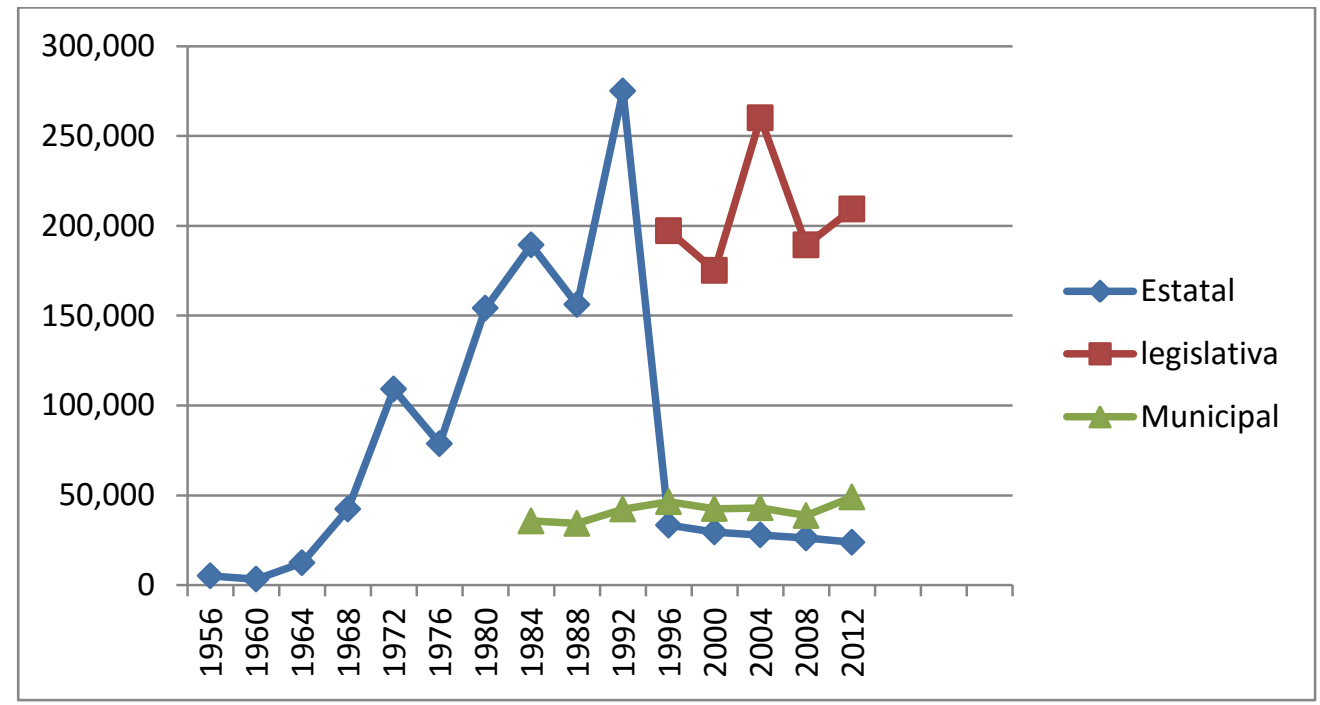

El elector puertorriqueño tiene ante sí tres papeletas el día de las elecciones. Tiene una papeleta "estatal", donde se encuentra la insignia del partido, el candidato a la gobernación y el cargo a la comisaría residente en Washington. La segunda papeleta es la legislativa, donde el elector puede marcar un representante y hasta dos senadores por su distrito. Puede, a su vez, ejercer el voto por un senador en la

\footnotetext{
${ }^{212}$ Oficina de servicios legislativos en línea. Página web: www.osl.pr.org. Consultado el 27 de febrero de 2016.

${ }^{213}$ Juan José Nolla-Acosta. Op. cit., (s/e).p. 622-623.
} 
lista de candidatos por acumulación y escoger también un representante por acumulación. La tercera papeleta es la municipal con una lógica distinta. ${ }^{214}$

Los partidos principales, al haber creado y adaptado los diferentes niveles electorales al interior de sus respectivos partidos, promueven una fuerte comunicación entre regiones. En 1900 se implementa el modelo de mayoría a un solo nivel, en 1917 se duplican los niveles y se añade un liderato nacional (acumulación), en 1947 con la creación de un ejecutivo electo se inaugura el doble liderato (partido y gobierno) y en 1952 se aumentan los curules y se formalizan las instituciones políticas del ELA. Fue este proceso gradual que permitió que desde 1968 hubiese, lo que se ha denominado en P.R. por mucho tiempo, un "bipartidismo cerrado". Su articulación se demuestra en la diferencia entre los votos mixtos versus los íntegros. Estos últimos en promedio representan el $90 \%$ de los votos y los mixtos no pasan de 20\% (Figura 8).

Desde el 1952, el movimiento anexionista creció de 20,000 a 400,000 votos en el 1968, año en el que gana las elecciones (Figura 9). El Partido Independentista Puertorriqueño (PIP) pasó de ser la segunda fuerza electoral a la tercera. No es casualidad que en 1952, el PIP obtuviera más de 120,000 votos, en 1956 descienden a 80,000 y para el 1960 llegaron sólo a 20,000. En ocho años el PIP perdió poco más de 80,000 votos, lo que representa una disminución de 40 mil votos por cuatrienio. Recordemos que estos años fueron los de mayor persecución en contra del independentismo (Véase figura 13).

Por décadas la independencia fue la línea principal de los partidos de mayoría al igual que una tendencia política que se ha mantenido desde el comienzo del sistema político. ${ }^{215}$ Luego de 1952 el PPD abandona el autonomismo ${ }^{216}$ para

\footnotetext{
${ }^{214}$ No es de nuestro interés en este trabajo. La papeleta municipal incluye el ejecutivo y el legislativo así como el vice alcalde. De manera que el control de los ejecutivos en los municipios es mayor.

${ }^{215}$ Desde que el Partido Unión lo adopta en 1904 hasta que el PPD lo abandona en 1944, luego el PIP en 1946.
} 
entregarse por completo a defender el status quo (ELA). Esto, favorecido con el contexto de "industrialización por invitación", de persecución política, de modernización y de crecimiento del estado benefactor, fortaleció el incentivo ideológico de ambos partidos: la unión permanente con los EE.UU. No es extraño que los dos partidos grandes se hayan alineado en todo el sentido a los intereses estadounidenses. Pasaron de ser partidos de izquierda y partidos socialistas, uno con propuesta de autonomía y otro con anexión, a ser defensores del status quo y del neoliberalismo estadounidense.

Figure 8: Votos Mixtos e íntegros por partido 1984-2012.

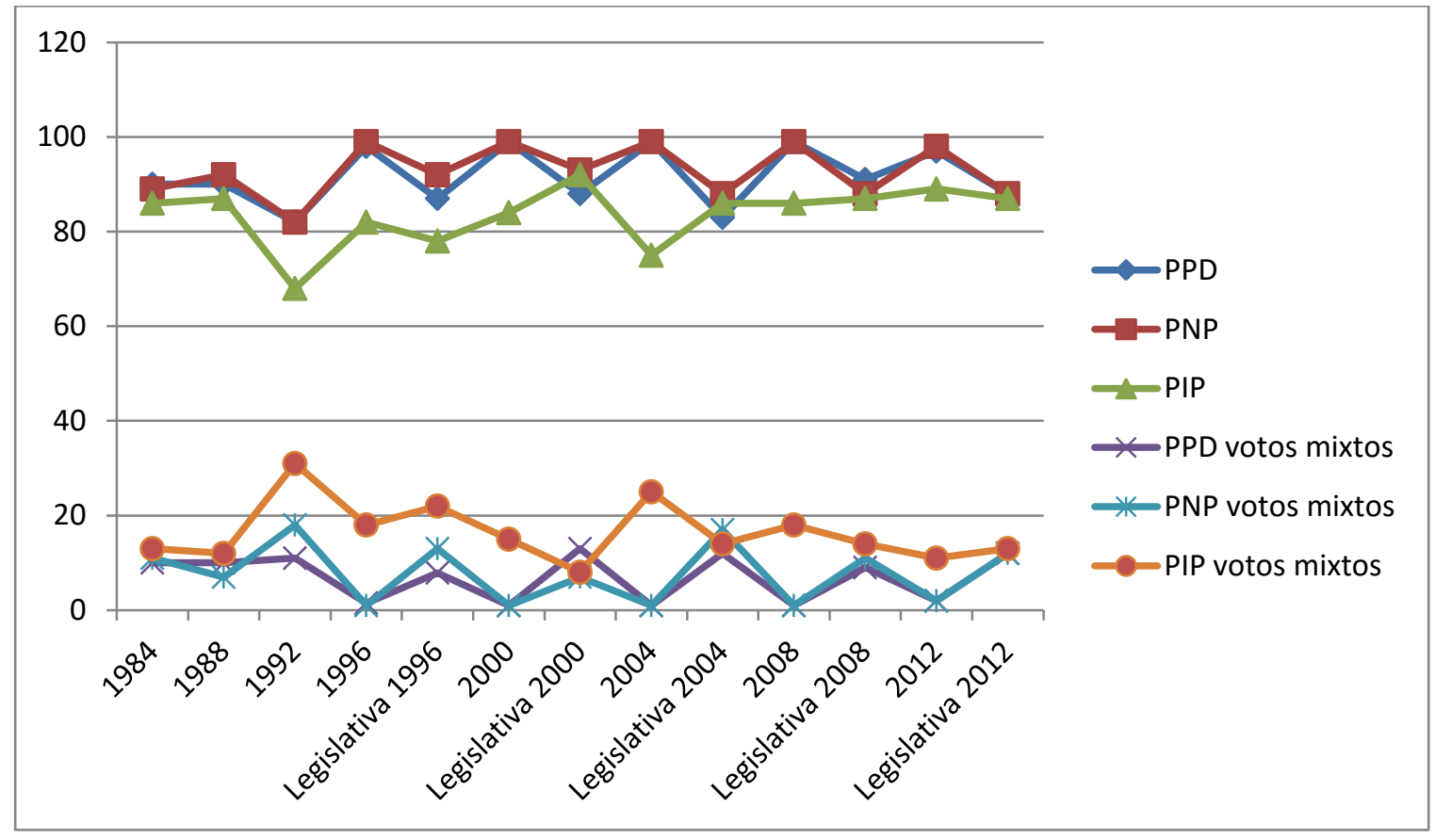

216 Tendencia que había defendido su padre Luis Muñoz Rivera desde el Partido Liberal tradicional, el Partido Unión, el Partido Liberal moderno de donde provenía el propio Muñoz Marín y el propio Partido Popular en sus comienzos antes del establecimiento del ELA. 
Figura 9. Votos a los partidos: 1951-2012 217

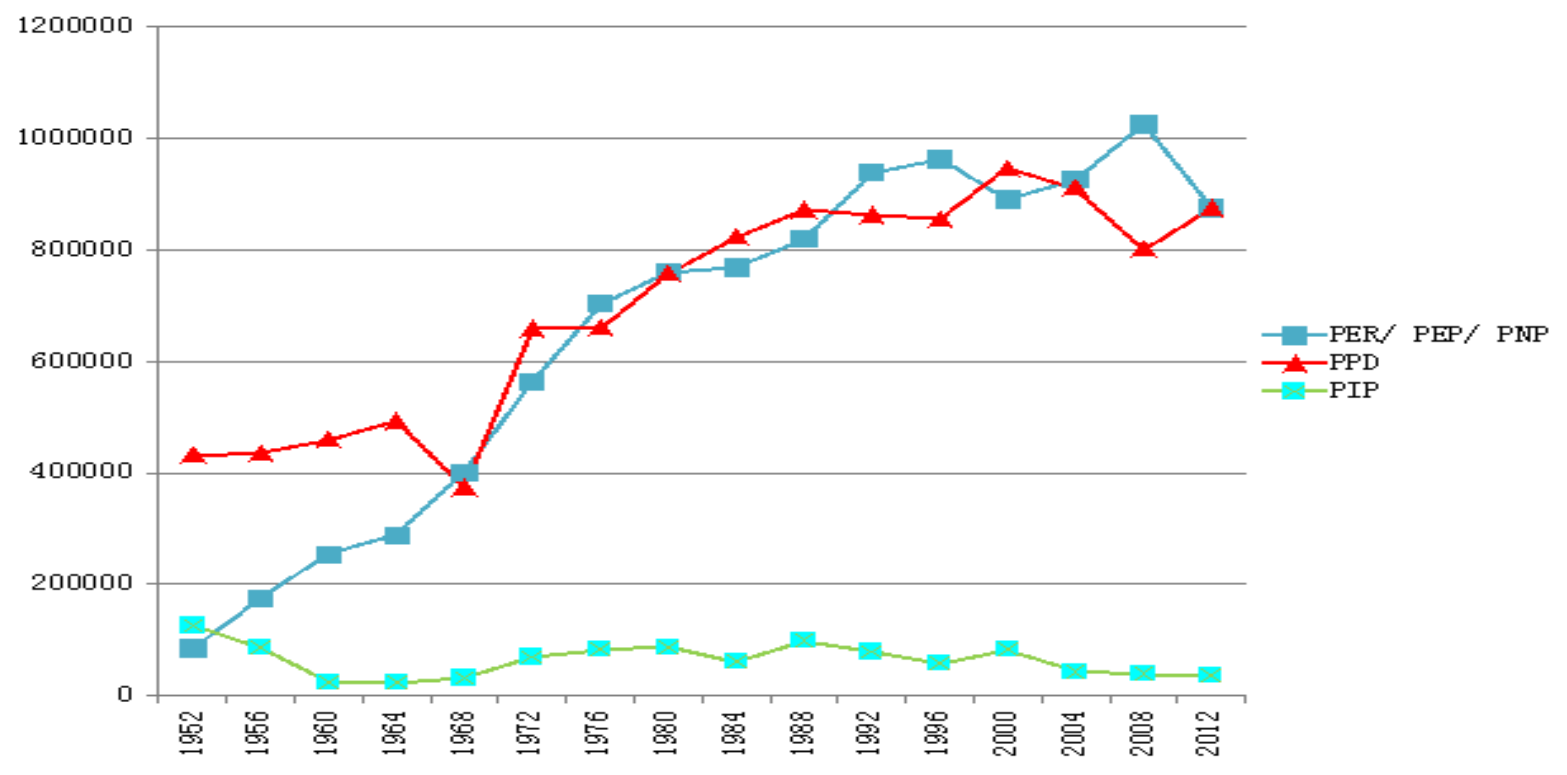

Así las cosas, al momento en que estas dos fuerzas se consolidan, el sistema electoral mayoritario los mantiene por sus dos efectos, el técnico y el psicológico $^{218}$, que operan al unísono en P.R. En el aspecto técnico, el sistema electoral puertorriqueño sobre-representa al partido ganador como ha ocurrido desde 1900 y se mantiene hasta ahora. En el 2008, el PNP ganó las elecciones con el $53.64 \%$ de los votos bajo la insignia y el $52.84 \%$ para la gobernación, en el senado obtuvo $81.48 \%$ de la representación y en la cámara el $74.50 \%$. Estos resultados del 2008 son un ejemplo del "winner takes all". Como contraste, además de esta posibilidad donde el ganador se lo lleva todo, también existen los gobiernos compartidos o los que no tienen mayoría absoluta.

En la etapa más actual (2012-2015), el gobierno del PPD tiene mayoría relativa y no mayoría absoluta en la legislatura. En 2012, el PNP obtuvo el $48.43 \%$ de los

\footnotetext{
${ }^{217}$ Los datos fueron obtenidos de tres fuentes: La Comisión Estatal de Elecciones, las últimas cuatro se encuentran en su página web: www.ceepr.com. Eventos electorales. 2012. Carmen Ramos Santiago, op. cit., Universidad de Puerto Rico (UPR). Juan José Nolla-Acosta, op. Cit., (S.E).

${ }^{218}$ Mauricie Duverger, op. cit., Fondo de Cultura Económica. Tomamos estos conceptos de la teoría de Mauricio Duverger para interpretarla en Puerto Rico de manera empírica con números que demuestren su manifestación.
} 
votos, el PPD el $48.20 \%$ y el PIP 2.03\%. En el senado el PPD obtiene el 66\% de los escaños, el PNP 29\% y el PIP solo un escaño, lo que representa un 0.03\%. En la cámara, el PPD obtiene el 54\% y el PNP 46\%. Hay una distorsión injusta en la representación que promueve el sistema electoral vigente. La desproporción promedio para este caso en el efecto mecánico se observa en .30. Solo en tres ocasiones desde 1952 hasta 2012 hubo menos de .20 en desproporción (véase Figura 5).

Según dicta la Ley de Duverger ${ }^{219}$ partidos que sistemáticamente quedan excluidos de la legislatura o parlamento nacional en su país, tienden a desaparecer. En el periodo de 1952-2012, es decir bajo el modelo electoral creado en la constituyente, se excluyeron a 21 partidos políticos de representación, incluyendo partidos que habían logrado el 10\% de los votos (véase Tabla 11).

Tabla 11. Cambios de partidos en la legislatura: 1952-2012

\begin{tabular}{lcccc}
\hline Cuatrienio & $\begin{array}{c}\text { Partidos de } \\
\text { mayoría }\end{array}$ & $\begin{array}{c}\text { \% de representación de } \\
\text { partidos en minoría }\end{array}$ & $\begin{array}{c}\text { Número de } \\
\text { partidos por } \\
\text { legislatura }\end{array}$ & $\begin{array}{c}\text { Partidos } \\
\text { participantes }\end{array}$ \\
\hline $1953-56$ & PPD & Estadistas (11\%); PIP (16) & 3 & 4 \\
$1957-60$ & PPD & Estadistas (18); PIP (9) & 3 & 3 \\
$1961-64$ & PPD & Estadistas (25) & 2 & 4 \\
$1965-68$ & PPD & Estadistas (21) & 2 & 4 \\
$1969-72$ & Dividido:PNP:PPD & - & 2 & 5 \\
$1973-76$ & PPD & PNP (28); PIP (5) & 3 & 6 \\
$1977-80$ & PNP & PPD (40) & 2 & 4 \\
$1981-84$ & PNP & PPD (49) & 2 & 4 \\
$1985-88$ & PPD & PNP (31); PIP (2) & 3 & 4 \\
$1989-92$ & PPD & PPD (29); PIP (3) $(2)$ & 3 & 3 \\
$1993-96$ & PNP & PPD (26); PIP (2) & 3 & 3 \\
$1997-00$ & PNP & PNP (27); PIP (2) & 3 & 3 \\
$2001-04$ & PPD & PIP (2) & 3 & 3 \\
$2005-08$ & Dividido:PNP:PPD & PPD (31) & 2 & 4 \\
$2009-12$ & PNP & PNP (40); PIP (1) & 3 & 6 \\
$2013-16$ & PPD & Cambios: 6 & Partidos & Sin \\
\hline 16 elecciones & Cambios: 9 & nuevos:1* & representación**:21 \\
\hline
\end{tabular}

Nota. *Con esto nos referimos al momento en que aparece alguna nueva tendencia o partido.**Número total de partidos sin representación en la legislatura. Sumando todos los cuatrienios.

${ }^{219}$ Ibid. 
Los conflictos legislativo - ejecutivo suelen generarse más cuando hay un gobierno dividido, donde el éxito de la mayoría legislativa depende de la destrucción política del gobernador. Esto ocurre aún en Puerto Rico, que tiene un sistema mayoritario y bipartidista. De las elecciones de 2004 surgió el segundo gobierno dividido luego de 1968. Bajo su insignia, el PPD recibió el 48.4\% de los votos, el PNP el 49.3\% y el PIP 2.3\%. El senado se reparte entre el PNP con 51.4\% de los escaños y el PPD con 48.5\%. En la cámara, reciben el PNP 51.4\% de los curules y el PPD 48.6\%. Estos porcentajes reflejan que incluso bajo un gobierno divido, aunque en menor grado, hay una sobrerrepresentación del ganador. Como ocurría bajo los pasados sistemas electorales Foraker y Jones, cuando se exacerba el bipartidismo se cierra la brecha de la sobre y sub-representación entre el primero y segundo partidos en votación.

Los gobiernos divididos no son muy comunes en el sistema puertorriqueño y sólo han ocurrido dos veces en su historia legislativa, ya que los individuos prefieren ejercer su voto directamente bajo la insignia del partido (Véanse Figuras 7 y 8), lo que es característico del sistema presidencial y mayoritario. Este tipo de votación le da mayor preeminencia al candidato de más alta jerarquía que, mediante un efecto de arrastre, se lleva la atención de las demás candidaturas. ${ }^{220}$ Esto es lo que se conoce en Puerto Rico como el hábito tradicional de los votantes: el voto íntegro por la lista completa de los candidatos de un partido, al marcar "una sola cruz" bajo la insignia del partido.

En las elecciones del 2012, por ejemplo, en la papeleta estatal no votaron bajo la insignia del partido alrededor del 70,595 electores, lo que representa el $0.03 \%$, contrario al $90 \%$ que votó sólo bajo la insignia del partido y no por candidatos. En

\footnotetext{
220 Scott Mainwaring,y Matthew S. Shugart, Presidencialismo y democracia en América Latina, Buenos Aires,Paidós, 2002.
} 
la papeleta legislativa este porcentaje de $0.3 \%$ aumenta al $19 \% .{ }^{221}$ Los votos bajo la insignia, como estamos ante partidos estructurados, también se llevan al nivel del distrito donde estos partidos están organizados, y donde gana el partido casi siempre el legislador gana el escaño.

Los partidos en campaña piden una sola cruz en cada papeleta: una sola cruz "bajo la pava" (PPD) o "bajo la palma" (PNP) en las tres papeletas. La figura de más alta jerarquía en la papeleta se lleva más del $90 \%$ de los votos hace más de tres décadas en Puerto Rico. Los votos bajo la insignia de los dos partidos de mayoría acaparan casi 2 millones de votantes cada uno. Lo que constituye algo más de la mitad de la población. En P.R. el modelo presidencial mayoritario y la fortaleza del ejecutivo con respecto al legislativo fomentan un acaparamiento de la atención de los líderes nacionales. Es por ello que se concentra el poder y el voto íntegro.

De manera que si seguimos la definición de un partido estructurado de Sartori ${ }^{222}$ "cuando los electores votan por insignia y no por notables", estamos ante dos partidos fuertemente estructurados y sostenidos por el sistema mayoritario que, en su aspecto mecánico sobre-representa al ganador. Los pocos votos mixtos y por candidatura se reparten entre los candidatos por acumulación.

En cambio, los senadores y representantes por distrito no son conocidos y, en general, no poseen un fuerte vínculo con su electorado, contrario a lo que se esperaba cuando se estableció "un solo voto por persona". Se pretendía que los electores se informaran de sus candidatos y que ejercieran el voto directo con el fin de crear un fuerte vínculo elector-legislador. La realidad es que ni hay información por parte del elector sobre estos candidatos, ni tampoco se ejerce el voto directo hacia estos. En una encuesta realizada alrededor de todo el país, solo un $17 \%$ de

\footnotetext{
${ }^{221}$ Comisión Estatal de elecciones. Archivo de elecciones. 2012. Página web: www.ceepr.com. Consultado el 18 de mayo de 2015. Estos datos se pueden corroborar en el libro que los organiza del abogado Juan José Nolla-Acosta,op. cit., (S.E).

${ }^{222}$ Giovanni Sartori, op. cit., Fondo de Cultura Económica.
} 
puertorriqueños mencionaron correctamente a sus senadores por distrito y un $20 \%$ a sus representantes por distrito (Tabla 12). Un porcentaje cercano al de los votos mixtos y por candidatura en la papeleta legislativa.

En comparación con otros países, P.R. estaría entre los diez países con menor conocimiento sobre sus legisladores por distrito. ${ }^{223}$ El voto directo se utiliza poco y los electores tienen un bajo conocimiento de sus legisladores. La intención de los constituyentes no se cumple para este tipo de representación.

La ley de minoría no necesariamente beneficia al tercer partido. Como señalamos anteriormente, tiende a fortalecer el bipartidismo ya que los escaños serán asignados a los candidatos con mayor número de votos, y que están en el partido de segunda mayoría. Los terceros partidos, si pretenden quedar representados bajos las condiciones actuales en la legislatura, deben coordinarse con el sistema electoral para postular un candidato en cada cámara; dar a conocer a ese candidato a nivel nacional; y, si es posible que esos candidatos acumulen una buena cantidad de votos mixtos, solo entonces quedan electos y sub-representados.

El PIP, tercer partido, postula candidatos en todos los distritos y alcaldías. No obstante, hace varios años sólo postula un candidato por acumulación en cada cámara. Esto, con la intención de que el candidato acumule los votos que van a la insignia del partido. Estos candidatos, en las candidaturas por acumulación, como verdaderamente deben aglomerar votos de todo el país, tienen por lo regular una visión más nacional de los problemas. En ocasiones no excepcionales, su candidato o candidata resulta electo(a) por votos directos, como ha ocurrido con la senadora María de Lourdes Santiago en las elecciones de 2012.

\footnotetext{
223 Base de datos libre "The comparative study of electoral systems: 1996-2013". Porcentaje de personas que contestaron correctamente la pregunta Q6: Do you happen to remember the name of any candidate that run in your constituency in the last parliamentary election? Se puede conseguir en la página web: $\underline{w w w . c s e s . c o m}$. En el archivo de bases de datos: 1996-2001.
} 
Tabla 12

Conocimiento político de los puertorriqueños sobre las personas que ocupan puestos en el gobierno

Dice conocer el nombre del candidato $(\%)$

Gobernador

Comisionado Residente

Representante por distrito

Senadores por distrito

Alcalde

96.2

77.8

26.4

24.6

88.6
Menciona correctamente el nombre del candidato $(\%)$

Nota: Estos datos fueron recopilados por un grupo de investigación subsidiado por el programa de iINAS (Iniciativa de Investigación Subgraduada) de la UPRRP. Sus recopiladores fueron Joe Umpierre, Angie Maldonado, Alexandra Mulero, Jesús E. Vélez y Luis Nieves bajo la asesoría del Dr. Javier Colón Morera. N=625.

Los elementos anteriormente mencionados complementan el efecto mecánico. Mientras más estructurados estén los partidos más efectiva es la sub y sobrerrepresentación. Por ello, no es extraño que a medida en que se fortalece el bipartidismo la exclusión a terceros se haga más recurrente. Desde 1952 hasta 2012 hubo, en toda elección, más de tres partidos en competencia (Véase Figura 3). De 1917 a 2012 solo hubo una elección con dos partidos en competencia. A pesar de ello, la mayoría de las legislaturas únicamente tuvieron presencia de dos partidos.

Al momento en que se transfieren los votos a escaños, se obtienen resultados muy desiguales y desproporcionales (sobre-representa al ganador y sub-representa a los perdedores) que se agudizan cuando un partido obtiene más del 50\% de la votación y disminuyen -pero no desaparece- cuando surgen gobiernos divididos.

Este efecto mecánico de exclusión de la minoría no opera por sí solo, sino que existe también un efecto psicológico. El sistema de mayoría le provee al ganador una mayor capacidad de otorgar incentivos, debido a la sobrerrepresentación que este partido obtiene en la legislatura y otras entidades gubernamentales. El segundo partido, aunque sub-representado, se divide los recursos con la mayoría. En el proceso de campaña los recursos están exponencialmente ubicados en estos dos 
partidos, en conjunto con la posibilidad de ganar. Incluso, quienes no poseen fuertes vínculos con el partido, al recibir propaganda de estos y al ir observando los resultados elección tras elección entienden que no es posible que el tercer partido llegue al poder. Es por eso que estos electores suelen ejercer su voto por el "menos malo".

Así se resume el efecto psicológico. Como la minoría no ganará las elecciones se vota por el "menos malo" entre los dos partidos mayores (PPD y PNP). ${ }^{224}$ El efecto psicológico se manifiesta de dos formas. Primero, en el voto de castigo y segundo, en el llamado "pivazo" -que es también algo similar al voto de castigo, pero con resultados distintos-. Ambos fenómenos determinan quién ganará la contienda: PNP o PPD.

Duverger, en sus leyes, describe el voto de castigo como un efecto del sistema electoral. En P.R. se ha entendido como el voto que se le da a uno de los partidos de mayoría con la intención de sacar de la gobernación al otro, por su "mala práctica política durante el cuatrienio". Si evaluamos las votaciones, esta situación se hace mucho más palpable desde la victoria de Hernández Colón (PPD) y la derrota de Aníbal Acevedo Vilá (PPD).

Por ejemplo, bajo el gobierno de Acevedo Vilá, por primera vez se creó un Impuesto sobre Ventas y Uso (IVU). A su vez, hubo un conflicto con el sindicato de maestros que provocó una huelga y, en consecuencia, el cierre de las escuelas. Por primera vez, también, el gobierno cerró, por falta de un acuerdo sobre el presupuesto nacional.

La figura en el poder, a pesar del gobierno dividido, era la del gobernador Acevedo Vilá. Es decir, la imagen del líder máximo del PPD por el carácter presidencial del sistema. En la elección de 2008 y, en parte, como resultado de los

\footnotetext{
${ }^{224}$ Mauricie Duverger, op. cit, Fondo de Cultura Económica.
} 
pasados conflictos, el PNP ganó las elecciones por alrededor de 250,000 votos, un triunfo histórico para este partido. El PPD perdió, en comparación con la elección de 2004, alrededor de 160,000 votos, número que no puede comparase con el aumento en 75,000 votos del PNP. El voto de castigo, en este caso, fue que miles de votantes del PPD no asistieron a las elecciones y la base del PNP, en su mayoría, acudió a votar.

Si se comparan los votos íntegros al PNP y al PPD, se aprecia un margen de diferencia de 208,306 votos a favor del PNP. Este partido logra la victoria con sus propios votos, sin necesidad de que los miembros de otros partidos voten bajo sus candidatos. Esto es un escenario del voto castigo donde el PPD no tiene la capacidad de movilizar sus votantes contrario al PNP.

La segunda manifestación es el llamado pivazo que beneficia al PPD otorgándole, en ocasiones, la victoria a este partido. Los independentistas, que entienden que el candidato del PIP no tiene posibilidades de ganar, votan de manera mixta ubicando una marca bajo la insignia del PIP y otra bajo alguna candidatura del PPD. También ocurre con anexionistas. Estos votos se distinguen claramente en los resultados de las elecciones de 2004 y de 2012. Cuando el PPD obtiene la victoria lo hace por la acumulación de los votos mixtos y por candidatura.

Una excepción al caso anterior, son las elecciones del 2000 (Tabla 13), cuando el PPD gana la gobernación solo con sus propios votos. No obstante, en la legislatura le resultaron necesarios los votos mixtos y por candidatura para ganar la mayoría. El PNP recibió en la papeleta legislativa 890,976 votos íntegros, en cambio, el PPD recibió 946,133. En los votos mixtos y por candidatura de la papeleta legislativa es que el PPD supera al PNP; el primero recibe 28,218 y el segundo 32, 727. 
Tabla 13. Votos íntegros, mixtos y por candidatura: elecciones 1992-2012

\begin{tabular}{|c|c|c|c|c|}
\hline Año Electoral & Partido & Votos íntegros & Voto combinado & Partido ganador \\
\hline \multirow[t]{2}{*}{1992} & PNP & 816,758 & 122,211 & PNP \\
\hline & PPD & 676,010 & 186,979 & \\
\hline \multirow[t]{2}{*}{1996} & PNP & 963,538 & 42,793 & PNP \\
\hline & PPD & 855,960 & 19,892 & \\
\hline \multirow[t]{2}{*}{2000} & PNP & 890,976 & 28,218 & PPD \\
\hline & PPD & 946,133 & 32,727 & \\
\hline \multirow[t]{2}{*}{2004} & PNP & 926,619 & 33,118 & PPD \\
\hline & PPD & 910,657 & 52,646 & \\
\hline \multirow[t]{2}{*}{2008} & PNP & 988,212 & 37,756 & PNP \\
\hline & PPD & 779,906 & 21,165 & \\
\hline \multirow[t]{2}{*}{2012} & PNP & 870,324 & 14,451 & PPD \\
\hline & PPD & 866,232 & 29,828 & \\
\hline \multirow[t]{2}{*}{ Mayor votación } & PPD: & 2000 & $1992,2000,2004,2012$ & \\
\hline & PNP: & 1992, 1996, 2004, 2008, 2012 & 1996,2008 & \\
\hline
\end{tabular}

Fuente de elaboración propia con datos de: Comisión Estatal de Elecciones. Página web:

www.ceepur.org.

El llamado pivazo ${ }^{225}$ son votos de miembros de otros partidos que por no tener otra posibilidad de ganar elecciones, ejercen su voto por el "menos malo". Para aglutinar el voto de independentistas, el PPD ha construido todo un discurso que demoniza la anexión como pérdida de la identidad y sugiere la autonomía y la soberanía, conceptos cuya definición no tiene consenso dentro del partido, pero tiene la intención de captar votos de independentistas. A su vez, promueve el discurso pro americano, que intenta llamar a la unión permanente con los EE.UU. Con estos discursos, se asegura el pivazo y exilio de unos pocos electores del PNP,

\footnotetext{
${ }^{225}$ Se le denomina así porque es, tradicionalmente, un voto por el PIP a la insignia y otro por el candidato del PPD que se identifica con la pava (un símbolo de un jíbaro con un sombrero de paja o pava como se llama en PR). Por eso la pava y el PIP pivazo. Sin embargo esto no ocurre solo bajo la insignia del PIP. En menor grado también ocurre bajo la insignia del PNP. Esto tiene que ver con la naturaleza de partido del PPD que intenta atrapar todas las ideologías, es un partido de centro derecha porque actualmente (2016) promueve políticas neoliberales con muy pocos proyectos inclusivos que muchas veces terminan debilitándose.
} 
lo que lo hace un partido más pragmático y un tipo de partido moderno "atrapa todo". 226

El voto de castigo se manifiesta más como la abstención de votantes del PPD y una victoria del PNP. El efecto psicológico en sus dos manifestaciones no contempla la tercera alternativa partidista como opción, no en el sentido moral sino técnico: no es que el tercer partido no valga la pena, es que tiene escasas posibilidades de ganar y por ello la opción reside en el "menos malo".

Se fabrican dos mayorías, sostenidas en la imposibilidad del tercero. El efecto principal del sistema electoral en P.R. es el mantenimiento del bipartidismo. Dos estructuras de partidos organizadas en todo el país, cuyo origen y sostenimiento han sido el colonialismo y el sistema electoral. El colonialismo, al mantener la represión al independentismo y al generar el status quo, provocó la entrada en juego de estos dos partidos, con un tercero en gran desventaja y perseguido políticamente. El sistema electoral promueve la sobrerrepresentación así como la victoria de una o dos fuerzas que acaparen la estructura gubernamental en todo el país. Estos dos partidos: "Han monopolizado la vida pública puertorriqueña...convirtiéndose en las únicas dos entidades políticas capaces de obtener el control del gobierno del Estado Libre Asociado y de los gobiernos municipales de Puerto Rico...una situación de fuerzas equilibradas". ${ }^{227}$

El Gobierno se convierte en un botín que, de alguna u otra manera, los dos partidos se aseguran en algún momento, y la fuerza de estos dos partidos es percibida como invencible e inmortal "por culpa del elector" que vota "siempre por

\footnotetext{
226 Jane E. Wolinetz, "Más allá del partido catch all: enfoques para el estudio de los partidos en las democracias contemporáneas". En Richard Gunther, José Ramón. Montero y Juan. Linz (eds), Partidos políticos. Viejos conceptos y nuevos retos. Madrid: Editorial Trotta, 2007.

227 Angel Israel Rivera Ortiz, "La cultura política y la estabilidad del sistema de partidos en Puerto Rico", Rio Piedras, Caribean Studies, Vol. 24, n. 3/4, 1991, pp. 175-220.
} 
los mismos". ${ }^{228}$ Es aquí cuando el dualismo de partidos comienza a ser peligroso para el sistema puertorriqueño: fomenta la exclusión y genera impotencia en el electorado. Ahora, como el mago que no conoce como revertir su magia ${ }^{229}$, el modelo bipartidista parece inquebrantable. Los segundos y terceros partidos llegan a la elección y al momento de la repartición de escaños quedan sub-representados o excluidos. Es normal que los partidos pierdan hasta la franquicia electoral y tienen que recoger alrededor de 60,000 firmas o peticiones de endoso para lograr figurar en la papeleta de la elección próxima.

Desde 1917 hasta 1952 solo ha habido desproporciones de menos de 10 en una ocasión (1980) y de menos de 20 en dos ocasiones. La mayor parte de los resultados electorales son altamente desproporcionales. Se han excluido alrededor de 32 partidos de la representación legislativa.

Hay una diferencia significativa en estos periodos. El segundo periodo de 19171952 contiene una mayor volatilidad de partidos que el tercero de 1952 hasta 2012 (véanse tablas $8,10,11,14)$. Los partidos logran crear estructuras fuertes luego de que tuvieran candidatos ejecutivos, se ampliara el sistema legislativo y se oficializara todo en una constitución.

Para efectos de la representación por género este modelo electoral falla. En el 2000, hubo 15 mujeres en el parlamento puertorriqueño, en el 200415 también, en 2008 fue el mejor de los casos con 23, pero en el 2012 su representación se redujo a 12 escaños. La representación de féminas corresponde al $23 \%$ en el mejor de los casos, y en el peor escenario un 14\% desde 1980, cuando comienza a aumentar un poco la presencia de la mujer en el parlamento.

\footnotetext{
${ }^{228}$ Es muy común escuchar en la radio puertorriqueña algún cuestionamiento de: ¿por qué los puertorriqueños siempre votan por los mismos? Generalmente se concluye que es porque no hay alternativas viables. Sin embargo, como se ha visto, la realidad política es que la institución ha promovido la discusión centrípeta manteniendo el status quo. La persecución hacia el movimiento independentista tuvo como resultado el vaciamiento del independentismo en Puerto Rico. Una realidad inescrutable, con gran consenso académico, legal, y político.

${ }^{229}$ Esto es una frase muy conocida. En este caso le hemos escuchado de Enrique Dussel en sus conferencias al referirse al sistema económico.
} 
Este periodo (1952-2016) mantiene un Índice de Representatividad en el Parlamento (IRP) de 80. Es el más alto de los tres momentos que analizamos. Sin embargo, se evidencia que desde 1898 el sistema de partidos en la legislatura estuvo siempre enmarcado en el dualismo de tendencias (véase tablas de partidos 7, 9 y 14) porque el sistema electoral promovía la exclusión del perdedor.

Tabla 14. Partidos Políticos: 1948-1968 (*continúan hasta hoy)

\begin{tabular}{ccc}
\hline 1948 & 1956 & 1968 \\
\hline *Partido Popular Democrático (-actualidad) & & Partido Estadista \\
Republicano & *Partido Nuevo \\
Partido Estadista Puertorriqueño & & Progresista \\
\hline $\begin{array}{c}\text { *Partido Independentista Puertorriqueño (- } \\
\text { actualidad) }\end{array}$ & &
\end{tabular}




\section{Capítulo 4.}

\section{Conclusiones}

La presente tesis tuvo como objetivo evaluar si los momentos fundacionales incluyentes (x) promueven parlamentos inclusivos (y) para el caso de Puerto Rico. Tomando en cuenta que los momentos fundacionales inclusivos permiten el acuerdo de un sistema electoral (z) que promueve una alta representatividad en el parlamento. Para cumplir con este objetivo se analizaron tres periodos (1898-1916; 1917-1951; 1952-2012) en Puerto Rico, que abarcan 33 eventos electorales.

Los resultados de cada una de las etapas se sintetizaron bajo tres índices: el IRMF, el IRSE y el IRP. En general, el caso de Puerto Rico marca el camino establecido en la hipótesis hecha por Colomer: los sistemas electorales se dirigen de excluyentes a más inclusivos. ${ }^{230}$ En la Figura 10 se observa el aumento en representatividad de los periodos. La línea asciende a medida que aumenta la representatividad en los tres índices.

Los resultados de los tres periodos permiten corroborar las dos hipótesis principales de este estudio (Figura 10 y Figura 11). De 1898 a 1916 el resultado total en el Índice de Representatividad del Parlamento (IRP) es de 56.5. Por su parte, dicho índice para el periodo 1917-1951 es de 64 (Figura 10). El aumento en proporción del primer hasta el segundo periodo para el IRP es de 13.3\% (Figura $11)$.

El índice de representatividad del momento fundacional de este periodo 19001914 era de cero. Pero en el segundo periodo aumenta en 0.5. Para este interperiodo (1900-1916; 1917-1951) se puede observar que a medida que aumenta la

\footnotetext{
${ }^{230}$ Josep Colomer, Como votamos: Los sistemas electorales en el mundo. Pasado, presente y futuro, Madrid, Gedisa, Barcelona, 2004, pp.25-27.
} 
variable independiente (IRMF) aumenta tanto la variable intermedia (IRSE) como la dependiente (IRP).

El Momento Fundacional de 1952 donde se lleva a cabo la constituyente cumple, teóricamente, con lo que establece Colomer en la "regla micro-mega": "Unos pocos partidos grandes tienden a preferir asambleas pequeñas, magnitudes de distrito pequeñas, reglas basadas en cuotas pequeñas para asignar escaños, mientras múltiples partidos pequeños tienden a preferir asambleas grandes, magnitudes de distrito grandes y cuotas grandes". 231

Por ello, no es extraño que en procesos excluyentes donde un partido obtiene mayoría aplastante como ocurrió en la constituyente de 1952, se mantenga el modelo restrictivo de mayoría en distritos pequeños. De igual forma, concuerda con la postura de los partidos en minoría como el PSP, el PER y el PIP que promovían la representación proporcional.

En el segundo inter-periodo $(1917-1951 ; 1952-2012)$ se aprecia un aumento en proporción de $18.2 \%$ en el IRMF mientras en el IRP de $25 \%$-ambos son los más altos de los dos inter-periodos. En el IRSE hay un aumento de 0.5 a $2^{232}$. Se repite el aumento en los tres índices. La relación que nos muestran nuestros resultados para la segunda hipótesis no es fortuita, es el señalamiento histórico del modelo electoral y su relación con el sistema de partidos y los estratos sociales. Henry Droop $^{233}$, Hamilton - cuando favorece el plan de Virginia-, Maurice Duverger ${ }^{234}$, Douglas W. Rae ${ }^{235}$, Dieter Nohlen ${ }^{236}$, Giovanni Sartori ${ }^{237}$, Pippa Norris ${ }^{238}$ entre

\footnotetext{
${ }^{231}$ Ibidem.p.25.

${ }^{232}$ Esto representa un cambio de $300 \%$ es por ello que preferí dejarlo en números absolutos.

${ }^{233}$ Henry Droop, “On the Political and Social Effects of Different Methods of Electing Representatives", London, W. Maxwell \& Son, 1869.

${ }^{234}$ Mauricio Duverger, Los partidos políticos, México, Fondo de Cultura Económica, 2012.

${ }^{235}$ Douglas W. Rae, The Political Consequences of Electoral Laws, New Haven, Yale University Press, 1967.

${ }^{236}$ Dieter Nohlen, Elecciones y sistemas electorales, Caracas, Nueva Sociedad - Fundación Friedrich Ebert, 1966.

${ }^{237}$ Giovanni Sartori, op. cit.., Fondo de Cultura Económica.

238 Pippa Norris: "Choosing Electoral Systems: Proportional, Majoritarian and Mixed Systems", en International Political Science Review, Vol.18, no. 3, 1997, pp.297-312.
} 
otros, reconocen que el sistema electoral tiene un impacto en la representación del parlamento. Las leyes de Duverger son altamente conocidas. Sartori ${ }^{239}$ entiende que los sistemas electorales tienen reductores que varían de fuertes a débiles. Mientras más fuertes sean estos reductores, asemejándose al sistema mayoritario, más se restringe la representación. Por el contrario, mientras más débiles o nulos los reductores, asemejándose al sistema proporcional puro, menos restricciones habrá para obtener representación.

Pippa Norris ${ }^{240}$ concuerda en que los sistemas cerca de la lógica proporcional promueven no sólo una mayor participación electoral, sino una mayor representación de la mujer en parlamento. En P.R., la representación por género, en promedio no llega a 10\%, nunca ha habido representación étnica y sólo ha habido un extranjero dominicano en toda la historia de la legislatura, a pesar de que conforman el 10\% de la población. Así, la relación entre el aumento IRSE y del IRP en conjunto en cada inter-periodo no nos debería sorprender.

Figura 10. Cambios en variable y periodos ${ }^{241}$

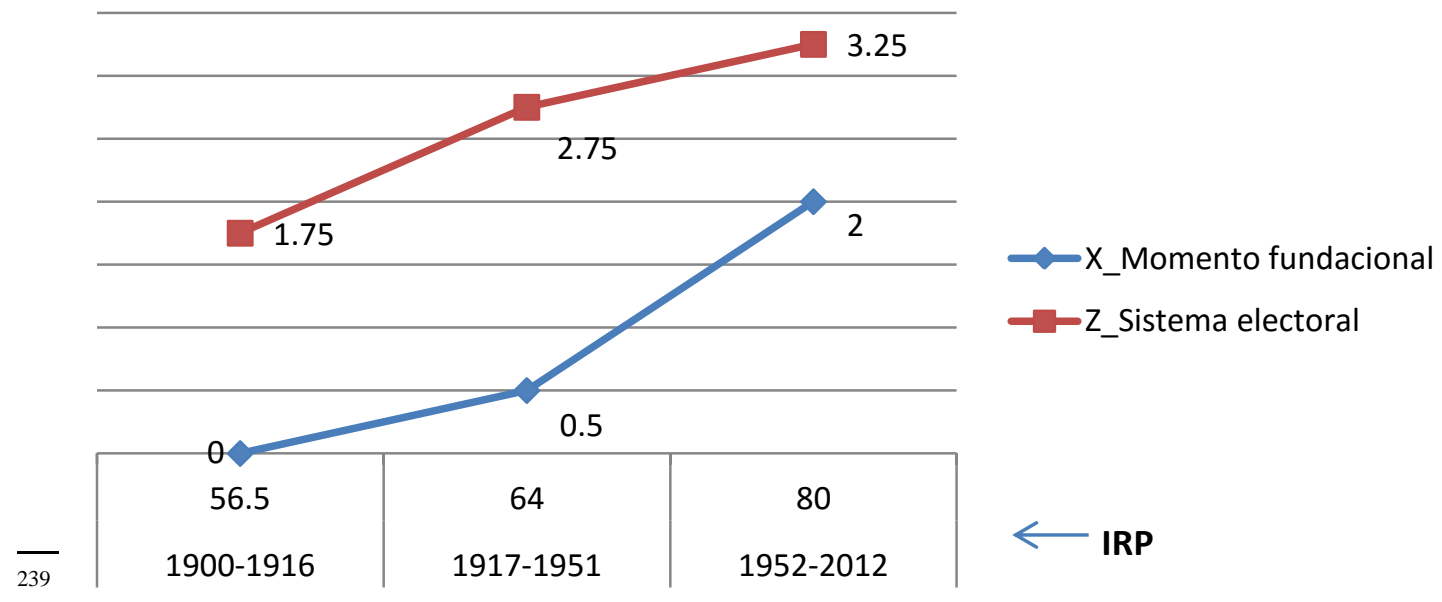

${ }^{240}$ Pippa Norris, "Choósing electoral systems: Proportional, majoritarian, and mixed systems", En International political science review”, Vol.18, no. 3, 1997, pp.297-312.

${ }^{241}$ Los datos fueron obtenidos de tres fuentes: La Comisión Estatal de Elecciones, las últimas cuatro se encuentran en su página web: www.ceepr.com. Eventos electorales. 2012. Carmen Ramos Santiago, El gobierno de Puerto Rico: Desarrollo constitucional y político, Rio Piedras, Universidad de Puerto Rico (UPR), 1965. Juan José NollaAcosta, Elecciones en Puerto Rico, 1899-2012, San Juan, (s/e), 2015. 
En la Figura 10 los porcentajes de aumentos en el IRMF y los porcentajes de aumento en el IRP son similares para ambos inter-periodos. Según nuestra hipótesis, se espera que la representatividad que se promueve en el momento fundacional sea similar a la que finalmente se establezca en el parlamento. Quienes están representados en el momento fundacional de un sistema electoral querrán estar presentes en el parlamento y por ello impulsan sistemas electorales que les otorguen espacio en la toma de decisiones legislativas.

Por esta razón, el sistema electoral utilizado en la constituyente de 1952 es similar al que finalmente se acuerda, aunque la versión final es menos representativa que la de la constituyente: sistema de mayoría con ley de minoría añadiendo un distrito senatorial y algunos legisladores por acumulación.

Si se analizan en su conjunto los tres periodos podemos afirmar que nuestras hipótesis se acercan de manera correcta al fenómeno (Figura 11). El IRMF aumentó desde 1900 hasta 1952 de 0 a 2 pts. La constituyente de 1952 reformó el sistema electoral y provocó un aumento de 1.75 a 3.25 en el IRSE con respecto al sistema electoral impuesto bajo la Ley Foraker en el 1900. Como resultado, el IRP aumentó de 56.6 en 1900 a 80pts en el periodo de 1952-2012. 
Figura 11. Márgenes de mejora en el IRMF, IRSE e IRP según inter-periodo ${ }^{242}$

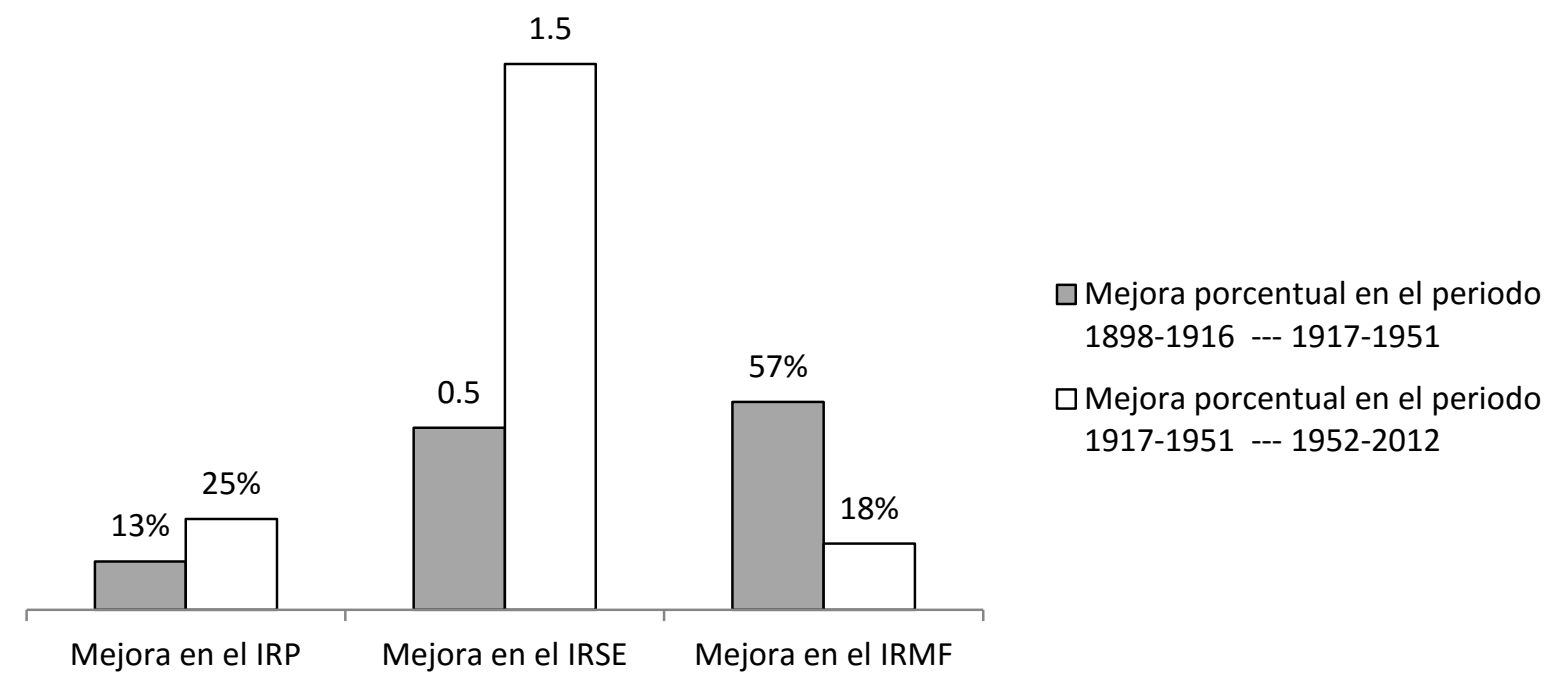

Finalmente, podemos concluir que la representatividad en los parlamentos está influida por el momento fundacional para el caso de Puerto Rico. El sistema electoral de mayoría, impuesto por los EE.UU. mantiene el bipartidismo en Puerto Rico, sub-representando y excluyendo segundos y terceros partidos. El sistema electoral siempre fue de mayoría porque nunca cambió la lógica del modelo original impuesto. Las reformas ampliaron los curules, añadiendo elementos a las estructuras internas de los partidos, permitiendo el dualismo de partidos pero restringiendo el multipartidismo.

De igual forma, como mencionaba Duverger ${ }^{243}$, el sistema electoral impacta también de manera psicológica al electorado al mantener, por más de un siglo, dos opciones con posibilidades de ganar, promoviendo el voto por el "menos malo". ¿Existe en Puerto Rico un formato de dos partidos? Taagepera establece cuatro condiciones para medir el bipartidismo que nos pueden ayudar a enmarcar a Puerto Rico en una tipología de partidos.

\footnotetext{
${ }^{242}$ Ibid. Los cambios en IRSE no son cambios porcentuales. Es un cambio de 0 a 0.5 y de 0.5 a 2 lo que representa $300 \%$ y por ello no aparecen en porcientos. El resto de las variables tiene cambios porcentuales. No obstante, esto nos permite observar que sí hubo cambios importantes en cada una de las variables por cada periodo.

${ }^{243}$ Mauricie Duverger, op. cit., Fondo de Cultura Económica.
} 
1) Que todas las elecciones conduzcan a una mayoría suficiente ${ }^{244}$;

2) Que todas las elecciones conduzcan a una oposición fuerte ${ }^{245}$;

3) Que haya una paridad de largo plazo en el número de elecciones ganadas ${ }^{246}$;

4) Que exista una alternancia regular entre los dos partidos ${ }^{247}$.

Para el caso de Puerto Rico podemos observar en las Figuras 12 y 13 que el bipartidismo comienza a desarrollarse claramente a partir del tercer periodo en 1968 según establecen estas condiciones de Taagepera. Para el primer periodo 1900-1914, de las cuatro condiciones solo se cumplen dos. La condición que se cumplen parcialmente es la de 3) Paridad, con una media aritmética de .50. Hubo cambios de gobierno en un 50\% de las elecciones. La condición que se cumple a la perfección es la de mayoría suficiente con un 100\%. En todas las elecciones el partido de mayoría obtuvo el 52\% de los escaños.

Esto último, demuestra la existencia de un monopartidismo porque en cada legislatura hubo una mayoría partidista. Entre 1912 y 1914 se cumplen tres de las cuatro condiciones a excepción de la alternancia. Esto corresponde con la primera ley de minoría en 1912.

\footnotetext{
${ }^{244}$ Esto implica que el partido de mayoría tiene un 52\% o más de los escaños.

${ }^{245}$ Que el segundo partido obtenga, al menos, un 30\% de los escaños.

${ }^{246}$ Se calcula según la fórmula Gaines-Taagepera.

${ }^{247}$ R. Taagepera (2015): "La balanza inclinada. Probando la 'Ley de Duverger' en el nivel nacional". De Política, México, AMECIP, núm. 4/5. pp.9-20.
} 
Figura 12. Condiciones de Taagepera para medir el bipartidismo aplicado a Puerto Rico ${ }^{248}$.

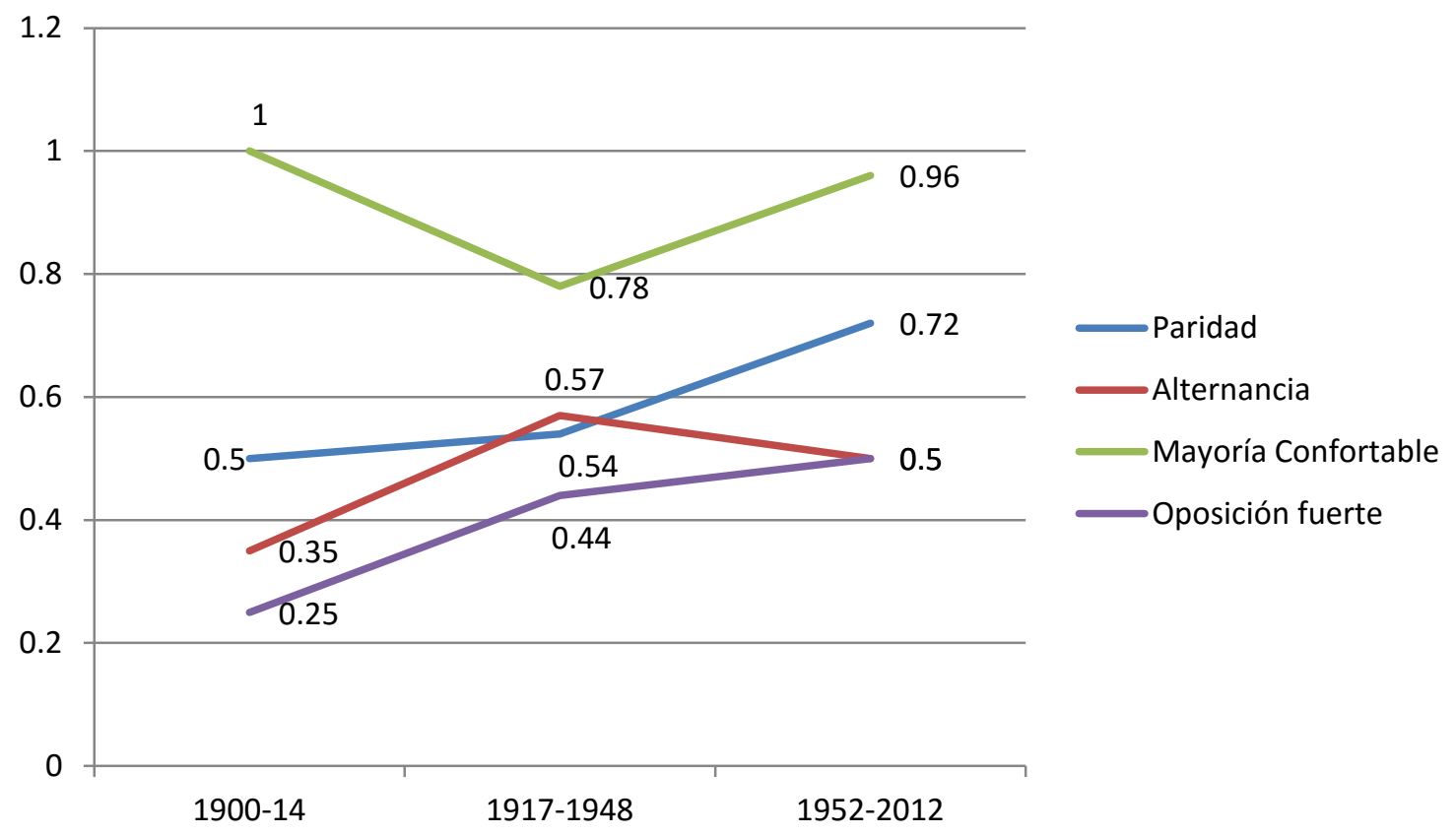

Pero luego del cambio institucional, para el periodo de 1917-1948 los niveles en que se cumplen estas condiciones aumentan a excepción de la de mayoría suficiente, aunque continua siendo alto el nivel de este índice. El índice de mayor aumento es el de oposición fuerte. Esto confirma la idea de que las reformas intentaron aminorar la tendencia al monopartidismo que existía en Puerto Rico, abriendo paso al bipartidismo.

Así también se confirma finalmente en el tercer periodo un aumento en las cuatro condiciones. Sin embargo, desde 1944 hasta 1968 existió en Puerto Rico un sistema de partido hegemónico que impidió que tres de las cuatro condiciones se cumplieran en las elecciones de 1944, 1948, 1956 y 1960. Lo que confirma el monopartidismo en estas cuatro elecciones es que el índice más alto entre las cuatro condiciones es el de mayoría suficiente nuevamente. Sin embargo, desde 1968 hasta 2012 se comienzan a cumplir las cuatro condiciones. De manera que

\footnotetext{
${ }^{248}$ Los datos fueron obtenidos de tres fuentes: La Comisión Estatal de Elecciones, las últimas cuatro se encuentran en su página web: www.ceepr.com. Eventos electorales. 2012. Carmen Ramos Santiago, op. cit., Universidad de Puerto Rico (UPR). Juan José Nolla-Acosta,op. cit., (s/e).
} 
existe en efecto un bipartidismo. Por ello, observamos en la figura 13 donde sumamos los cuatro índices, que el nivel de bipartidismo aumenta por periodo llegando a representar en 2012 casi 3.0pts. Así se demuestra de forma clara el denominado "bipartidismo cerrado".

Figura 13. Suma de condiciones de Taagepera para medir el bipartidismo aplicado a Puerto Rico

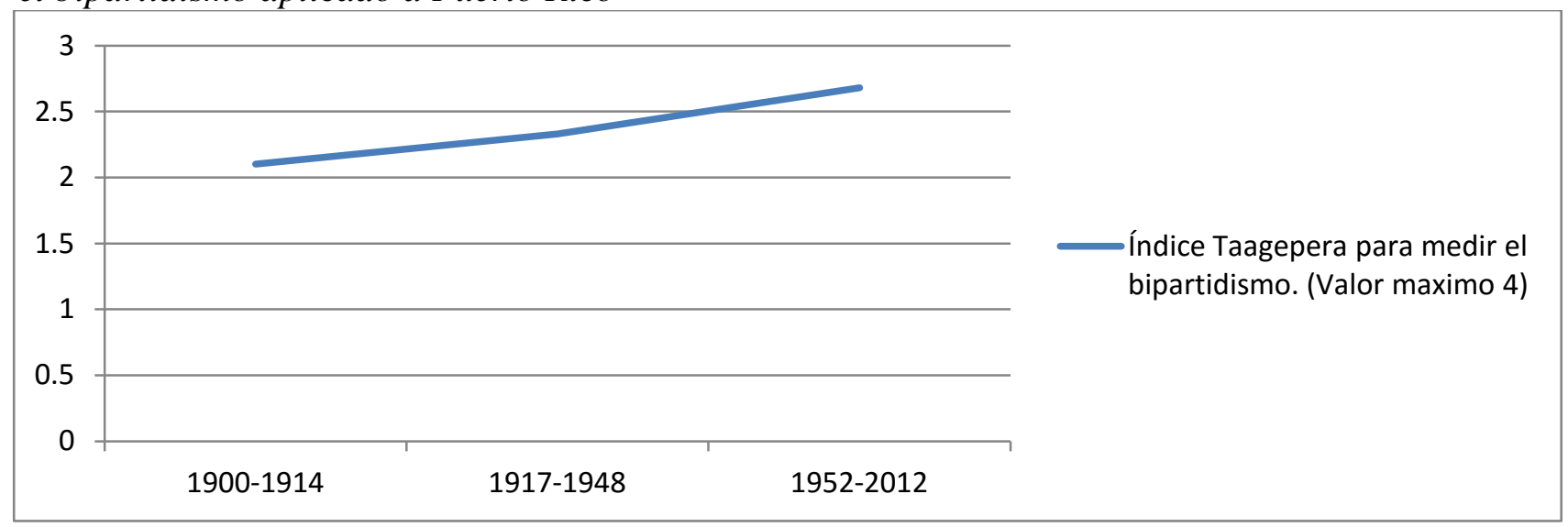

Sin embargo, el sistema electoral por sí solo no explica esta realidad. En el transcurso de nuestra narración histórica, pudimos observar que el contexto antidemocrático influyó en la disminución de la fuerza política independentista. Así, nuestra variable dependiente (IRP) es influida no sólo por el momento fundacional (IRMF), la variable independiente en nuestra hipótesis, ni por lo que promueve el sistema electoral (IRSE) que se impone, sino también por el contexto colonial. $^{249}$ La imposición de parte de la metrópoli de un sistema de mayoría así como la represión a las fuerzas políticas independentistas promovió en Puerto Rico

\footnotetext{
${ }^{249}$ Esta afirmación la realizamos ceteris paribus e implica que debemos tener en cuenta que existen otras variables que influyen en el fenómeno y que los postulados se cumplirán siempre y cuando estas variables que no tomamos en cuenta se mantengan constantes.
} 
que esta fuerza anti status quo disminuyera. Aunque, como menciona Yin: "las fronteras entre el fenómeno y su contexto no son muy evidentes". ${ }^{250}$

Es difícil identificar con claridad en nuestro estudio donde comienza la influencia colonial y donde comienzan a influir las variables del sistema electoral en la formación del bipartidismo. Lo que si conocemos claramente es que ambas variables influenciaron. En la figura 14 puede observarse como la tendencia independentista pasó de ser la principal fuerza política a ser la más débil luego de 1930-1980, los años de mayor represión política. De manera que una vez más se demuestra lo multidimensional que puede ser un fenómeno. El aporte de esta investigación conlleva lo que se ha denominado "carácter de "transferibilidad" 251 en el cual los resultados de un estudio de caso pueden generalizarse a otras latitudes con "situaciones teóricas similares",252, como podrían ser otros territorios de ultramar o colonias.

Figura14. Tendencias ideológicas en Puerto Rico: 1904-1988

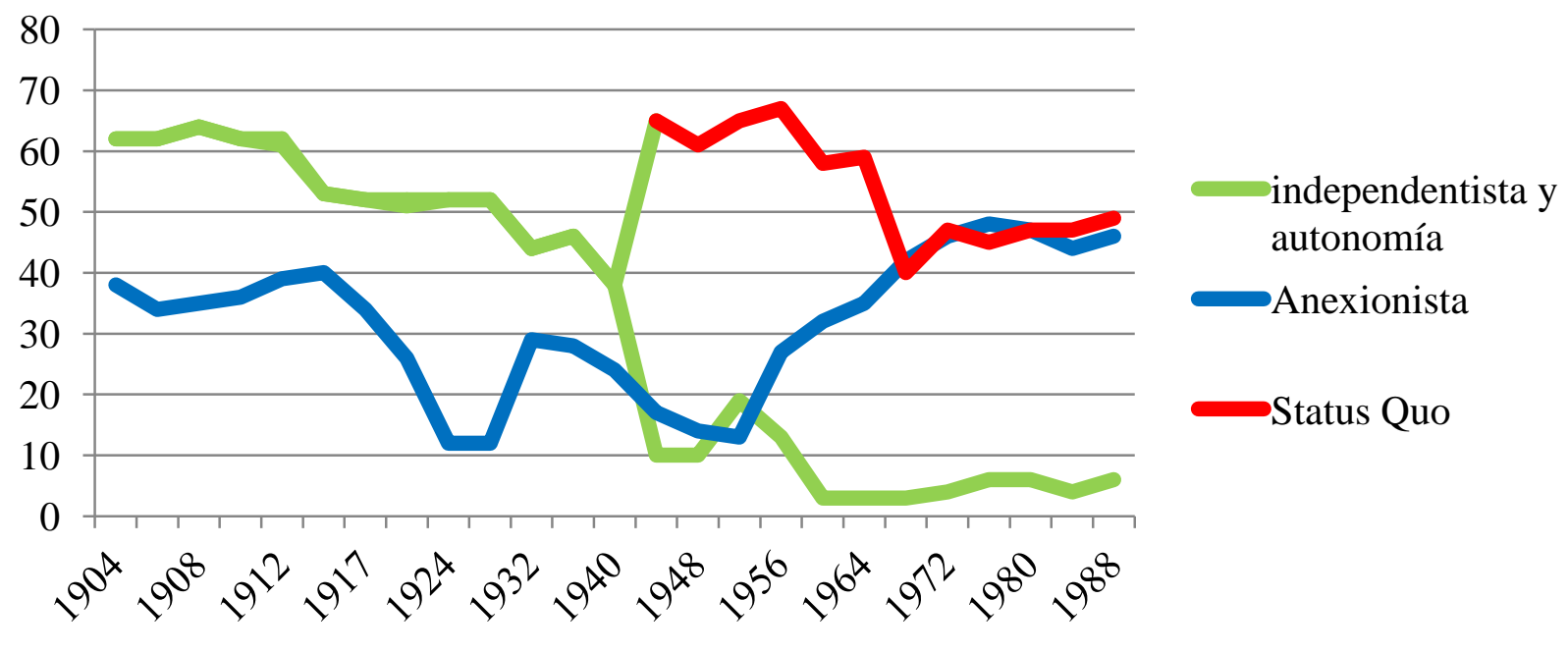

${ }^{250}$ Robert Yin, Case Study Research: Design and Methods, Applied social research, Newbury Park, CA, Sage (Methods Series), 1984, p.23.

${ }^{251}$ Neal Maxwell, "Designing a Qualitative Study", en L. Bickman D. J. y Rog (Eds.), Handbook of Applied Social Research Method, Newbury Park, CA, Sage, 1998, pp. 69-100.

${ }^{252}$ Piedad Martínez, "El método de estudio de caso. Estrategia metodológica de la investigación científica", Pensamiento \& Gestión, núm. 20, julio 2006, pp. 165-193. 
Una de las limitaciones que presenta este estudio es que no se contrasta el caso de P.R. con contextos alternos. Esto nos impide conocer cómo funcionan o interactúan las variables consideradas en este estudio para otros casos. Futuras investigaciones podrían contemplar un mayor número de casos de modo que podrían confirmar o refutar las hipótesis planteadas.

También podrían esclarecer el punto de porque un caso determinado pudiera adoptar un modelo proporcional, e implicaría medir cuanta representatividad promueven ciertos sistemas a los que se le acusa de ser poco representativos -como el de España, por ejemplo-. Dinamarca también tiene elementos interesantes por su énfasis en la representatividad. Italia, que transitó de un modelo proporcional a uno mixto y luego a uno mayoritario. Casos latinoamericanos similares al de Puerto Rico hay muchos y podríamos enumerar a toda Latinoamérica colonial del Caribe e hispana. Pero, a pesar de las limitaciones señaladas es importante identificar las fortalezas que presenta este estudio.

Esta investigación nos permite estudiar, en específico, el tema del bipartidismo en Puerto Rico. Contestamos una parte del por qué y el cómo de este fenómeno. Este estudio de caso nos permitió profundizar en la historia del sistema electoral y sus reformas y en la configuración del sistema de partidos. Inevitablemente, como en todo estudio de caso, el contexto fue determinante en explicar nuestros fenómenos y entender la exclusión de la tercera fuerza política ${ }^{253}$.

Además de estos aspectos metodológicos, nuestra investigación es importante porque siempre ha habido cierta admiración al periodo de estabilidad que se vivió

\footnotetext{
${ }^{253}$ Sylvie Chetty, "The case study methods for research in small -and medium- size firms", International Small Business, octubre 1996, pp.73-85. Menciona que el método de estudio de caso: Es adecuada para investigar fenómenos en los que se busca dar respuesta a cómo y por qué ocurren. Permite estudiar un tema determinado. Es ideal para el estudio de temas de investigación en los que las teorías existentes son inadecuadas. Permite estudiar los fenómenos desde múltiples perspectivas y no desde la influencia de una sola variable. Permite explorar en forma más profunda y obtener conocimiento más amplio sobre cada fenómeno, lo cual permite la aparición de nuevas señales sobre temas que emergen.
} 
en Puerto Rico desde 1952. En parte, porque había una transición del poder relativamente pacífica entre dos partidos. Y porque no hubo derrocamientos militares, la revuelta de 1952 no tuvo éxito, el independentismo disminuyó su fuerza electoral, aunque continuaba en ciertos frentes promulgando la lucha armada.

No obstante, en esta investigación pudimos observar que la estabilidad en Puerto Rico implicó exclusión. También, es posible afirmar que el sistema electoral mayoritario en P.R. nunca respondió a la realidad social e ideológico-política del momento. Por ello, los sistemas electorales no siempre son "endógenos" como mencionaba Anthony Downs. ${ }^{254} \mathrm{Al}$ menos en P.R. no lo es. Es precisamente por esta razón que sus resultados son excluyentes. La imposición implica la total exclusión por lo que el sistema electoral de mayoría impuesto promovió parlamentos excluyentes.

A pesar de que los partidos de mayoría se han beneficiado del status quo en términos de relaciones Estados Unidos-Puerto Rico, en los últimos años el modelo económico del ELA ha ido degenerándose hasta llevar el gobierno de Puerto Rico a una quiebra económica. En las pasadas elecciones de 2012, el gobierno de mayoría del PNP impulsó un plebiscito promovido e ideado por el PIP, para que los electores votaran en una primera columna: ¿Quieres permanecer con el status actual territorial? (ELA) con opciones para contestar la pregunta de "sín" o "no". El $56 \%$ de los votantes contestó que "no" a la pregunta quitándole la falsa legitimidad de la que gozaba el ELA desde que se aprobó la constitución por la constituyente en 1952 .

De esta forma el ELA pierde la artificial hegemonía que EE.UU le había adjudicado para justificar mantenerlo como territorio ante la comunidad internacional. Así como el ELA pierde legitimidad, el PPD pierde su incentivo

\footnotetext{
${ }^{254}$ Anthony Downs, An economic theory of democracy, México, Adison Wesley, 1956.
} 
ideológico y comienza a encontrar dificultades en ganar elecciones porque no obtiene estos votos mixtos que le permitían ganar mayoría. Podemos observar en la tabla 15 como el PPD ha ido perdiendo la capacidad de ganar elecciones obteniendo márgenes de ganancia cada vez más bajos.

Tabla 15

Márgenes de ganancia de cada partido: elecciones del año 1952-2012

\begin{tabular}{llll}
\hline Año de elección & $\begin{array}{l}\text { Partido } \\
\text { victorioso }\end{array}$ & $\begin{array}{l}\text { Margen de } \\
\text { ganancia en votos }\end{array}$ & $\begin{array}{l}\text { Aumento (-), disminución (+), o neutro } \\
\text { (o) con respecto a la anterior }\end{array}$ \\
\hline 1952 & PPD & 305,181 & O \\
1956 & PPD & 260,572 & $-44,609$ \\
1960 & PPD & 206,517 & $-54,055$ \\
1964 & PPD & 204,027 & $-2,490$ \\
1968 & PNP & 26,775 & 0 \\
1972 & PPD & 95,247 & $-108,780$ \\
1976 & PNP & 43,567 & $+16,792$ \\
1980 & PNP & 3,037 & $-40,530$ \\
1984 & PPD & 53,750 & $-41,497$ \\
1988 & PPD & 51,516 & $-2,234$ \\
1992 & PNP & 75,980 & $+72,943$ \\
1996 & PNP & 130,479 & $+54,499$ \\
2000 & PPD & 59,666 & $+8,150$ \\
2004 & PPD & 3,566 & $-56,100$ \\
2008 & PNP & 224,894 & $+94,415$ \\
2012 & PPD & 11,285 & $+7,719$ \\
\hline Total de & PPD: siete (7) & PNP: una (1) & \\
disminución del & disminuciones & disminución & \\
margen & & & \\
\hline Total de aumento: & PPD: dos (2) & PNP: ocho (8) & \\
& aumentos. & aumentos & \\
\hline Fente dabor & & \\
\hline
\end{tabular}

Fuente de elaboración propia con datos de: www.ceepur.org.

En el 2012 el PPD obtuvo la mayoría legislativa de votos pero con menos de .5\% de diferencia con el PNP, a pesar de que este partido despidió miles de empleados públicos y enfrentó violentamente una huelga de la universidad y aumentó dramáticamente la deuda pública así como en su cuatrienio se había presentado el año con mas asesinatos violentos en la historia de Puerto Rico. A pesar de que se esperaba que el PPD arrasara en las elecciones, este partido ganó estrechamente. 
Las encuestas recientes así como el sentir y la tendencia estadística electoral nos muestran que el PNP arrasará con una mayoría absoluta en las elecciones de 2016. Hay quienes auguran que volveremos a una etapa de monopartidismo bajo el PNP, situación que no sería nueva. Sabemos que cuando el contexto disminuye a una de las fuerzas electorales de mayoría, la posibilidad del monopartidismo está presente porque el sistema de mayoría lo permite. Esto podría suceder a pesar de que el PNP también da muestras de desgaste.

En las pasadas primarias de 2016 su candidato ganador obtuvo 100,000 votos menos que el candidato anterior que resultó derrotado en las pasadas primarias hace cuatro años. Esto demuestra que, aunque en menor grado que el PPD, el PNP también se encuentra en desgaste. ${ }^{255}$ En el PPD este desgaste está más pronunciado por la pérdida de su gran proyecto ideológico, el ELA. Nadie niega hoy que Puerto Rico sea una colonia a pesar de que por mucho tiempo el PPD y Estados Unidos negaron esta realidad.

Desde este punto de vista, en este cuatrienio el PPD podría impulsar un proyecto de reforma electoral para su propio beneficio porque quedando en segundo lugar, el sistema lo sub-representa y como ha ocurrido en otras ocasiones, a pesar de estar representados en el congreso, no tienen la capacidad de oponerse a nada y quedan relegados de todo proceso de la toma de decisiones.

Sin embargo, esta posibilidad no está presente y el tema de reforma electoral no está cerca de ser un tema de interés hasta el momento. Es extraña esta actitud de parte del PPD porque parecería que los políticos hacen lo que sea para ganar elecciones pero casi nunca hacen lo correcto. Por ello, en nuestro próximo apartado nos proponemos realizar una propuesta de reforma electoral para Puerto Rico que responde a promover una mayor representatividad en el legislativo.

\footnotetext{
${ }^{255}$ Frances Rosario, "Partidos no cumplen con sus expectativas en las primarias", 6 de junio de 2016. Página web: www.endi.com.
} 
El sistema electoral puertorriqueño debe reformarse con el objeto de fortalecer la presencia de minorías en el congreso. También, debe evitar la llegada de súper mayorías parlamentarias fabricadas por la fórmula electoral. Así también, debe intentar balancear la representatividad con un aumento en la libertad al elector para que este pueda ejercer su voto por quién podría ser la primera opción de preferencia. Debe aspirar hacia una lógica distinta para los representantes por acumulación y de distrito que balancee mejor los lideratos nacionales versus los regionales.

Considero que la reforma al sistema electoral debe implicar una gran discusión pública donde se evidencien los grados altos de exclusión que ha propiciado el sistema electoral puertorriqueño. También será necesario presentar las razones de por qué debe reformase el sistema incluyendo el hecho de que el pueblo de Puerto Rico debe construir su propia constitución sin injerencia extrajera. Eso debe ser el principio que rija la elección de la constitución, que se realice un proceso político constituyente altamente representativo. Esto debe tener como consecuencia incluir la creación de un sistema electoral lo menos excluyente posible.

Es cierto que la verdadera representatividad en el momento fundacional se dará solo cuando la soberanía política recaiga sobre el pueblo de Puerto Rico. De igual forma, el parlamento en Puerto Rico sólo gozará de verdadera representatividad en el momento en que tenga los poderes políticos necesarios para representar. Entrar en la representación parlamentaria de los estadounidenses no es más que auto-subrepresentarnos en otro sistema.

También esto equivaldría entrar en la lógica bipartidista norteamericana que de por sí es excluyente y con la cual la población puertorriqueña no se identifica, ni entiende, ni le interesa, y promovería la exclusión. Por ello, consideramos nuestra afirmación a favor de la representatividad como un medio para defender la independencia política de Puerto Rico. 
Así, se debe comenzar con un proceso de reforma inclusivo (el momento fundacional). Cuando el pueblo de Puerto Rico apruebe su propia constitución sin injerencia extrajera entonces se estará hablando de un proceso de verdadera descolonización legal y/o política y de mayor inclusión en la toma de decisiones. Este proceso de ingeniería constitucional debe considerar cuales son los elementos que pueden representar mejor cada tendencia y por ello propondremos un posible sistema electoral que puede servir de guía para la construcción del nuevo modelo consensado inclusivamente. 


\section{ANEXOS}

\section{Anexo I \\ Propuesta de sistema electoral para Puerto Rico}

En primer lugar, las cuotas raciales o de género son un elemento importante en materia de representación. En Puerto Rico ha existido siempre una ausencia de cuotas raciales y de género a pesar de que, tanto las mujeres, como dominicanos y cubanos han quedada o sub-representados o excluidos de representación. Las mujeres nunca han representado más de una cuarta parte de la composición legislativa, solo ha habido un dominicano en la legislatura y nunca ha habido cubanos. No es debatible señalar que la representatividad real requiere de cuotas. De igual forma, los elementos que sugeriremos a continuación pueden fomentar la participación de otros sectores en estos procesos debido a que el sistema electoral, a proponer, fomenta en un alto nivel la representatividad.

Es necesario que se mantengan dos elementos importantes del sistema electoral actual: el voto directo al candidato y la representatividad que promueve los niveles geográficos. Votar de manera directa por un candidato, aunque no mucha gente lo ejerza en Puerto Rico, se tiende a apreciar como un "voto inteligente". Se reconoce de esta manera, porque denota una evaluación particular de los candidatos y un alejamiento del partidismo, aunque no tiene por qué ser un voto más inteligente. El elector que vota por candidatura en ocasiones es decisivo y por ello, debemos mantener esta posibilidad de que el elector vote directo al candidato.

Las circunscripciones que se han creado en Puerto Rico como resultado de las tres reformas que analizamos tienen tres niveles electorales que lo componen ocho distritos senatoriales, 35 en la cámara y 22 por acumulación (11 en cada cámara). 
Cuando se quiere establecer un sistema de representación proporcional generalmente se establece una lista a nivel nacional para que la fórmula se mantenga lo mas íntegra posible reflejando una mejor proporcionalidad entre votos y escaños.

Sin embargo, nuestra intención es promover una mayor representatividad, lo que no es sinónimo de proporcionalidad. Mayor representatividad desde nuestro punto de vista implica mayor libertad del elector, mayor representación de áreas geográficas y una fórmula que promueva una mayor presencia de las minorías partidistas en el congreso. Esto último también implica fórmulas más cerca de la lógica proporcional.

De manera que lo que debe buscar una reforma electoral puertorriqueña es un balance teórico en estos aspectos, aunque hay que reconocer que esto resulta matemáticamente imposible. Por ello es una aspiración que una reforma electoral debe buscar alcanzar en lo mayor posible y donde inevitablemente se sacrificaran alguno de estos aspectos. La construcción de sistemas electorales implica considerar aquellos elementos que estamos dispuestos a sacrificar en pos de objetivos primordiales. Las propuestas que entendemos son las necesarias para establecer en Puerto Rico son las siguientes.

En la papeleta estatal, donde el elector puede ejercer un voto por la insignia del partido, un voto por el candidato a la gobernación y un voto por el candidato a la comisaría residente, sugeriremos un cambio fundamental que puede ayudar a aclararnos el panorama de las preferencias electorales.

Como respuesta al llamado pivazo, es necesario que el sistema electoral provea un mecanismo para la candidatura a la gobernación donde el elector podría tener una segunda opción de preferencia y el sistema electoral contabilizaría ese voto. Al obtener los resultados de las votaciones dividiremos los votos entre primeras y segundas opciones. La primera pregunta que se harán los que contabilizan es 
¿Quién obtuvo la mayor cantidad de primeras preferencias? Luego, ¿quién obtuvo la mayor cantidad de segundas preferencias? Estos candidatos serán separados de los demás y una tercera pregunta será ¿Cuál es candidato con el mayor número de votos, sumando las primeras y segundas preferencias? La contestación a esta pregunta será el candidato ganador. Este sistema permitirá que los electores con preferencias hacia las minorías puedan hacer reflejar su voto.

¿Qué sucede entonces con la composición del legislativo? Es necesario que la magnitud de los distritos respalde la representatividad en conjunto con la fórmula. A pesar de que en el 2005 hubo una votación a favor de una legislatura unicameral esta nunca se llevó a cabo. Cambiar de un sistema bicameral a uno unicameral puede ser beneficioso para efectos de esta propuesta. Como queremos construir una mayor representatividad, la contraparte a esto es lograr la aprobación de proyectos. La legislatura unicameral puede facilitar el proceso de aprobación de un proyecto, ya que, aunque haya una negociación severa en la cámara, una vez aprobada solo constará de la firma del gobernador y no de otra cámara.

Ahora debemos pensar cómo combinamos la ampliación de la magnitud de los distritos con una buena fórmula que otorgue representación a las minorías, no sólo al segundo partido de mayoría. Son varias las opciones. Se podría implementar un sistema proporcional puro con listas nacionales. No obstante, se perdería la representación geográfica e incluso si pretendemos tener un sistema puro proporcional las cuartas minorías quedarían sub-representadas y habría algunas desproporciones (Tabla 16). 
Tabla 16

Ejemplo de escaños asignados según composición actual del senado en una sola circunscripción y con la fórmula Hare

\begin{tabular}{lllll}
\hline Partidos & $\begin{array}{l}\text { Votos } \\
\text { obtenidos }\end{array}$ & $\begin{array}{l}\text { Divisor: Total de } \\
\text { votos/Total de escaños }\end{array}$ & $\begin{array}{l}\text { Escaños asignados } \\
\text { hasta el total: 27 }\end{array}$ & $\begin{array}{l}\text { Porcentaje de } \\
\text { representación }\end{array}$ \\
\hline PPD & 896,060 & $/ 6,952.15=128.889$ & 12 & $44 \%$ \\
PNP & 884,775 & $/ 6,952.15=127.266$ & 12 & $44 \%$ \\
PIP & 47,331 & $/ 6,952.15=6.808$ & 3 & $11 \%$ \\
PPT & 18,312 & $/ 6,952.15=2.634$ & 0 & $0 \%$ \\
MUS & 10,523 & $/ 6,952.15=1.536$ & 0 & $0 \%$ \\
PPR & 6,668 & $/ 6,952.15=0.959$ & 0 & $0 \%$ \\
Total & $1,877,179$ & 27 escaños & 27 & $100 \%$ \\
\hline
\end{tabular}

Nota: Datos extraídos del resultado electoral del 2012.

Fuente: Comisión Estatal de Elecciones (www.ceepur.org)

En otra opción de sistema electoral, si no aumentamos la cantidad de escaños y aplicamos la fórmula Hare, los dos partidos grandes obtendrían un balance en su representación, pero aun así, los terceros partidos quedarían excluidos del parlamento. Igualmente, si mantuviéramos los ocho distritos representativos con 10 curules cada uno y un sistema con fórmula Hare, ningún tercer o cuarto partido obtendría representación (tomando en cuenta los resultados de las elecciones 2012).

En este caso, sacrificaremos estricta proporcionalidad y algo de representación geográfica por una mayor presencia de las minorías en el congreso. La opción que proponemos es mantener los actuales ocho distritos senatoriales. No obstante, tendríamos que aumentar los escaños existentes por cada distrito para que en cada uno exista la posibilidad de que algún tercer o cuarto partido obtenga representación. Se escogerían candidatos en listas por partido. A su vez, como la intención de esta propuesta es representar más sectores, es necesario adoptar una 
fórmula que pueda captar más allá de la proporcionalidad genuina: la fórmula danesa de transferir votos en escaños ${ }^{256}$.

Teniendo en cuenta la propuesta de la formula danesa, se deben delinear nuevos distritos. Actualmente en Puerto Rico se delinean para el senado ocho distritos senatoriales que escogen dos senadores, cada uno. Al unir las cámaras nos quedamos con estos ochos distritos representativos nacionales. Los antiguos distritos de la cámara baja deben aparecer en otra modalidad, ampliando los curules que podrán resultar electos en las ocho circunscripciones. Cada circunscripción tendrá diez escaños, es decir, habrá tres curules adicionales por distrito. Fusionando de esta forma los distritos representativos y senatoriales en una sola cámara.

Proponemos entonces, un legislativo unicameral, electo a través de un sistema proporcional, con distritos grandes y una fórmula danesa para escoger los legisladores por distrito. Las listas serán abiertas y desbloqueadas. Como en el actual sistema, los electores podrán votar de forma directa por tres candidatos preferenciales por distrito para mantener este aspecto de nuestro actual sistema ${ }^{257}$. ¿Cómo deberían elegirse los representantes por acumulación? Los once escaños de circunscripción nacional se repartirían, con la fórmula danesa, de manera proporcional. El elector podría, según su preferencia, votar de manera directa por un candidato de cada partido. No debe permitirse votar por más de un candidato de cada partido, porque se perdería parte del carácter nacional de los candidatos al restarle poder a los partidos. Los electores tendrán tantos votos preferenciales como partidos asistan a la contienda. Esto reforzará su carácter de líderes

\footnotetext{
${ }^{256}$ Esta fórmula, como explicamos en el apartado referido a los sistemas electorales, es una modificación de la fórmula D'Hondt con la diferencia de que en vez de aumentar los divisores de uno a dos y luego tres dejaba márgenes de tres en medio de cada divisor aumentando la posibilidad de representar las minorías.

${ }^{257}$ Son tres porque antes el elector votaba directo por dos representantes por distrito y por un senador por distrito.
} 
nacionales $^{258}$ y permitirá al elector tener cierto poder sobre estos. Promueve cierta coordinación estratégica $^{259}$, ya que, si el elector no se identifica con un partido $\mathrm{X}$ puede votar por los menos malos entre los candidatos de ese partido, descartando las peores opciones y, a su vez, votando bajo su partido de preferencia.

En la repartición de los escaños, a cada partido le corresponderá, dependiendo de la votación para ambos niveles (nacional y distrito), cierta cantidad de curules. Estos escaños serán otorgados a quien, dentro de la lista, haya recibido la mayor cantidad de votos preferentes en orden descendente hasta llenar todos los escaños. Recordando que, como es ahora, un voto a la insignia del partido es un voto al primero de la lista.

La ley de minoría debe alterarse para convertirse en dos cláusulas de sobre y sub representación:

Primera: El partido que quede sobre-representado en los distritos (que obtenga un porcentaje de escaños superior al porcentaje total de votos recibidos en la papeleta legislativa) no podrá participar en la repartición de escaños por acumulación, aunque haya acumulado los votos necesarios.

Segunda: De quedar algún partido sub-representado (que obtenga un porcentaje de escaños menor al porcentaje del total de los votos en la papeleta legislativa)

\footnotetext{
${ }^{258}$ Los candidatos que quieren obtener la mayor cantidad de votos intentaran llamar la atención sobre temas nacionales para captar votos de otros sectores o de otros partidos, tendrá que "cruzar línea de partido".

${ }^{259}$ Gary Cox, La coordinación estratégica de los sistemas electorales en el mundo. Hacer que los votos cuenten, México, Gedisa, 2004. Menciona que los electores se coordinan con fines estratégicos de eliminar a ciertos candidatos. Es a esto lo que nos referimos cuando decimos que esta posibilidad de que elector pueda votar por tantos candidatos como partidos promueve que electores voten por candidatos menos malos dentro de partidos que no son de su preferencia descartando los que ellos consideren como los peores candidatos.
} 
aún con la repartición de escaños por acumulación, se añadirán escaños por acumulación hasta que se complete su representación ${ }^{260}$.

Con estas leyes y formas de escoger los representantes por acumulación se permite también cierto balance de poder en el candidato y el partido. Promueve cierta independencia al candidato porque puede acumular votos de miembros de otros partidos. Pero, de igual forma, el partido puede influir en su elección alterando el orden de la lista de candidatos por acumulación.

En resumen, la propuesta le otorga el poder al elector de votar en la papeleta estatal por dos candidatos a la gobernación en orden de preferencia. Elimina los distritos representativos y amplía los distritos senatoriales a 10 escaños por cada uno. Fusiona las dos cámaras en una sola con 91curules. Mantiene los ocho distritos senatoriales. Implementa la fórmula danesa para ambas representaciones, las distritales ( 8 circunscripciones con 10 curules) y las de acumulación (1con 11 curules). Reparte las candidaturas por acumulación con la fórmula danesa. También, el elector podrá votar de manera preferente por tantos candidatos como partidos participen en la contienda.

Añade dos cláusulas que intentan aminorar la sobre-representación y eliminar la sub-representación. La primera, establece que quien se encuentre sobrerepresentado en la repartición de los candidatos por distrito no participará en la repartición de escaños por acumulación. La segunda, menciona que el partido subrepresentado obtendrá los escaños necesarios para equilibrar su representación parlamentaria.

Para finalizar nuestra tesis, debemos aclarar como se dijo desde nuestra introducción, que la discusión sobre reforma electoral en Puerto Rico es nula. Para cuando se reforma cada cuatro años la ley electoral se llevan a cabo vistas públicas

\footnotetext{
${ }^{260}$ Esta segunda ley de minoría es muy similar a la que existe actualmente por precepto constitucional en la sección III, artículo7.
} 
donde se propone por parte de algunos colectivo el sistema proporcional. El licenciado José Julián Álvarez ha propuesto en varios foros el sistema de representación proporcional similar al sistema que existe en Alemania. El Dr. Ángel Israel Rivera Ortiz ha escrito varios artículos y ponencias promoviendo la implementación de un sistema RP. El PIP en su plataforma y en su historial legislativo tiene igualmente una propuesta de RP para Puerto Rico.

No obstante, los políticos de mayoría no ven la reforma al sistema electoral como un elemento que les beneficie políticamente. Pudiera ser que desconocen sobre los mecanismos electorales o porque entienden que todavía tienen la capacidad de ganar elecciones. El status quo en este sentido parece que todavía no cambiará. Sin embargo hay un elemento que no se ha mencionado hasta el momento. Como la reforma electoral implica reforma constitucional cada vez que se han reformado mínimamente las relaciones entre PR y EE.UU, se ha reformado también el modelo electoral.

A pesar de la situación de crisis que vive este archipiélago de Puerto Rico la reforma al sistema electoral está tan alejada o cercana como la solución a la situación colonial. Al fin y al cabo la dominación colonial que ha tenido Estados Unidos sobre Puerto Rico es congénito al sistema de mayoría y a la exclusión de la tercera fuerza de oposición, así como a la sub-representación de la segunda fuerza política. No es extraño que un proceso de colonización implique hegemonía y que esto a su vez conlleve la exclusión de buena parte de la población. 


\section{Anexo Metodológico}

Anexo 1. Índice de Representatividad del Momento Fundacional

\begin{tabular}{ccccccc}
\hline Fecha & \multicolumn{5}{c}{ Sumatoria por pregunta } & Total \\
\hline & Iniciativa & Elección & Fórmula & Minorías & Participación & \\
\hline $1898-1916$ & $1) 0$ & $2) 0$ & $3) 0$ & $4) 0$ & $5) 0$ & 0 \\
$1917-1951$ & $1) .5$ & $2) 0$ & $3) 0$ & $4) 0$ & $5) 0$ & .5 \\
$1952-2012$ & $1) 0$ & $2) .5$ & $3) .5$ & $4) .5$ & $5) .5$ & 2.0 \\
\hline
\end{tabular}

\section{Modo de cálculo del IRMF}

Para calcular el momento fundacional se tomó en cuenta de dónde surge la iniciativa de reformar el sistema electoral. En el primer periodo fue la "elite política", el congreso de EE.UU, quien reforma el sistema electoral en P.R. Por ello el valor de cero (0). El resto de las preguntas se descalifican por si solas para este índice.

En el segundo periodo la iniciativa surge del partido de turno, por lo que obtiene un valor de 0.5 (Véase total en Anexo 1). En el tercer periodo la iniciativa surge del partido de turno, pero se le añade una segunda pregunta iSe escogen representantes a la constituyente para elaborar la reforma? La respuesta es sí y por ello obtiene 0.5.Como se realiza una elecciones se debe escoger la formula de transferencia de votos a escaños. La formula en este caso fue la representación por mayoría relativa en distritos bi-personales y unipersonales. Esto último, le suma otro 0.5. Además, para calcular el IRMF se considera el porcentaje de participación de electores en las elecciones de delegados a la constituyente. Participó un 50\% de los electores hábiles. De acuerdo con el método utilizado para calcular este índice se le añade un valor de 0.5 . Por último, este periodo obtiene un 0.5 adicional porque se establecieron mecanismos para la representación de minoría como lo fue la ley de minoría para la constituyente. Esta sumatoria nos dan los totales que vemos por periodo en el Anexo 1. 
Anexo 2. Índice de Representatividad del Sistema Electoral

\begin{tabular}{ccccccc}
\hline Fecha & \multicolumn{9}{c}{ Puntuación por indicador } \\
\hline & $\begin{array}{c}\text { Tipo de } \\
\text { sistema } \\
\text { electoral }\end{array}$ & $\begin{array}{c}\text { Tamaño de } \\
\text { circunscripción }\end{array}$ & $\begin{array}{c}\text { Niveles } \\
\text { electorales o } \\
\text { Tiers }\end{array}$ & Cuotas & Papeleta & Total \\
\hline $1898-1916$ & .5 & .75 & 0 & 0 & .5 & 1.75 \\
$1917-1951$ & .5 & 1.5 & .5 & 0 & .25 & 2.75 \\
$1952-2012$ & .5 & 2.0 & 1.0 & .5 & .25 & 3.75 \\
\hline
\end{tabular}

\section{Modo de cálculo del IRSE}

En este caso, para calcular el índice de representatividad del sistema electoral en Puerto Rico se tomó en cuenta el tipo de sistema electoral, el tamaño de las circunscripciones, lo niveles (tiers en inglés), las cuotas de representación y el diseño de la papeleta. El primer y hasta el último periodo del sistema electoral la fórmula siempre fue de mayoría relativa que según nuestro índice solo otorga 0.5. Esta puntuación se le otorgó a los tres periodos para este indicador. Hay un cambio en el segundo indicador ya que en todas las reformas hubo una ampliación del tamaño de las circunscripciones. Por tener representación a nivel nacional y circunscripciones pequeñas, se le asigna al primer periodo .75 en este indicador. No se le otorga la puntuación total de 1.5 porque es sólo para una cámara. En el segundo periodo se realiza la reforma para permitir elegir la cámara alta obteniendo en este indicador el doble de la puntuación (1.5). Luego con la creación de la nueva ley de minoría y la ampliación de los curules por acumulación se obtiene .5 adicionales sumando 2.0 .

Nuestro tercer indicador son los niveles. Por cada nivel añadimos 0.5. El primer sistema electoral tiene un solo nivel electoral, el segundo sistema dos niveles y el último tres niveles. El cuarto indicador son las cuotas. Según nuestro método, al primer periodo le corresponde cero porque no hubo ninguno. Al segundo se le otorga 0.5 adicionales por la creación de la ley de minoría más representativa. Por último, debemos tomar en cuenta el diseño de la papeleta. En el primer sistema la 
papeleta tenía hasta dos votos preferentes. Luego fue solo uno por papeleta. Estos indicadores nos dan la sumatoria que se refleja en el Anexo 2 (véase totales por periodos).

\section{Anexo 3. Índice de Representatividad del Parlamento}

\begin{tabular}{ccrccc}
\hline Fecha & \multicolumn{3}{c}{ Sumatoria } & Total \\
\hline & Género & Etnicidad & Desproporciones & Partidos en la legislatura \\
\hline $1898-1916$ & $1) 0$ & $2) 0$ & $3) 55$ & $4) 1.5$ & 56.5 \\
$1917-1951$ & $1) 1$ & $2) 0$ & $3) 61$ & $4) 2.0$ & 64 \\
$1952-2012$ & $1) 4$ & $2) 1$ & $3) 72$ & $4) 3$ & 80 \\
\hline
\end{tabular}

\section{Modo de cálculo del IRP}

Este índice considera, primero, la representación por género, otorgando una puntuación según la Tabla 3 del primer capítulo. El primer periodo obtiene cero porque hubo nunca representación femenina en el parlamento. El segundo obtiene solo un punto porque la representación de féminas es de 1\%, en promedio, para todos los cuatrienios que componen cada periodo. El tercer periodo obtiene cuatro debido a que en promedio ha habido en la legislatura un 25\% de representación de mujeres.

En el segundo indicador tomamos en cuenta la representación étnica. En este caso solo el tercer periodo obtuvo representación de dominicanos en la legislatura de Puerto Rico. Como se utiliza también la Tabla 3 y solo hay $1 \%$ de representación, entonces solo se le otorga un punto a este indicador. Los periodos anteriores no obtienen representación en este renglón.

El tercer indicador del IRP es el promedio de desproporciones. Luego de calcular las desproporciones de nuestro periodo según lo indica el apartado de método y procedimiento (cálculo de: Arend Lijphart, Patterns of Democracy: Government Forms and Performance in Thirty-Six Democracies, New Haven: Yale University Press, 1999). 
Se procede a sacar el promedio de desproporciones en cada periodo. Nuestro índice debe ir en positivo a la representatividad y las desproporciones son un elemento negativo de la misma. Es por ello que a cada periodo se le resta 100 para así obtener la diferencia que mientras sea mayor quiere decir hay mucha representatividad contrario a si utilizamos sólo las desproporciones.

Por último, para el cuarto indicador utilizamos un promedio de partidos por legislatura y calculamos la media aritmética de la cantidad de partidos con representación legislativa en cada periodo. Luego se asigna esta puntuación al índice. En el Anexo 3 podemos observar los totales por periodo para este índice.

Anexo 4. Cuadro resumen

\begin{tabular}{cccc}
\hline & \multicolumn{2}{c}{ Variables } \\
Periodo e inter-periodo & $\begin{array}{c}\mathbf{Z} \\
\text { Parlamento } \\
\text { inclusivo }\end{array}$ & $\begin{array}{c}\text { Sistema } \\
\text { electoral }\end{array}$ & $\begin{array}{c}\text { Momento } \\
\text { fundacional }\end{array}$ \\
\hline 1898-1916 & $\boldsymbol{I R P}$ & $\boldsymbol{I R S E}$ & $\boldsymbol{I R M F}$ \\
1917-1951 & 56.5 & 0 & 1.75 \\
1952-2015 & 64 & 0.5 & 2.75 \\
Mejora porcentual en el periodo & 80 & 2 & 3.75 \\
1898-1916 --- 1917-1951 & $13.3 \%$ & 0.5 & $57.1 \%$ \\
Mejora porcentual en el periodo & & & \\
1917-1951 --- 1952-2012 & $25.0 \%$ & 1.5 & \\
\hline
\end{tabular}




\section{Referencias}

ACE. The Electoral Knowledge Network. 1998-2015. Página Web:

www.aceproject.org.

Acevedo, Héctor L., 2003, La generación de 40'y la convención constituyente,

Rio Piedras, Universidad Interamericana de Puerto Rico. ,2003, La generación de 40’ y la convención constituyente. Rio Piedras.

Universidad Interamericana de Puerto Rico. , SF, "María Libertad Gómez: La mujer Constituyente". SF.

Página web: http://www.rafaelhernandezcolon.org/. [Recuperado el: 1 de mayo de 2016].

Acosta, Ivonne, L., 1989, La mordaza, San Juan. Editorial EDIL. 1989

Anderson, Robert, W., 1973, Gobierno y partidos políticos en P.R. Madrid. Tecnos.

Andrews, Josephine y Jackman, Robert W., 2005, "Strategic Fools: Electoral Rule Choice under Extreme Uncertainty”. Electoral Studies, V.24,.65-84.

Base de datos libre "The comparative study of electoral systems: 1996-

2013.Página web: www.cses.com. En el archivo de bases de datos: 19962001.

Bayron, Fernando T., 1989, Elecciones y partidos políticos de Puerto Rico. Mayagüez, Isla, P.R.

Biebber, Fioran y Wolf, Stephan, 2007, The Ethnopolitics of elections, Routlege. Abigdon, Reino Unido.

Blais, André, 1999, "El debate sobre los sistemas electorales", en Revista conmemorativa del Colegio Nacional de Ciencias Políticas y 
Administración Pública. Coords. Víctor Alarcón Olguín y Héctor Zamitis Gamboa. México. pp. 187-224.

Boix, Carles, 1999, Setting the Rules of the Game: The Choice of Electoral Systems in Advanced Democracies, American Political Science Review, 93, 3, 609-624.

Calvo, Ernesto, 2009, "The Competitive Road to Proportional Representation.

Partisan Biases and Electoral Regime under Increasing Party

Competition", World Politics, n.61, v. 2, pp. 254-295.

Cámara , Luis R., 2004, The phenomenon of Puerto Rican voting, University Press of Florida.

Cansino, Cesar, 2011, "La filosofía política", en: Enrique Dussel, Eduardo Medieta, Carmen Bohórquez (editores). El pensamiento Filosófico latinoamericano, del Caribe y latino: (1300-2000). Historia, corrientes, temas, filosófos, Siglo Xxi, México.

Carstairs, Andrew M., 2010, A short history of electoral systems in western Europe, Routlege Library: Political Science.

Carta Autonómica de España a Cuba y Puerto Rico. Madrid. Artículos: III. VI. 1987.

Chetty, Sylvie, 1996, "The case study methods for research in small -and medium- size firms ", International Small Business. October.

Colomer, Josep, 1998, aplica en su libro Transición a la democracia española. Madrid. Anagrama. , 2004, Cómo votamos. Los sistemas electorales en el mundo: Pasado, presente y futuro. Barcelona, Gedisa.

Colón, José J., y Pérez, Ramón, 1997, Las carpetas. Persecución política y derechos civiles en Puerto Rico. Rio Piedras. Ed. UPR. 
Comisión electoral de Nueva Zelandia. www.eceproject.org. Paul Harris. Electoral Commission of New Zealand. Comments during review of text, August 17, 2000. [Recuperado 16 de enero de 2016].

Comisión Estatal de Elecciones.Recuperado en: www.ceepr.com, 2012, Sección de eventos electorales. [Recuperado el 18 de marzo de 2015]

Cox, Gary, 2004, La coordinación estratégica de los sistemas electorales en el mundo, Barcelona, Gedisa, pp.68-71.

Cusack, Thomas, Iversen, Torben y Soskice, David, 2007, "Economic Interests and the Origins of Electoral Systems, American Political Science Review", n.101, v.3, pp. 373-391.

David Farrel, 1998, Comparing electoral systems, Machillan, London.

De Sousa Santos, Boaventura, 1999, Reinventar la democracia. Reinventar el Estado, Sequitur, España.

Delgado, José A, 2015, Historia de Puerto Rico desde la perspectiva de las carpetas. Con referencia al libro de Dennis. War against all Puertoricans:

Revolution and terrorism in America's colony. New York. 2015. Página web: www.endi.com. [Recuperado el 30 de junio de 2016]. , "Obama convierte en Ley proyecto PROMESA". Endi. 30 de junio de 2016. Página Web: www.endi.com. [Recuperado el 30 de junio de 2016].

Demografía de Puerto Rico. Datos censales 1910-2010. Página web : www.demografía.pr.net. [Recuperado el 27 de febrero de 2016]. Diamond, Larry y Plattner, Marc F., 1996, El resurgimiento global de la democracia, UNAM-IIS. México.

Díaz, Luis, 1960, Rosendo Matienzo Cintrón: Orientador y Guardián de una cultura, Tomo 1, San Juan, Instituto de Cultura Puertorriqueña. 
Dietz James L., 1986, Economic History of Puerto Rico: Institutional Change and Capitalist Development. New Jersey: Princeton University Press,

Dimock, Marshall, 1951, "Los objetivos de la reorganización gubernamental”. En la reorganización de la rama ejecutiva. Informe para la constituyente. Dobrzynska, Agnieska y Indridason, Inridi, H., 2005, “To Adopt or Not to Adopt Proportional Representation: The Politics of Institutional Choice”. British Journal of Political Science.Volume 35 / Issue 01 /, pp. 182-190.

Downs, Anthony, 1956, An economic theory of democracy, Adison

Wesley, México City.

Droop, Henry, 1869, “On the Political and Social Effects of Different Methods of Electing Representatives", London, W. Maxwell \& Son.

Dussel, Enrique, 2015, 20 Tesis de Política, Siglo XXI, $2^{a}$ reimp, México.

Duverger, Mauricie, 1995, "La influencia de los sistemas electorales sobre la vida púbica”, en Diez textos básicos de ciencia política, Barcelona, Ariel. , 2015, Los partidos políticos. México. Fondo de Cultura Económica.

Fernós, Antonio, Ser nosotros mismos, Rio Piedras, UPR.

Gaines y Taagepera, 2013, How to operationalize twopartyness, Journal of Elections, Public Opinion and Parties 23: 387-404.

Gallagher, Michael, 1991, "Proportionality, Disproportionality, and Electoral Systems", Electoral Studies n.10. pp.33-51. , 1992, "Comparing Proportional Representation Electoral

Systems: Quotas,Thresholds, Paradoxes and Majorities", British Journal of Political Science. n.22, pp.469-496.

Gallagher, Michael y Mitchell, Paul (eds.), 2005 The Politics of Electoral System, Nueva York: Oxford University Press.

Gargarella, Roberto, 2002, Crisis de representación política, Fontamara, México. 
Géigel, Vicente P, 2003, La farsa del Estado Libre Asociado, Rio Piedras, Edil, 2010.

González Casanova, Pablo, 2000, (Coord). El Estado en América Latina: teoría y práctica, México, Siglo XXi, 3ra reimp.

González-Ulloa, Pablo Armando, 2009, Declive y reconfiguración de la democracia representativa, México, Miguel Ángel Porrúa.

Grcic, Josep, 2000, Ethnics and political Theory, Lanham, Maryland, University Press of America.

Hermet, Guy, et.al., 1982, ¿Para qué sirven las elecciones?, FCE, México.

Huerta, Magdalena y Magar, Eric (coord.), 2006, Mujeres Legisladoras en México: Avances, obstáculos, consecuencias y propuestas", México.

IDEA International, 1997, Manual para el diseño de sistemas electorales, México, IFE.

Katz, Richard, 2005, "Why Are There So Many (or So Few) Electoral Reforms?" en M.Gallagher y P. Mitchell (eds.), The Politics of Electoral Systems, Nueva York: Oxford University Press, pp. 57-76.

Kreuzer, Markus, 2010, "Historical Knowledge and Quantitative Analysis: The Case of the Origins of Proportional Representation", American Political Science Review, n. 104 v.2, pp. 369-392.

Lechner, Norbert, 1996, "La reforma del estado y el problema de la conducción política", Perfiles Latinoamericanos. Num.7, México, pp. 149-178.

Lexjuris. Ley Jones de 1917. Página web: www.lexjuris.com. [Recuperado el 12 de abril de 2016].

Lijphart, Arend, 1999, Patterns of Democracy: Government Forms and Performance in Thirty-Six Democracies. New Haven: Yale University Press. 
Linz, Juan, 1990, “The virtues of parlamentarism”, Jornal of Democracy. $1, n$. $4.84-91$.

Lundell, Krister, 2010, The Origin of Electoral Systems in the Postwar Era: A Worldwide Approach, Nueva York. Routledge.

Mainwaring, Scott, 1990, Politicians, parties and electoral systems: Brazil in comparative perspective, Notre Dame, The Helen Kellog Institute. Working Paper \#141.

Mainwaring, Scott y Shugart, Matthew S. 2002, Presidencialismo y democracia en América Latina, Buenos Aires, Paidós.

Martínez, Piedad, 2006, "El método de estudio de caso. Estrategia metodológica de la investigación científica", Pensamiento \& Gestión, núm. 20, pp. 165-193.

Maxwell, Neal, 1998, “Designing a Qualitative Study”, en L. Bickman D. J. y Rog (Eds.), Sage. Handbook of Applied Social Research Method. pp. 69-100. Mejía, Andrés, y Machado, Juan C., 2008, "La democracia asfixiada en los Andes Altos. Elecciones e inestabilidad en Bolivia, Ecuador y Perú", en Manuel Sáez, Alcántara y Díez, Fátima (coords), Elecciones y política en América Latina. México, IEEM-SOMEE-Miguel Ángel Porrúa, Muñoz Marín , Luis, 2003, Memorias 1940-1952, Hato Rey, Fundación LMM. Págs. 99-111.

Nazario, Juan, J. Persecución y carpetas. Página web: www.juanmariebras.org. [Recuperado el 1 de mayo de 2016].

Negrón, Mario, 3 de noviembre de 2005, La voz del Centro, "La Unicameralidad y el Informe de la Escuela de Administración Pública de la UPR a la Convención Constituyente en el 1952". Página web: www.lavozdelcentro.net. [Recuperado el 15 de mayo de 2016]. 
Nina, Daniel. 14 de agosto de 2013. "Una dominicana a la legislatura en Puerto Rico". El Post-Antillano. Página web: www.elpostantillano.net.

[Recuperado el 12 de febrero de 2016].

Nohlen, Dieter, 1996, Election and electoral systems, India, Macmillan. , 2004, Sistemas Electorales y Partidos Políticos, México, Fondo de Cultura Económica. ,1995, Elecciones y sistemas electorales, Caracas, Nueva Sociedad -Fundación Fredrich Ebert.

Nolla-Acosta, Juan, J., 2015, Elecciones en Puerto Rico, 1899-2012, San Juan. (S.E).

Norris, Pippa, 1997, “Choosing Electoral Systems: Proportional, Majoritarian and Mixed Systems", International Political Science Review Vol.18, No. 3, Contrasting Political Institutions, Institutions politiques contrastées, pp.297312.

Novaro, Marcos, 1999, Representación y liderazgo de las democracias contemporáneas, Homo Sapiens, p.27-28.

Ocaña, Francisco A. y Oñate, Pablo, 1999, “Índices e indicadores del sistema electoral y del sistema de partidos. Una propuesta informática para su cálculo", Madrid, Revista Española de Investigaciones Sociológicas, No. 86. abril-junio, pp.225-232.

Pagán, Bolivar, 1959, Historia de los partidos políticos puertorriqueños, Tomo 1. San Juan, Librería Campos.

Payne, Mark, Zovatto, Daniel y Mateo, Mercedes, 2006, La política importa: Democracia y desarrollo en América Latina, Washington, D.C: Banco Internacional de Desarrollo e Instituto Internacional para la Democracia y la Asistencia Electoral. 
Penadés, Alberto, 2008, “The Institutional Preferences of Early Socialist Parties. Choosing Rules for Government”, en Maravall Sánchez-Cuenca (eds.) Controlling Governments:Voters, Institutions and Accountability, Nueva York: Cambridge University Press.

Pradesh, Madhya, 2005, Ecology, Exclusion and Reform in Madhya Pradesh: Introduction, Economic and Political Weekly Vol. 40, No. 48, Noviembre 26 - Diciembre, pp. 5009-5013.

Rae, Douglas W., 1967, The political Consequences of electoral laws, New Haven, Yale University Press.

Ramos, Virgilio, 2011, Voto particular del miembro asociado, Junta constitucional de distritos senatoriales y representativos.

Reglamento del Partido Popular Democrático. Página web: www.partidopopulardemocrático.pr.com. [Recuperado el: 16 de marzo de 2016].

Reglamento del Partido Nuevo Progresista. Página web: www.partidonuevoprogresista.pr.com. [Recuperado el: 16 de marzo de 2016].

Reglamento del Partido Independentista Puertorriqueño. Página web: www.independencia.net. [Recuperado el: 16 de marzo de 2016].

Renwick, Alan, 2010, The Politics of Electoral Reform: Changing the Rules of Democracy, Nueva York, Cambridge University Press.

Riera, Pedro, 2013, "Los sistemas electorales y la cigüeña. Sobre el origen y la reforma de las reglas del juego democrático", en Revista española de Investigaciones Sociológicas, Madrid, CIS, no.142. Abril-Junio, pp.141150 . 
Rivera, Efrén, 1998, Hegemonía y legitimidad en el Puerto Rico contemporáneo, Barcelona, Ed.UPR, working paper. N. 129.

Rivera, Ángel I, 1991, "La cultura política y la estabilidad del sistema de partidos en Puerto Rico" Rio Piedras, Caribean Studies, Num, 3/4, Vol 24, pp. 175-220.

Linda Colón Reyes, 2011, Sobrevivencia, pobreza y mantengo: La política asistencialista estadounidense en puerto Rico: el PAN y el TANF, Rio Piedras, Callejón.

Rosario, Frances, "Partidos no cumplen con sus expectativas en las primarias", 6 de junio de 2016, Página web: www.endi.com.

Ruiz, José, F., 1974, Normación constitucional de los partidos políticos en América Latina, México, UNAM. Instituto de Investigaciones Jurídicas.

Santiago, Carmen, 1965, El gobierno de Puerto Rico: Desarrollo constitucional y político, Rio Piedras, Universidad de Puerto Rico.

Sartori, Giovanni, 1994, Ingeniería constitucional comparada, México, Fondo de Cultura Económica.

Sepúlveda, Denisse, 2010, "La variable etnia/raza en los estudios de estratificación social", México, Proyecto desigualdades.

Servicios Legislativos. Trámite legislativo. Proyectos Legislativos. Página web: Www.osl.pr.org. [Recuperado el 27 de febrero de 2016].

Sousa Santos, Boaventura de, 2009, Epistemología del Sur. México. Siglo XXI. Stavenhagen, Rodolfo, 2000, Conflictos étnicos y Estado Nacional. México. Siglo xxi.

Suárez, Limarys, 2016, "Se deshabita Puerto Rico de forma acelerada”. Lunes, 4 de enero de Página web. www.endi.com.

Taagepera, R, (2015): "La balanza inclinada. Probando la 'Ley de Duverger' en el nivel nacional", De Política, México, AMECIP, núm. 4/5, pp.9-20. 
Tremblay, Manon, 2008, Women in legislative representation: Electoral Systems, Political Parties, and Sex Quotas. London. Macmillan Palgrave.

Trias Monge, José, 1982, Historia Constitucional de Puerto Rico, T.3, Rio Piedras Ed.UPR.

Valdés, Leonardo, 1994, "El efecto mecánico de la fórmula electoral mexicana: 1964-1991”, Revista Polis, México, UAM-Iztapalapa, página web: www.juridicas.unam.mx.

Villanueva Montalvo, Aida 2012, "En torno a la representación especial indígena en el Perú: percepción de líderes indígenas y características del modelo peruano”, Debates en Sociología, n 37, pp. 43-76.

Webb, Jenn, 2009, Understanding representation. Los Angeles. Sage.

Weber, Max, 1969, Economía y sociedad. México, Fondo de Cultura Económica, $1^{\text {a }}$.reimp.

Wickham-Crowley, Timothy, 1992, Guerrillas and revolutions in Latin America's New Yersey, Pinceton.

Wolinetz, S, 2007, "Más allá del partido catch all: enfoques para el estudio de los partidos en las democracias contemporáneas", en Gunther, Montero, Linz (eds), Partidos políticos. Viejos conceptos y nuevos retos, Madrid: Editorial Trotta.

Yin, Robert, 1984, "Case Study Research: Design and Methods, Applied social research Methods Series”, Newbury Park CA, Sage.

Young, Lisa, 2008, Gender Equal Legislatures: Evaluating the Proposed Nunavut Electoral System, Canadian Public Policy / Analyse de Politiques, Vol. 23, No. 3 Septiembre,1997, pp. 306-315.

Zapata-Barrero, Ricard, 2001, Ciudadanía, democracia y pluralismo cultural: Hacia un nuevo contrato social, Barcelona, Anthropos. 